NBS Special Publication 686

\title{
State Weights and Measures Laboratories
}

\section{Program Description and Directory}

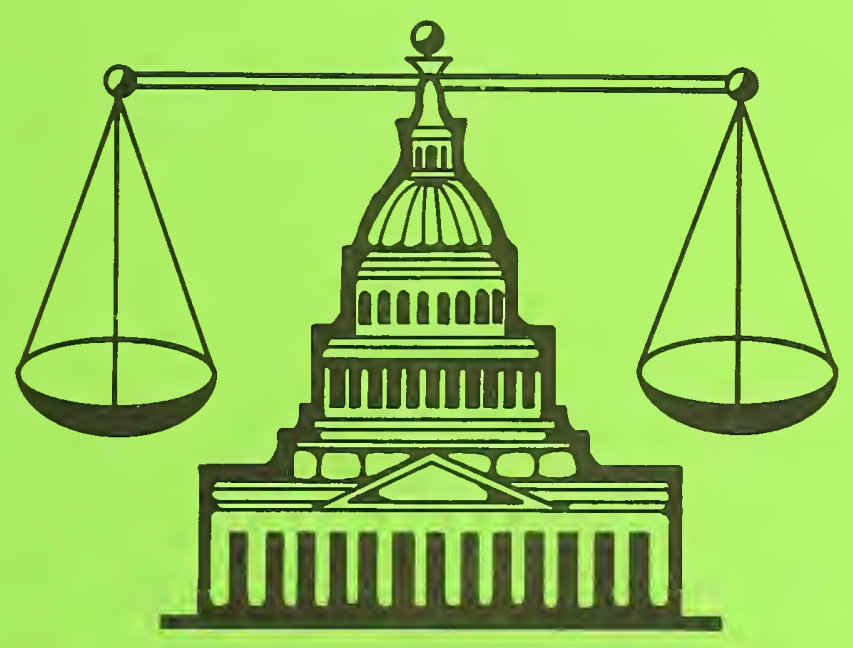

$-Q C$

100

.457

No, 686

1985

c. 2 JAN

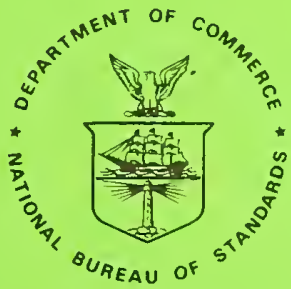

U.S. Department of Commerce

National Bureau of Standards

Gaithersburg, MD 20899 
he National Bureau of Standards' was established by an act of Congress on March 3, 1901. The Bureau's overall goal is to strengthen and advance the nation's science and technology and facilitate their effective application for public benefit. To this end, the Bureau conducts research and provides: (1) a basis for the nation's physical measurement system, (2) scientific and technological services for industry and government, (3) a technical basis for equity in trade, and (4) technical services to promote public safety. The Bureau's technical work is performed by the National Measurement Laboratory, the National Engineering Laboratory, the Institute for Computer Sciences and Technology, and the Center for Materials Science.

\section{The National Measurement Laboratory}

Provides the national system of physical and chemical measurement; coordinates the system with measurement systems of other nations and furnishes essential services leading to accurate and uniform physical and chemical measurement throughout the Nation's scientific community, industry, and commerce; provides advisory and research services to other Government agencies; conducts physical and chemical research; develops, produces, and distributes Standard Reference Materials; and provides calibration services. The Laboratory consists of the following centers:
- Basic Standards ${ }^{2}$

- Radiation Research

- Chemical Physics

- Analytical Chemistry

\section{The National Engineering Laboratory}

Provides technology and technical services to the public and private sectors to address national needs and to solve national problems; conducts research in engineering and applied science in support of these efforts; builds and maintains competence in the necessary disciplines required to carry out this research and technical service; develops engineering data and measurement capabilities; provides engineering measurement traceability services; develops test methods and proposes engineering standards and code changes; develops and proposes new engineering practices; and develops and improves mechanisms to transfer results of its research to the ultimate user. The Laboratory consists of the following centers:
- Applied Mathematics

- Electronics and Electrical Engineering ${ }^{2}$

- Manufacturing Engineering

- Building Technology

- Fire Research

- Chemical Engineering ${ }^{2}$

\section{The Institute for Computer Sciences and Technology}

Conducts research and provides scientific and technical services to aid Federal agencies in the selection, acquisition, application, and use of computer technology to improve effectiveness and economy in Government operations in accordance with Public Law 89-306 (40 U.S.C. 759), relevant Executive Orders, and other directives; carries out this mission by managing the Federal Information Processing Standards Program, developing Federal ADP standards guidelines, and managing Federal participation in ADP voluntary standardization activities; provides scientific and technological advisory services and assistance to Federal agencies; and provides the technical foundation for computer-related policies of the Federal Government. The Institute consists of the following centers:
- Programming Science and Technology

- Computer Systems Engineering

\section{The Center for Materials Science}

Conducts research and provides measurements, data, standards, reference materials, quantitative understanding and other technical information fundamental to the processing, structure, properties and performance of materials; addresses the scientific basis for new advanced materials technologies; plans research around cross-country scientific themes such as nondestructive evaluation and phase diagram development; oversees Bureau-wide technical programs in nuclear reactor radiation research and nondestructive evaluation; and broadly disseminates generic technical information resulting from its programs. The Center consists of the following Divisions:
- Inorganic Materials

- Fracture and Deformation ${ }^{3}$

- Polymers

- Metallurgy

- Reactor Radiation 


\section{State Weights and Measures Laboratories}

\section{Program Description and Directory}

H. V. Oppermann

National Bureau of Standards

Gaithersburg, MD 20899

U.S. DEPARTMENT"ÓF COMMERCE, Malcolm Baldrige, Secretary NATIONAL BUREAU OF STANDARDS, Ernest Ambler, Director 
Library of Congress Catalog Card Number: 84-601142

National Bureau of Standards Special Publication 686 Natl. Bur. Stand. (U.S.), Spec. Publ. 686, 69 pages (Jan. 1985)

CODEN: XNBSAV 


\section{CONTENTS}

\section{Page}

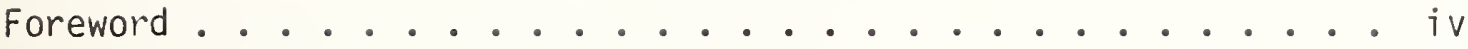

Part I - Program Description .............. I

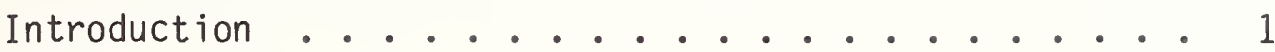

Measurement Areas for Certification ......... 1

Tolerance Testing ............ 2

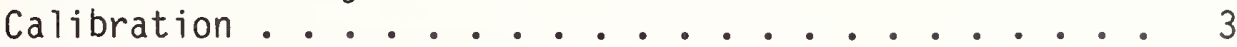

Requirements for Laboratory Certification . . . . . 4

Training and Evaluation .......... 4

Measurement Control ............ 5

Internal Control Programs ........... 5

External Control Programs .......... 6

Conclusion and Summary ........... 7

PART II - State Directory ............. 13 


\section{FOREWORD}

As part of its mission to promote uniform standards of measurement throughout the colntry, the National Bureau of Standards (NBS) received funding in 1965 to issue new standards of mass, length, and volume to state weights and measures laboratories. This program included the equipment needed to perform calibrations in these measurement areas.

To maintain the validity of these standards and to assure that the standards are used properly. NBS trains state metrologists in the test procedures used in the NBS laboratories and conducts a voluntary certification program for state weights and measures laboratories. As part of the certification requirements, NBS requires that a state have adequate facilities in which to perform the measurements; the metrologist must receive the necessary training and submit data demonstrating the results of applying the test procedures; and the laboratory must stablish measurement control programs acceptable to NBS in the various measurement areas. The certification program is described in Part $I$.

The directory in Part II lists state weights and measures laboratories and the services they provide to state and local weights and measures agencies as well as industry. It is intended to assist potential users in locating and obtaining needed services. This directory provides:

\footnotetext{
- a reference to laboratory services

- definition of services

- rees, if any, for services.
} 


\section{PART I}

\section{STATE LABORATORY CERTIFICATION}

\section{INTRODUCTION}

The National Bureau of Standards (NBS) conducts a program whereby State weights and measures laboratories are certified by measurement areas. This certification does not mean that the measurements made by a state are certified, but only recognizes that an apparent capability to perform reliable measurements exists and that the metrologist has been trained in the proper procedures to provide these measurements. Additionally, the certification indicates that the metrolngist has fulfilled the requirements and submitted the data requested by NBS for certification. Each State laboratory is responsible for the validity of its measurements.

The fact that a ?aboratory is not certified should not imply that the laboratory is inadequate or that its measurements are not valid. Rather, it indicates that a laboratory has not provided the necessary information to permit the NBS to evaluate its capability. Consequently, the NBS cannot take a position regarding the capability of this laboratory. Such laboratories must provide their own documentation to justify the validity of their measurements.

In 1965, Congress provided funds for NBS to issue new standards of mass, volume, and length to the States, the District of Columbia, Puerto Rico, and the Virgin Islands to update their weights and measures laboratories and increase their measurement capabilities. This was called the New state standards Program. This program included the necessary laboratory equipment to use these standards and provide measurement services. Each jurisdiction was responsible for providing a laboratory and a metrologist to be trained to use the standards and the equipment. The standards were issued to the States from 1967 through 1978. Since that time, many states have purchased additional equipment to increase their measurement capability and to expand into other measurement areas, such as liquid-in-glass thermometry, the frequency testing of tuning forks for police radar guns, and the tusting of large-volume provers.

\section{MEASUREMENT AREAS FOR CERTIFICATION}

A brief summary of each measurement area contained in the certification program is provided under the headings of Tolerance Testing and Calibration. Some states provide measurement services in other areas, but the NBS has not developed criteria to serve as the basis for laboratory certification in these areas. Consequently, they are not included in the certification program. 
Each laboratory certified in a given area has been judged to be capable of providing the measurement services indicated. The range of standards that can be tested by a laboratory will depend upon the equipment it has purchased in addition to that received through the New State Standards Program. A general classification of the range of standards that can be tested is indicated by the headings of the tables of services available. The mass classifications for tolerance testing are given in pounds whereas the mass classifications for calibration are given in kilograms because inch-pound standards are usually used in tolerance testing and metric standards in calibrations. Comparable standards in other mass units of measure can also be tested.

\section{TOLERANCE TESTING}

A tolerance can be simply defined as the permitted difference between the nominal value of the standard and its actual value under specific conditions. Tolerance testing is the process in which a standard is tested to determine if the actual value of the standard is within tolerance. To be certified to a tolerance class, a standard must comply with the specifications and tolerances for the specified tolerance class.

\section{Mass}

Tolerance testin!; of mass standards is usually done according to specifications insluded in:

- NBS Handbook 105-1

- American Society for Testing and Materials Standard E617, Classes 4, 5, and 6

- NBS Circular 547, Classes P, Q, and T

- NBS Circular 3, Classes A, B, and C.

Tolerance testing to International Organization of Legal Metrology tolerances of classes $F_{2}, M_{1}$, and $M_{2}$ and other tolerances can be performed upon request.

\section{Volume}

Tolerance testing of volume standards is divided into small-, intermediate-, and large-volume standards depending upon the laboratory standards to be used. Small-volume standards may have a capacity up to 25 gallons. Glassware standards may be tested to NBS Handbook 105-2 tolerances or the tolerances stated in Federal regulations. Metal field standards are tested to NBS Handbook 105-3. 
The capacities of intermediate-volume standards range from 25 through 500 gallons. Large-volume standards have capacities in excess of 500 gallons. These standards are usually tested to NBS Handbook 105-3.

\section{CALIBRATION}

Calibration is the process of comparing an unknown standard to a known standard and assigning a value, along with an uncertainty, to the unknown standard. The uncertainty expresses the extent to which that assigned value may be in error relative to its reference base, which typically is the national standard. When calibrated by a state laboratory, the assigned value may or may not be within the specified tolerance; hence, the correction and uncertainty assigned to the standard should be used in subsequent measurements. In some cases, the uncertainties assigned to standards will exceed the specified tolerances. The uncertainties reflect the level of precision the State laboratories can achieve. The uncertainty will differ from one laboratory to another depending on standards and equipment available to perform the measurement. Potential customers should contact the state weights and measures laboratory to verify that the assigned uncertainty is adequate for their needs.

\section{Mass}

Calibrations are usually performed on mass standards designed to:

American Society for Testing and Materials Standard E617, Classes 1,2 , and 3

NBS Circular 547, Classes J, M, S, and S-1

International Organization of Legal Metrology Classes $E_{2}$ and $F_{1}$.

Depending on the laboratory, air buoyancy corrections may or may not be made. Customers should specify the apparent mass reference density desired for their calibration and the density of the mass standards.

\section{Volume}

Small glassware standards are usually calibrated gravimetrically or by volume transfer. The capacity of metal standards is typically 5 gallons or 20 liters.

\section{Length}

Steel tapes up to several hundred feet may be calibrated. The uncertainties are typically a few thousandths of a foot. Rigid rules up to 12 inches can be calibrated with uncertainties of several thousandths of an inch. 


\section{Prequency}

The frequency calibration services are usually limited to tuning forks used with police radar guns.

\section{Temperature}

Temperature calibration is generally limited to liquid-in-glass thermometers. Some states test only clinical thermometers of this type. The standards for most states are also liquid-in-glass thermometers. The uncertainties for temperature calibration will vary among the laboratories. Many requests for calibrations involve tolerances specified by the customer.

\section{REQUIREMENTS FOR LABORATORY CERTIFICATION}

There are three general requirements for certification:

1. The state must have adequate laboratory facilities and equipment to provide the services that are offered.

2. The metrologist must receive regular training and demonstrate the ability to perform the laboratory measurements.

3. The metrologist must implement and maintain measurement contro: programs in various measurement areas as required by NBS.

The requirements for the laboratory facilities and general operation are contained in the NBS handbook entitled "State Weights and Measures Laboratories - Program Handbook." Each laboratory is evaluated through a self-appraisal checklist submitted by the metrologist, usually followed by an on-site evaluation. The metrologist is evaluated on the basis of performance in training seminars, the work submitted to NBS as part of the laboratory assignments, participation in technical meetings, and a review of laboratory data and test procedures during the on-site evaluation. The quality of a laboratory's measurement results are evaluated through its control charts and round robin experiments. Brief discussions of these topics follow.

\section{TRAINING AND EVALUATION}

The NBS trains state metrologists in the basic laboratory metrology procedures for mass, volume, and length measurement during a two-week seminar. The test procedures are described in NBS publicaiions. The metrologists must then complete a series of laboratory assignments and submit the data to NBS to document their understanding of the procedures and the calculations. Additional laboratory problems are assigned to each laboratory to establish measurement control programs in several measurement areas. 
Each metrologist is expected to attend the intermediate metrology seminar to receive additional training in laboratory procedures and in the corrections needed for high precision measurement. Following this seminar, the metrologists are assigned a series of problems to demonstrate their understanding of the seminar material.

States that expand into other areas of measurement are encouraged to attend specialized seminars conducted by the NBS calibration laboratories. Examples of these areas are temperature and pressure measurements. The laboratories must then establish measurement control programs in these measurement areas to assure agreement with NBS results.

Each State is expected to participate in Regional Measurement Management Programs (RMMPs). These RMMPs are groups of laboratories in given geographical areas that have joined together to conduct meetings for the purpose of training and demonstration of procedures, and to conduct round robin experiments to promote uniform measurements in their geographical area. The knowledge exhibited by metrologists in these meetings and their results on the round robin experiments are included as part of the evaluation of the state laboratories.

\section{MEASUREMENT CONTROL}

The NBS criteria require state weights and measures laboratories to utilize formal quality control techniques to ensure that their measurements are sufficiently accurate to meet their needs on a continuing basis. If such techniques are properly employed, it is possible to quantify the uncertainties of the measurements. Monitoring them over time can assure that they remain sufficiently small to meet operational requirements. The NBS has been working closely with the state weights and measures laboratories to help them improve and demonstrate their ability to perform high-quality calibrations.

Measurement control programs have been established for mass calibration and the volume transfer testing of glass volume standards. These programs will be expanded into the other measurement areas. Round robin experiments are conducted to "investigate the agreement of the State laboratories in the other measurement areas.

The measurement control programs consist of two parts: internal control programs and external control programs.

\section{INTERNAL CONTROL PROGRAMS}

The internal measurement control programs generally consist of repeated measurements on the same objects over an extended period of time. The data are then plotted on control charts to establish the limits of random errors in the measurement processes. If these repeated measurements are made on the standards themselves, this approach monitors the standards as well as the variability of the measurement 
process. Statistical confidence tests are used to monitor the stability of the standards and the variance of the measurement process. The control chart data can be used to document the validity of measurements made on a given day. Finally, the control chart data are used to determine if the standards agree with the NBS-reported values. Disagreement with the NBS-reported values requires corrective action. If the problem persists, the standards must be recalibrated by NBS.

In some measurement areas it is not possible to keep a standard or standards in the laboratory simply for the purpose of measurement control. In these instances, repeated measurements are run on each standard submitted for test. Differences in test results are then plotted on a "range" chart. The process variance is estimated from the range in the measurements made on many standards. The range chart is also used to verify that repeated measurements made on a given standard fall within the indicated limits.

In some instances, such as the volume transfer testing of glass flasks, a combination of control and range charts is used. The type of measurement control program depends on the criticality of the measurements, the availability of standards for use as "check" standards, and the tolerances for the standards under test. The frequency of measurements made to control the measurement process and the type of control program utilized are tailored to the measurement area under investigation.

\section{EXTERNAL CONTROL PROGRAMS}

In the external measurement control programs, standards external to the laboratory are submitted to the laboratory for test. These external standards are usually calibrated by the NBS to provide a reference value. These standards are usually circulated as part of round robin experiments conducted and coordinated by the Regional Measurement Management Programs (RMMPS). Although the NBS provides values for the circulating standards, the round robin experiments are developed, coordinated, and analyzed by the RMMPS. The NBS participates in the data analysis and the regional meetings to identify any problems and to provide training to eliminate discrepancies. This information is vital to the NBS certification program. The RMMPs are thus an integral part of the NBS certification program and reduce the amount of effort necessary to monitor the state laboratories.

The external measurement control programs are used to compare the RMMP results to the NBS values. These programs investigate the presence of systematic errors and can be used to test the variance of the measurement processes. Plots of interlaboratory results are frequently used to analyze data. Internal measurement control programs should be established before a laboratory participates in round robin experiments to obtain maximum benefits from these external measurement control programs. 
The RMMPS are groups of state and, to a limited extent, private laboraturies that have joined together to conduct meetings and perform round robin tests in mass, length, and volume to promote uniformity in test procedures and measurement results. Five RMMPs provide the opportunity for all the States, the District of Columbia, Puerto Rico, and the Virgin Islands to participate (Figure 1):

- Northeastern Measurement Assurance Program (NEMAP)

- Southeastern Measurement Assurance Program (SEMAP)

-. Western Regional Management Group (WRMG)

- Mid-America Measurement Assurance Program (Mid-Map)

- Southwestern Assurance Program (SWAP)

The NBS goal is to provide an external measurement control system that is available to all states. The overall goal is for each state to participate in one of the five RMMPS. The RMMPs promote uniform measurement results by:

1. providing training through the presentation of papers prepared by members,

2. demonstrating test procedures to assure uniformity,

3. conducting round robin experiments to investigate the presence of measurement errors, and

4. addressing mutual problems.

Uniformity among RMMPS is attained through additional NBS training at the meetings, the calibration of standards used in the round robin experiments, and the evaluation of the round robin results. The RMMPs interact further through the Metrology Workshops held in conjunction with the National Conference on Weights and Measures. Members of each RMMP report on activities and round robin results and discuss ways of improving their condition.

\section{CONCLUSION AND SUMAARY}

Each state must have a trained metrologist and an adequate laboratory facility, and must demonstrate on a continuing basis that it is capable of providing valid measurements in order to be certified in a particular measurement area. The certification by NBS indicates that the laboratory is capable of providing a measurement service, but each state must justify the validity of its own measurements.

The table that follows summarizes the certified areas of measurement for each state. Part II provides detailed information to assist industry and government agencies in locating laboratories that provide needed measurement services. 


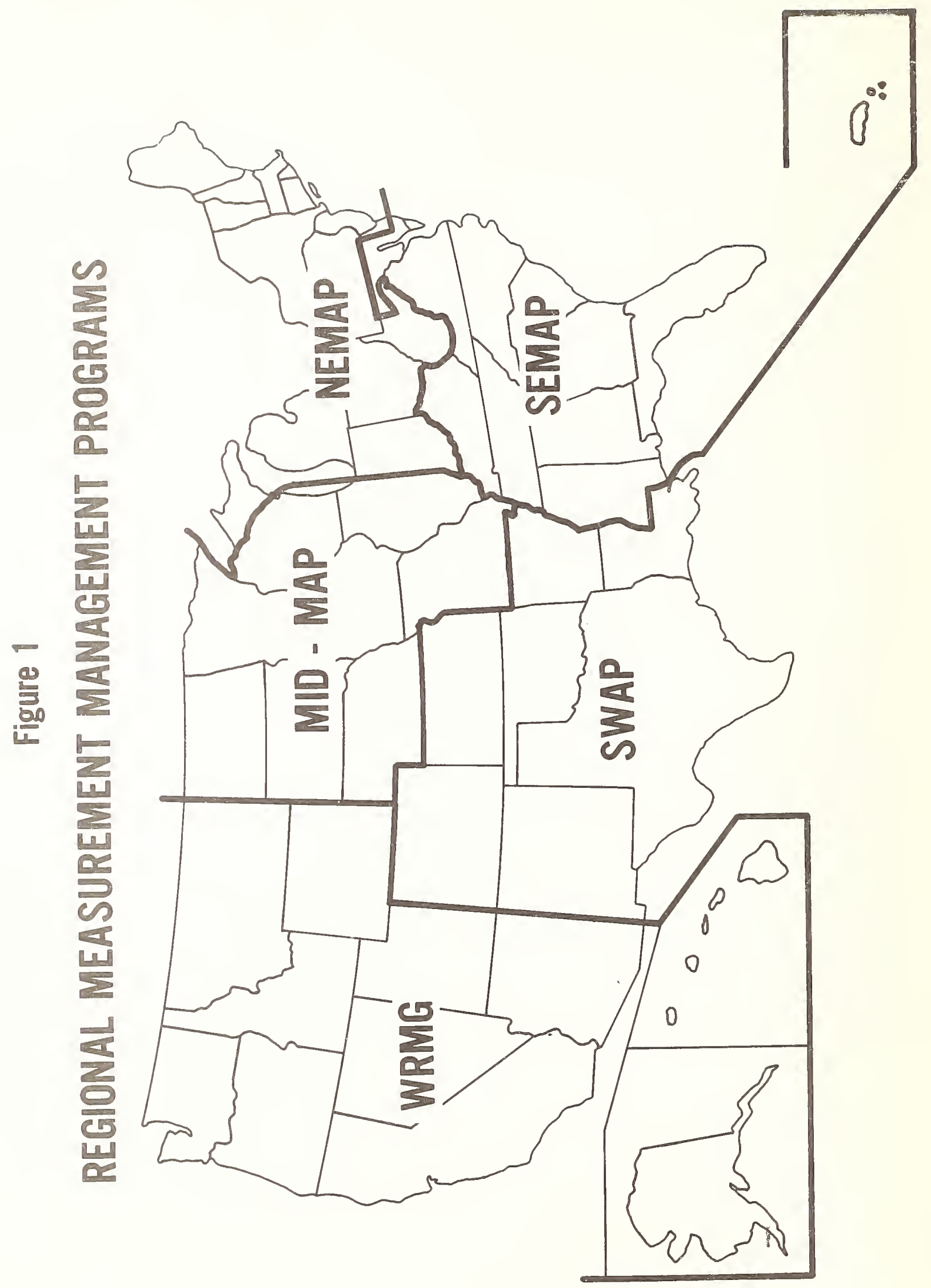




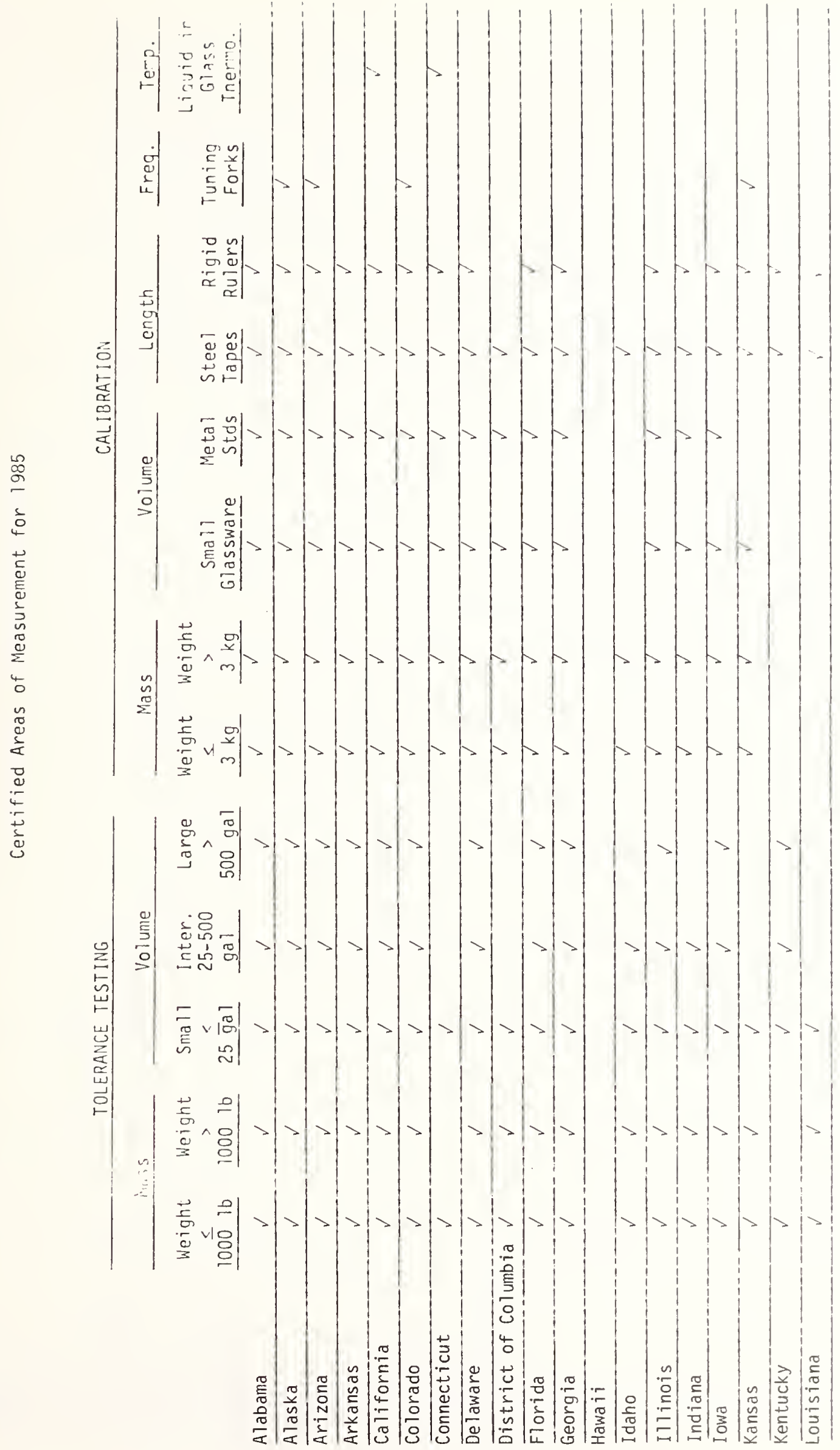




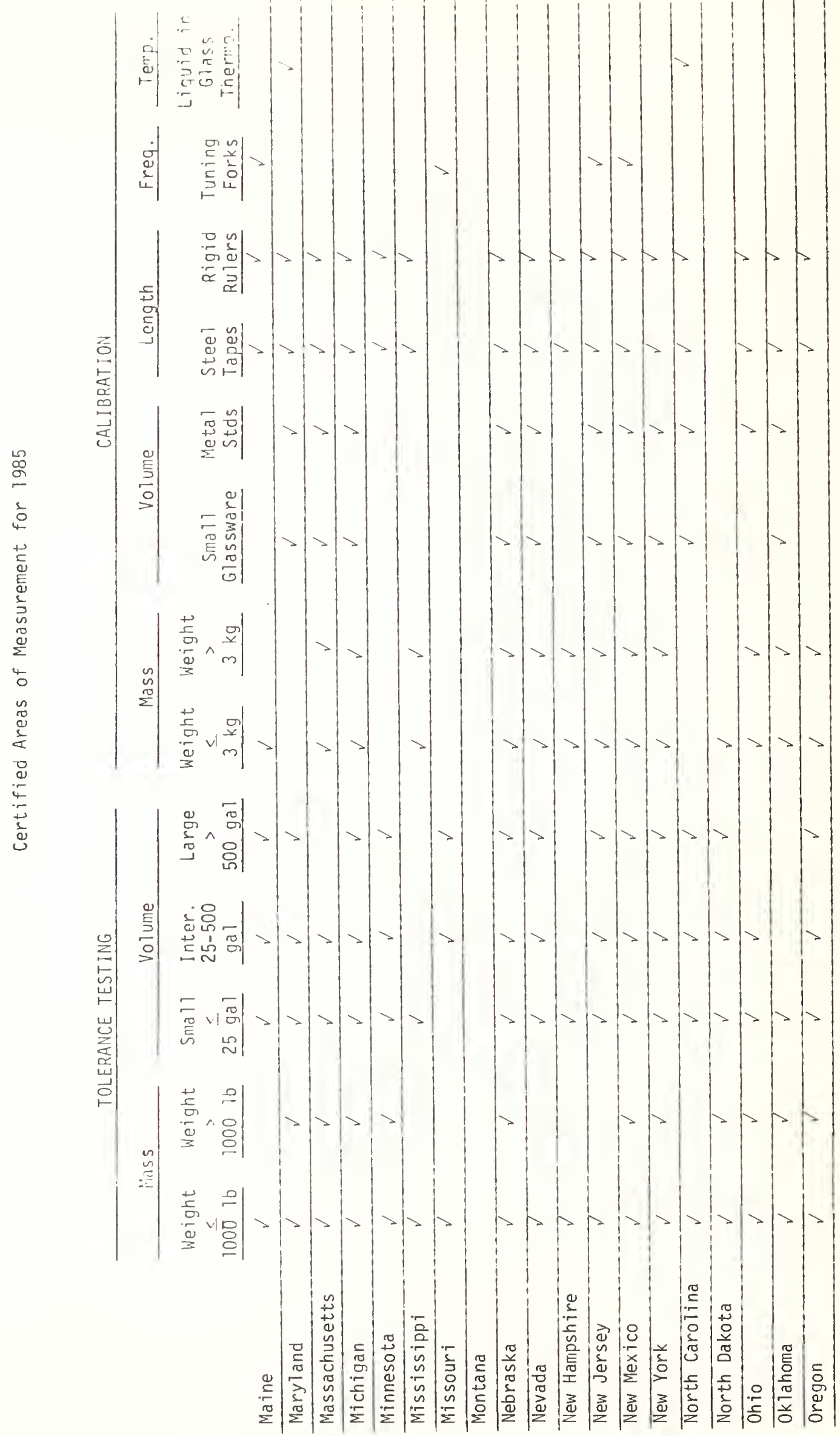




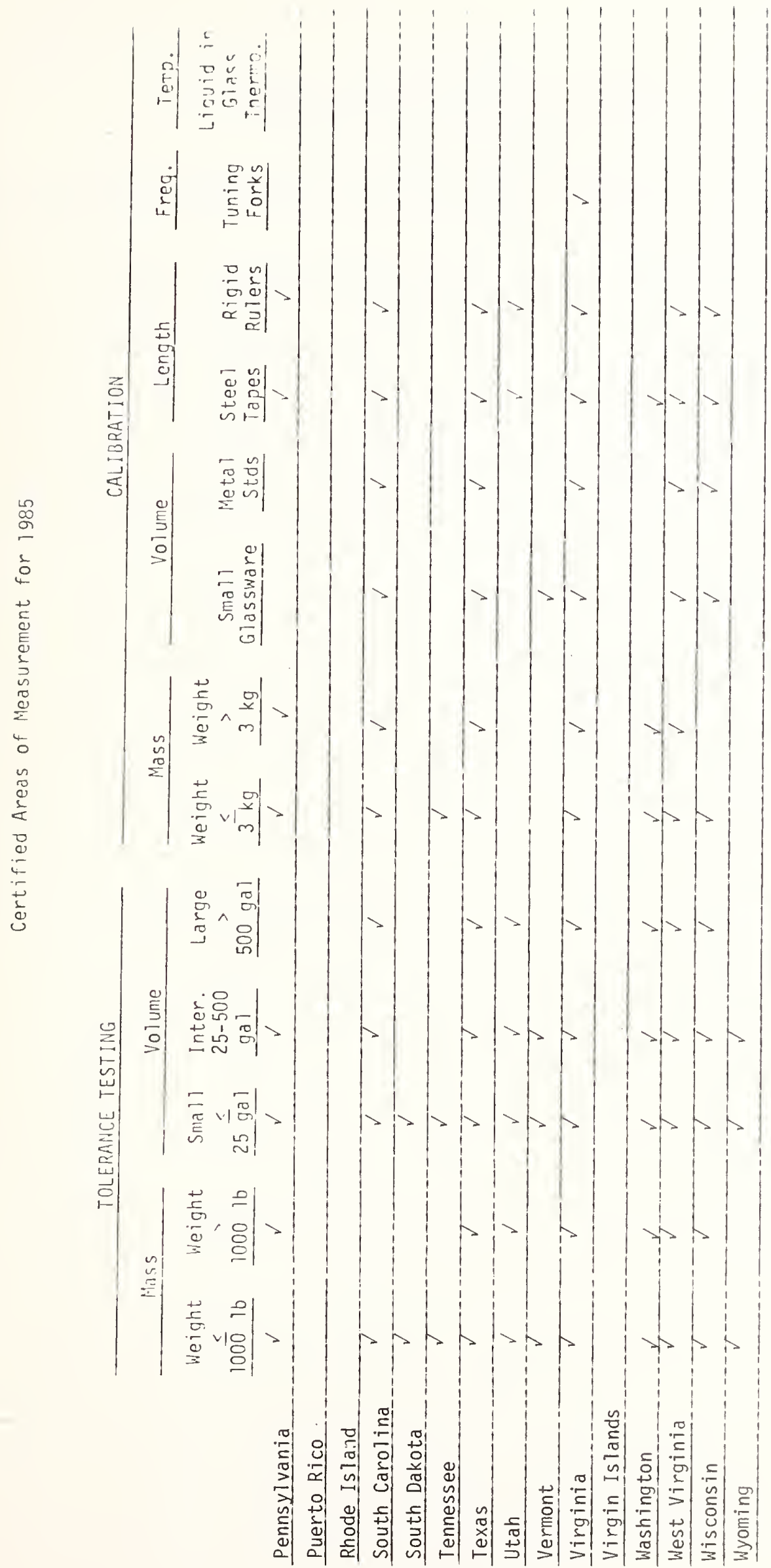





\section{PART II}

\section{DETAILED INFORMATION BY STATE}

This section contains the following information by state (in alphabetical order):

1. Name(s) of Iaboratory staff

2. Mailing address

3. Telephone number(s)

4. Services available (see Part I for definitions of services)

5. Fee structure (if any). 


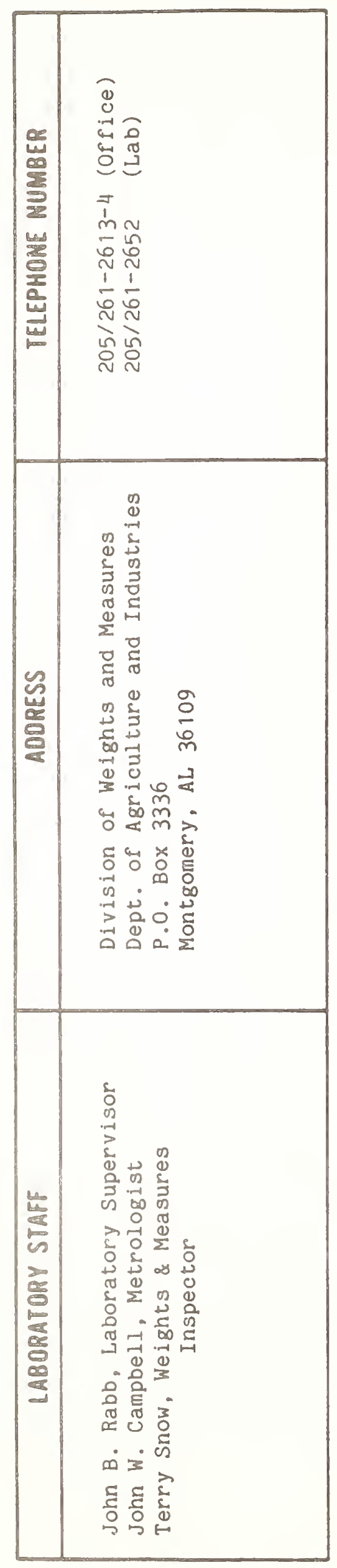

Alabama

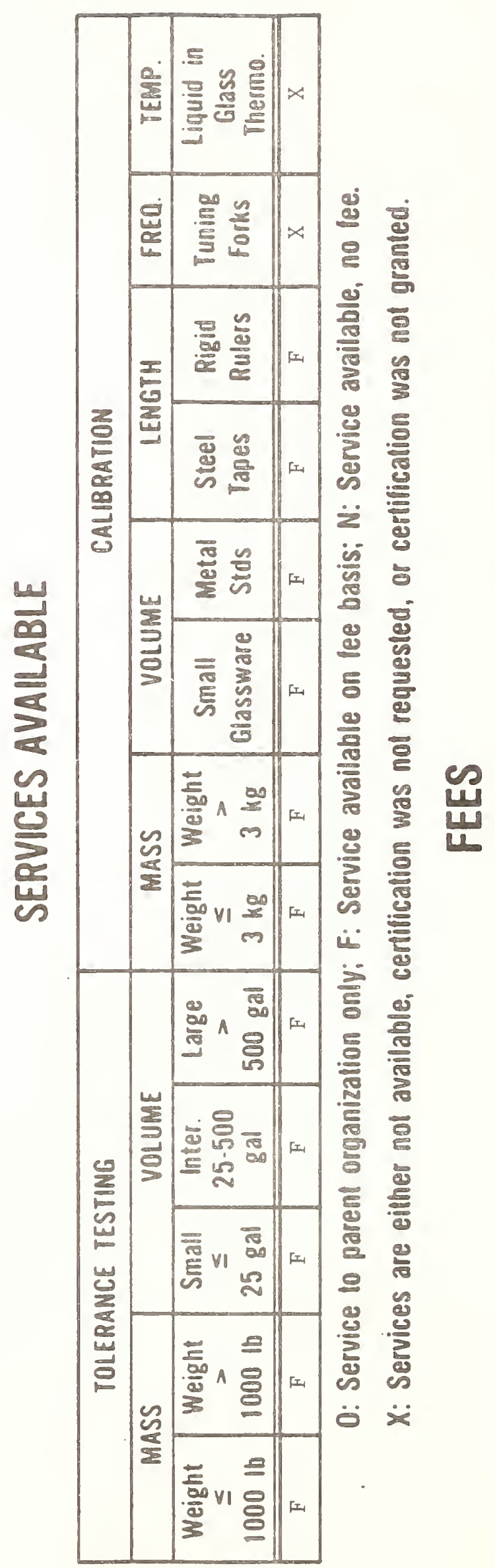




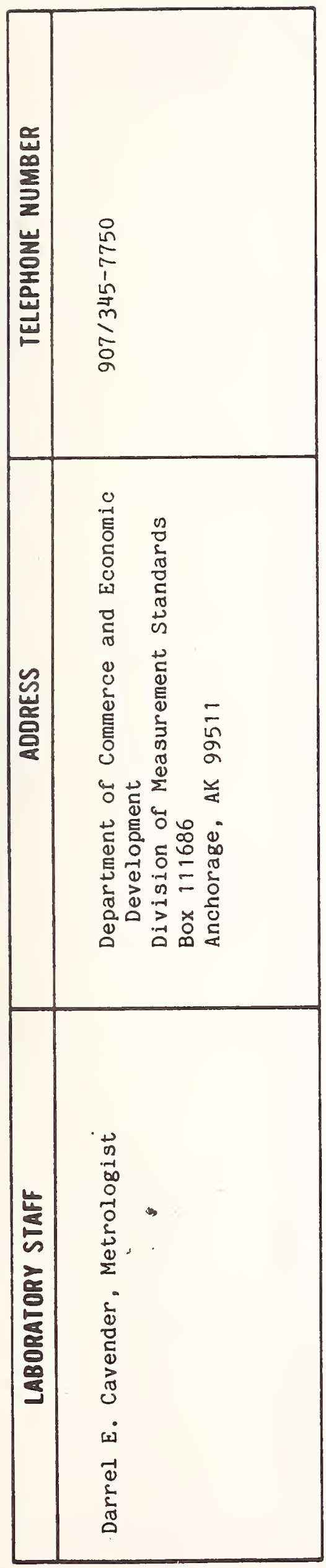

Alaska

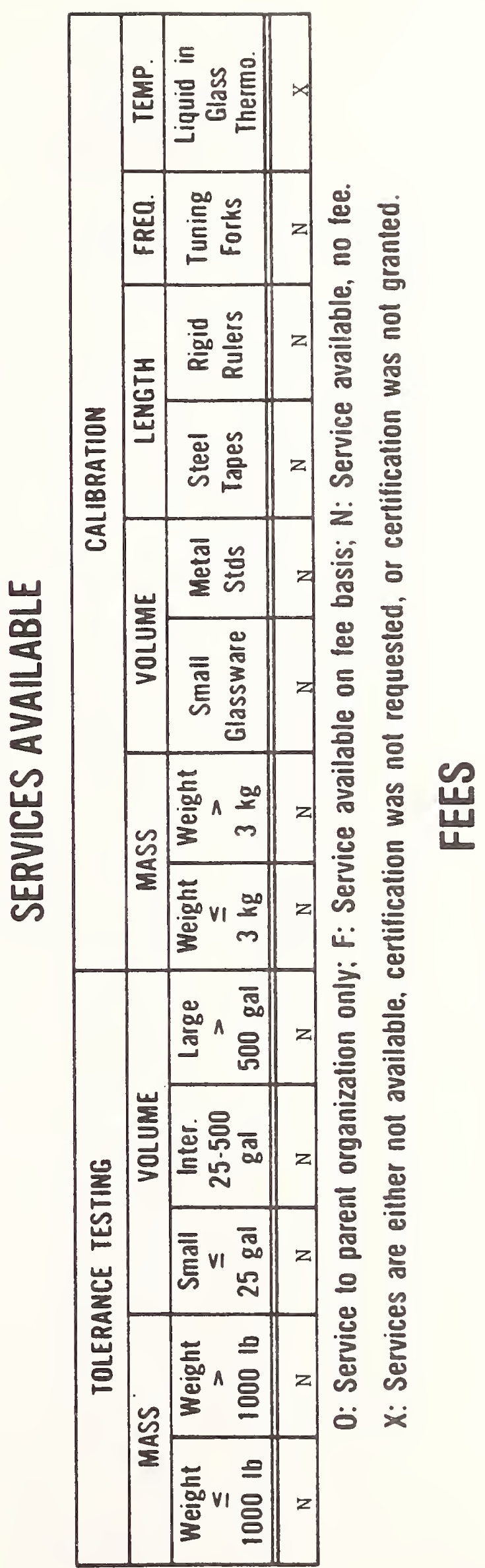




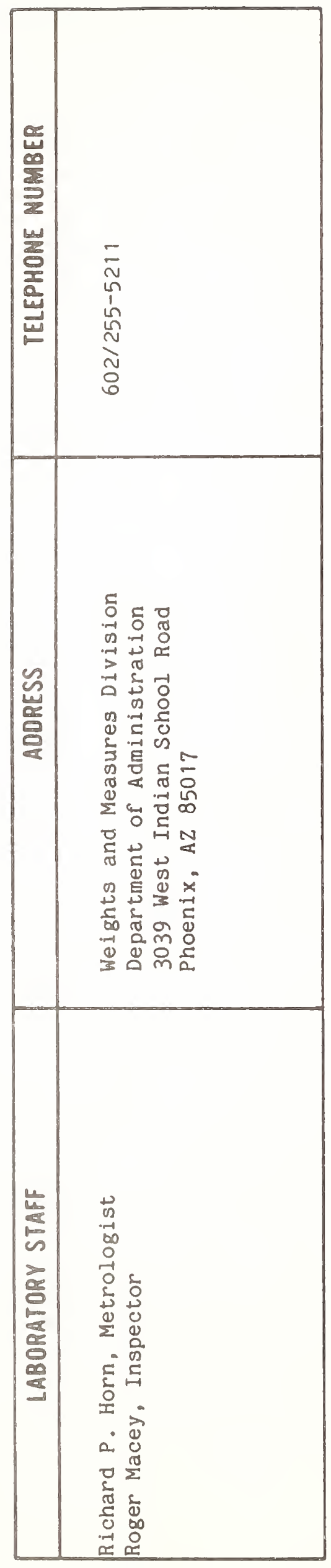

Arizona

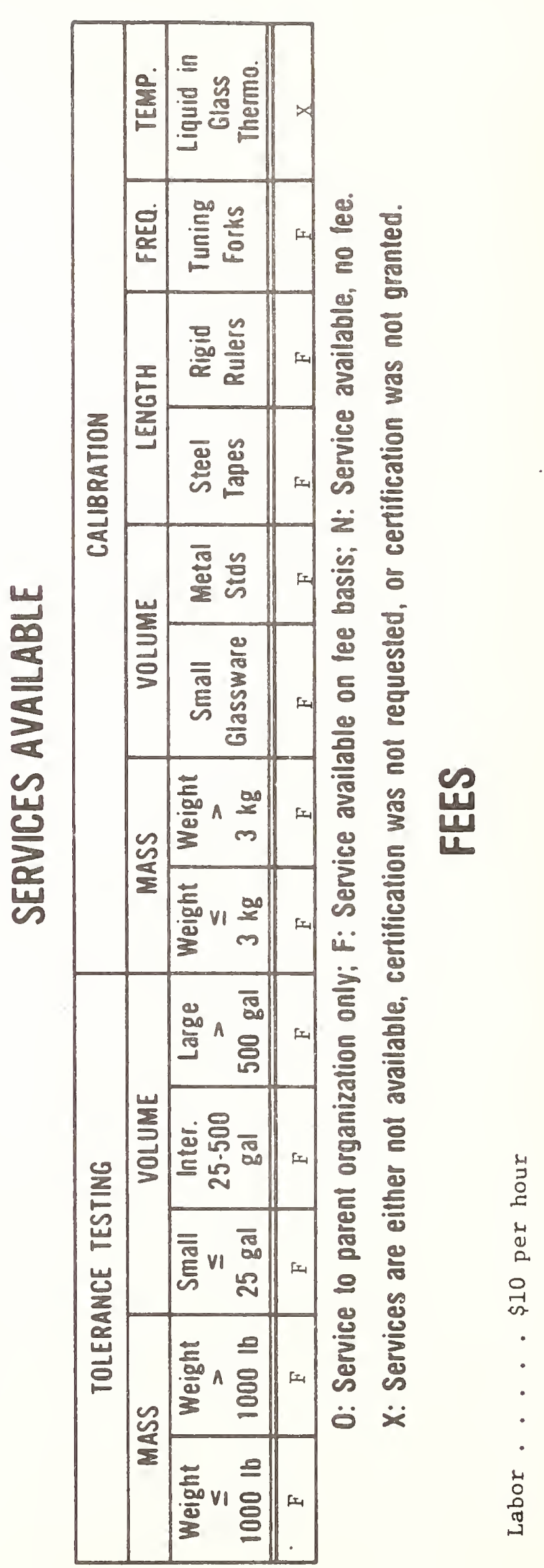




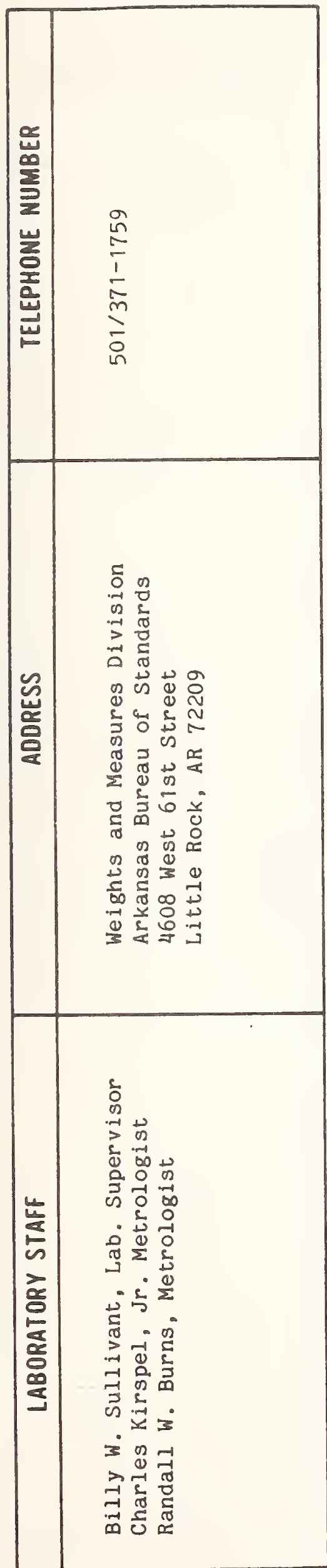

Arkansas

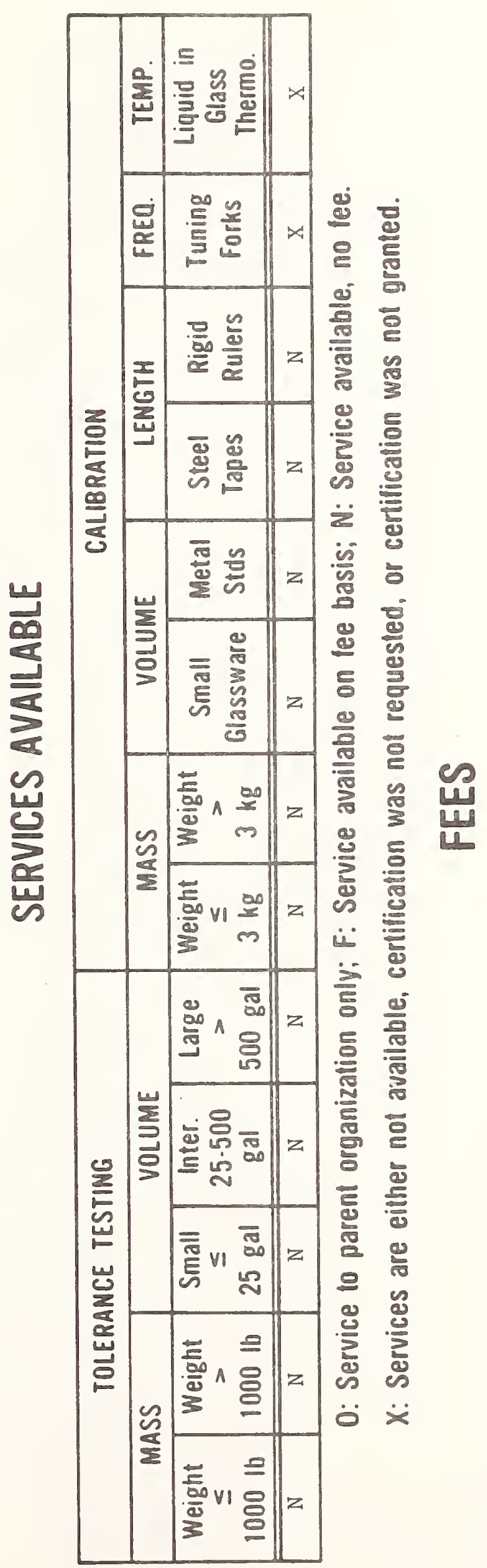




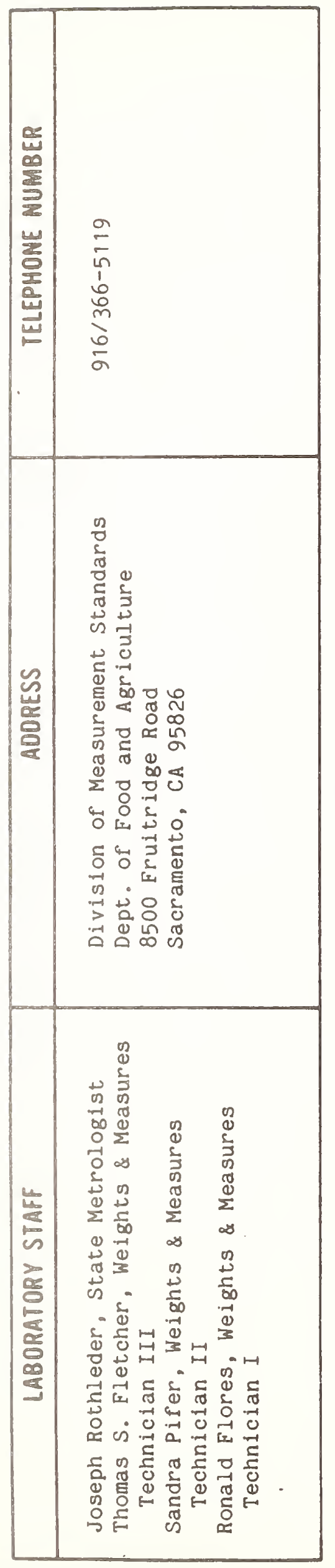

\section{California}

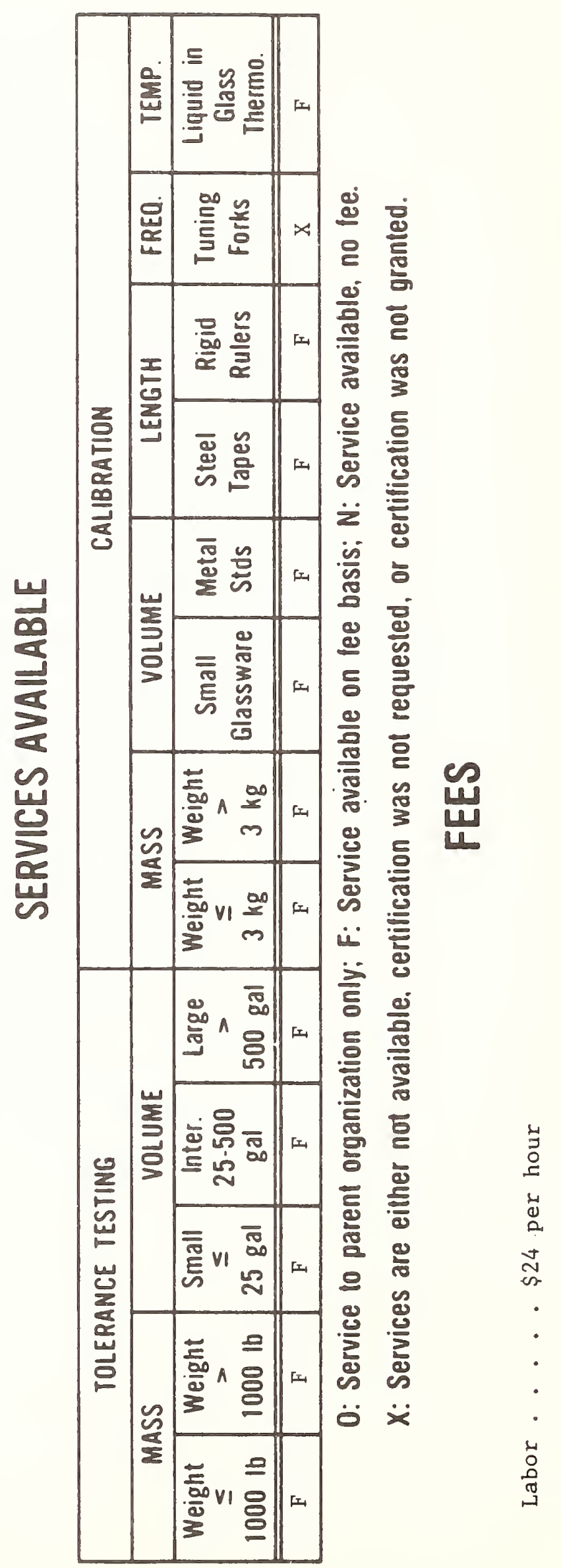




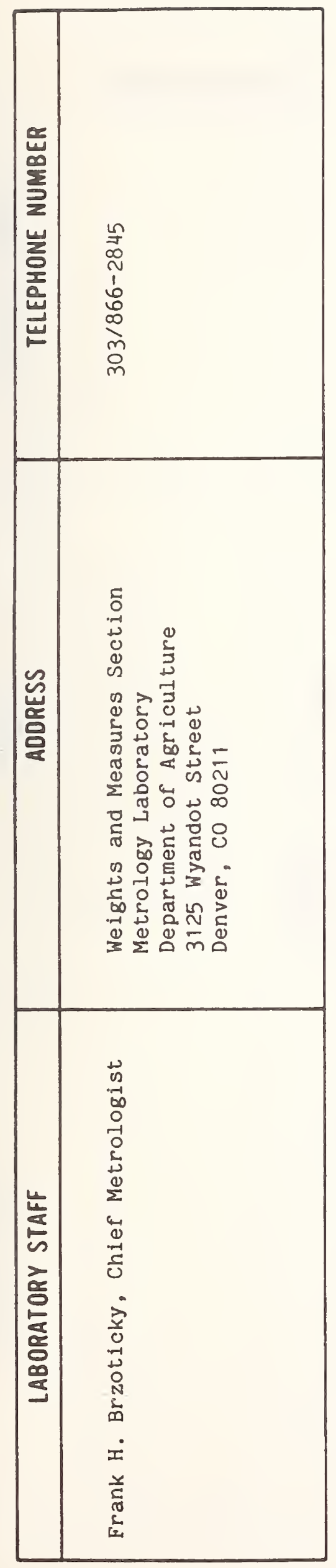

Colorado

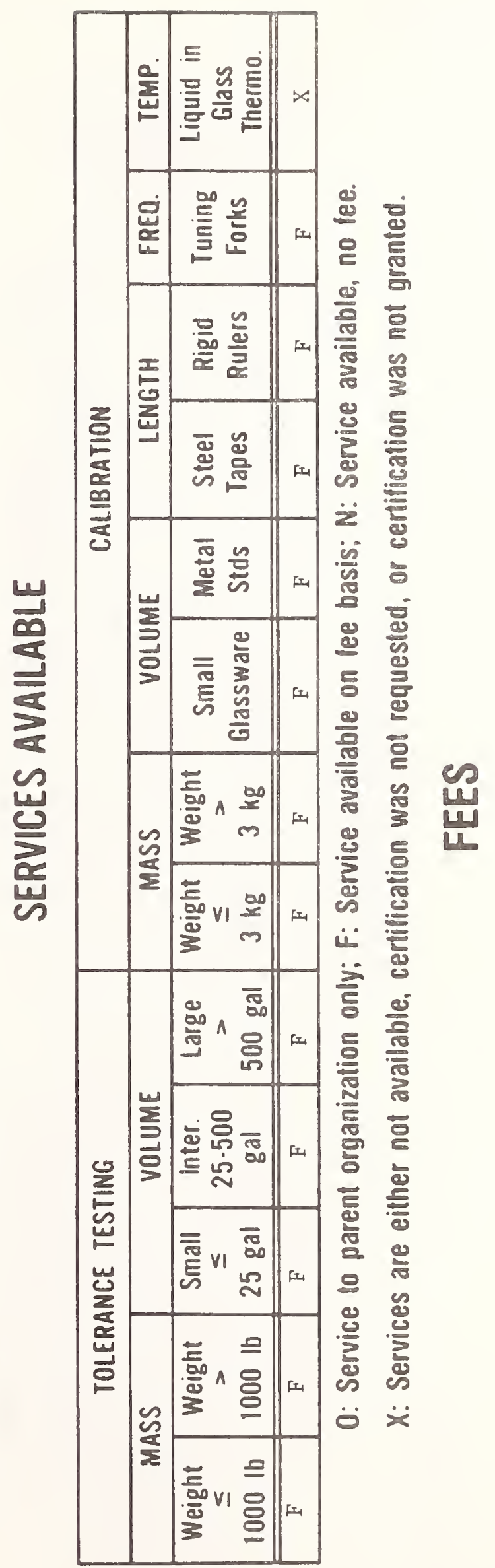

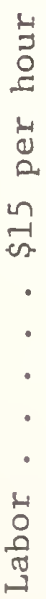




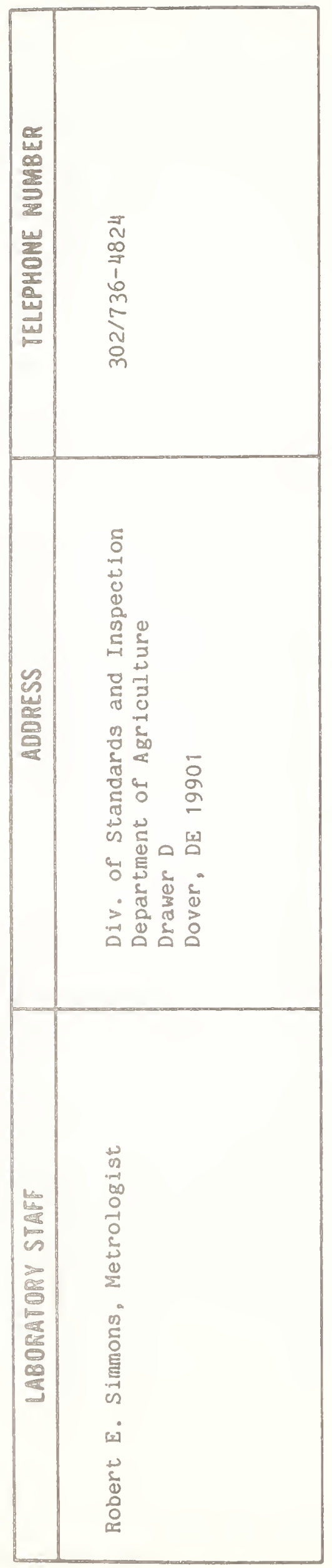

Delaware

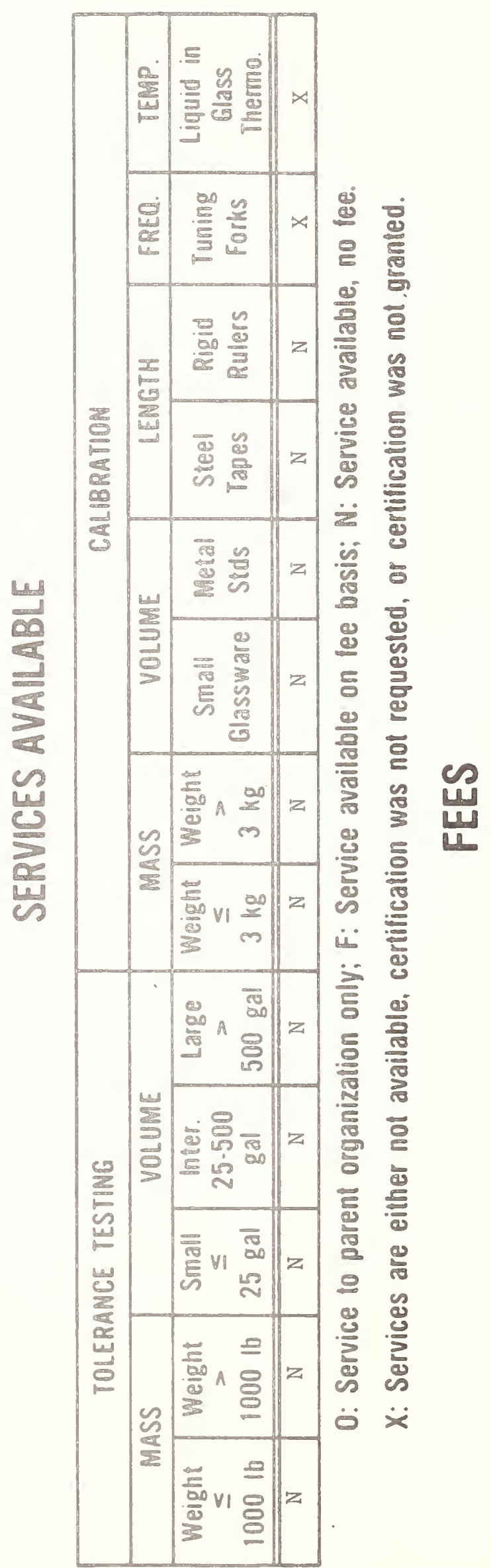




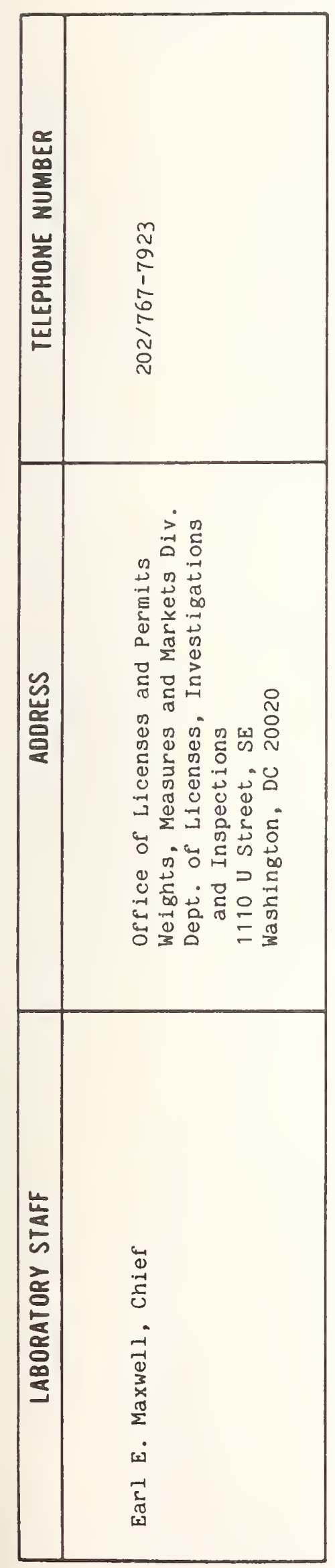

\section{District of Columbia}

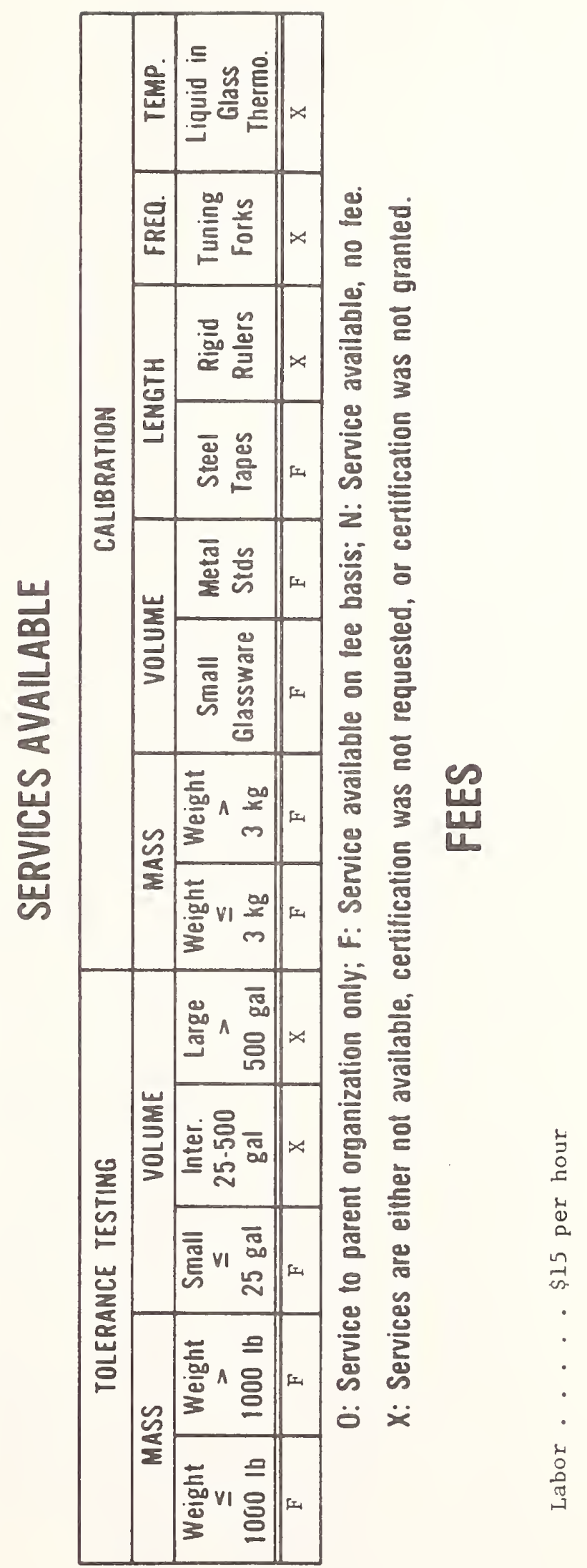




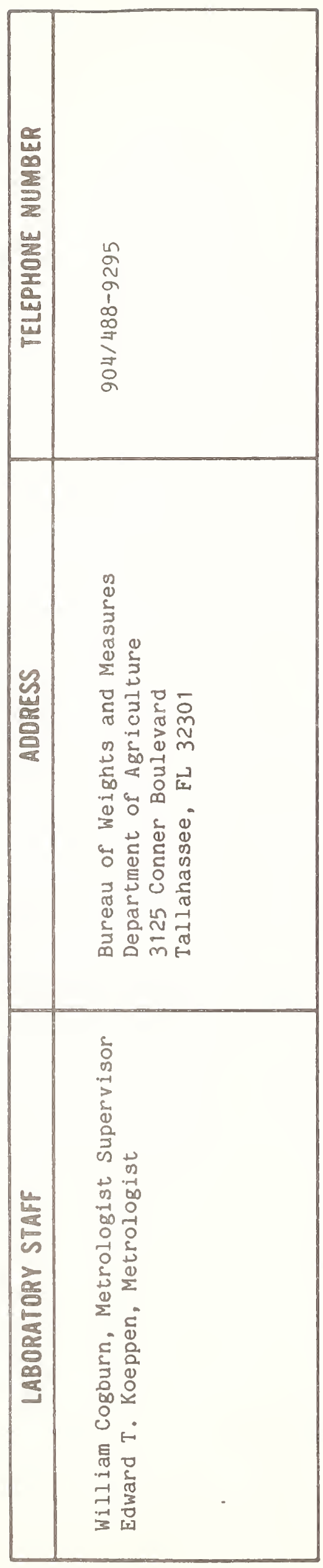

Florida

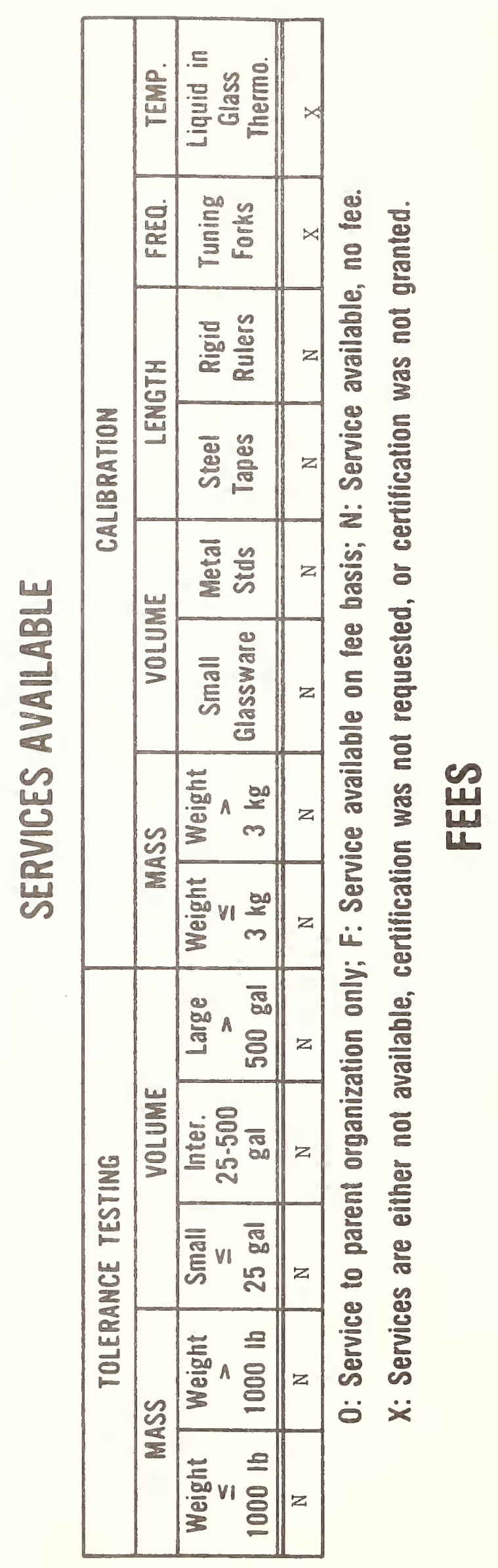




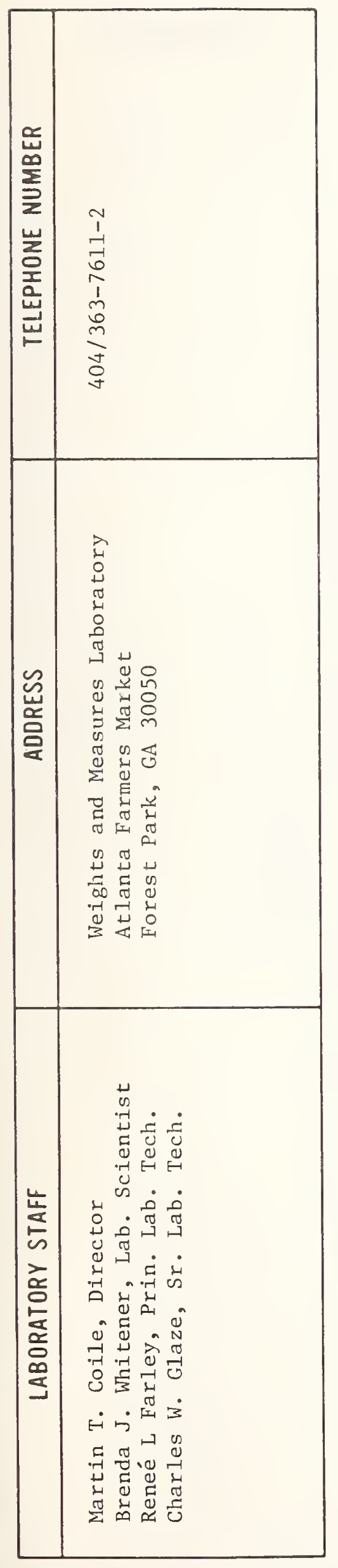

Georgia

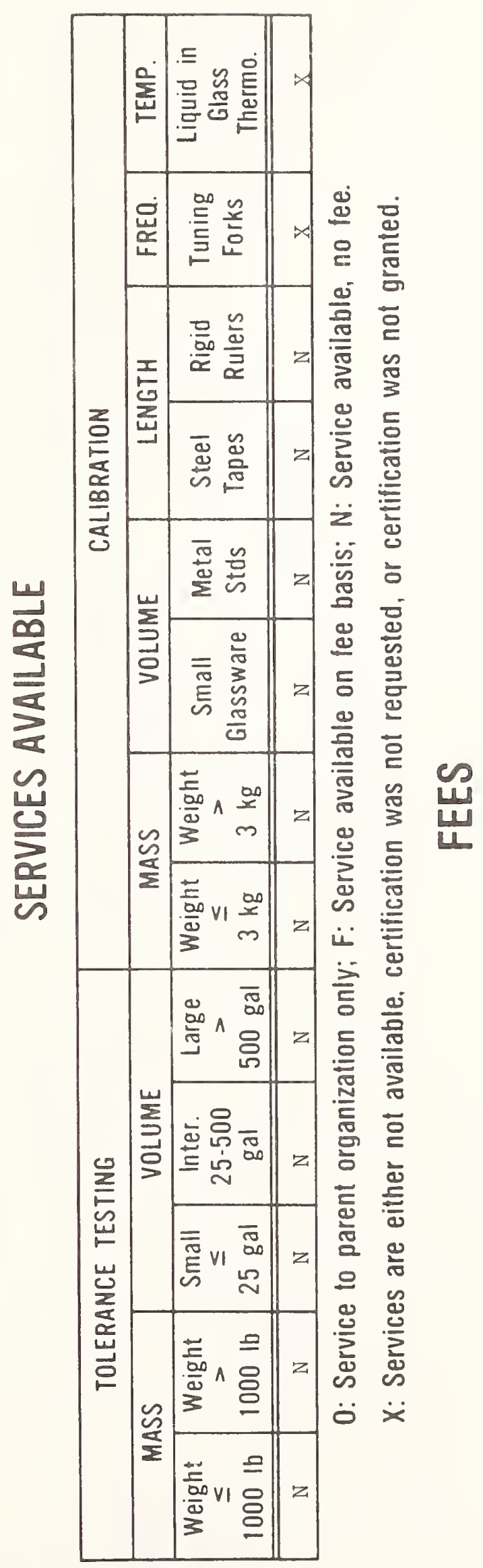




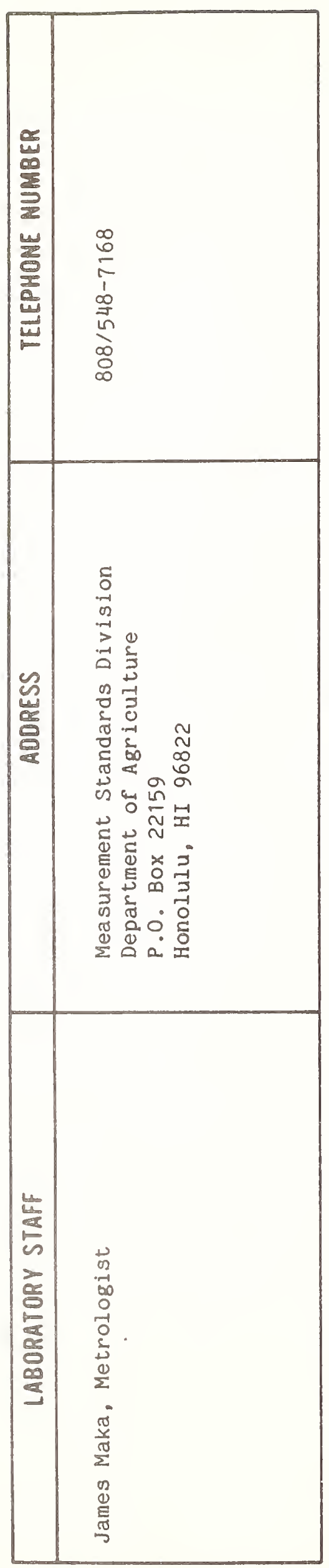

Hawaii

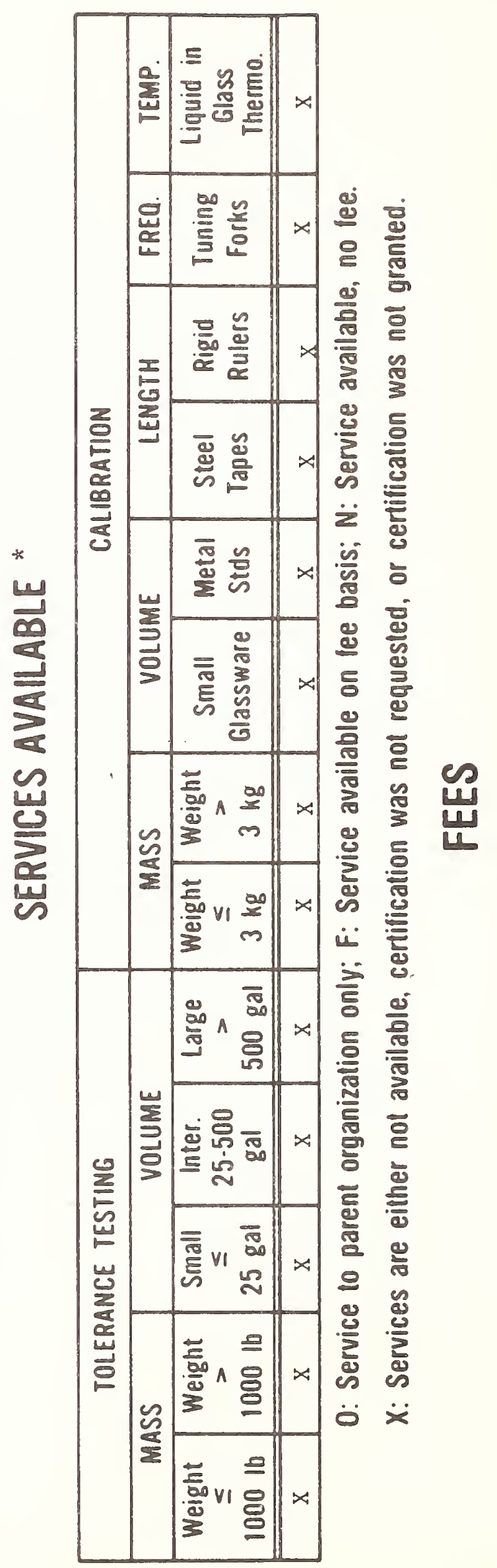

 


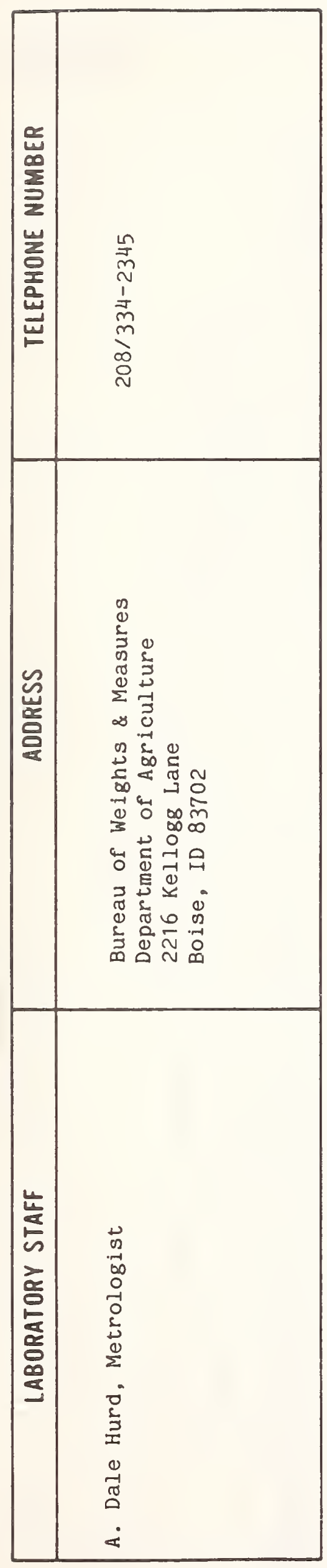

Idaho

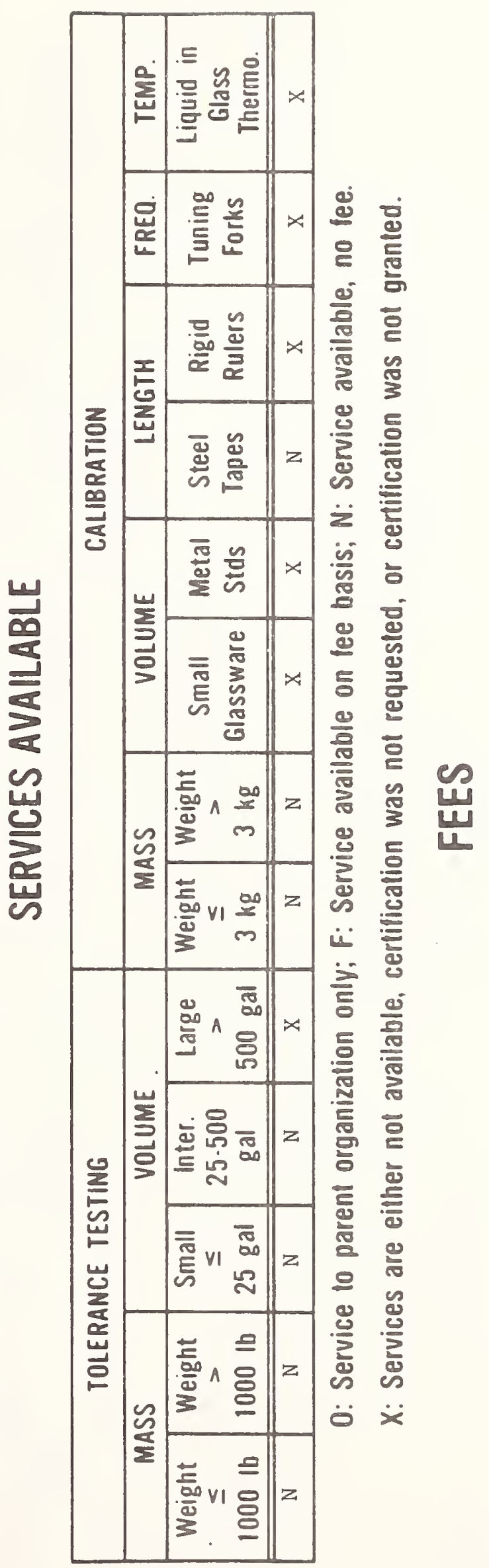



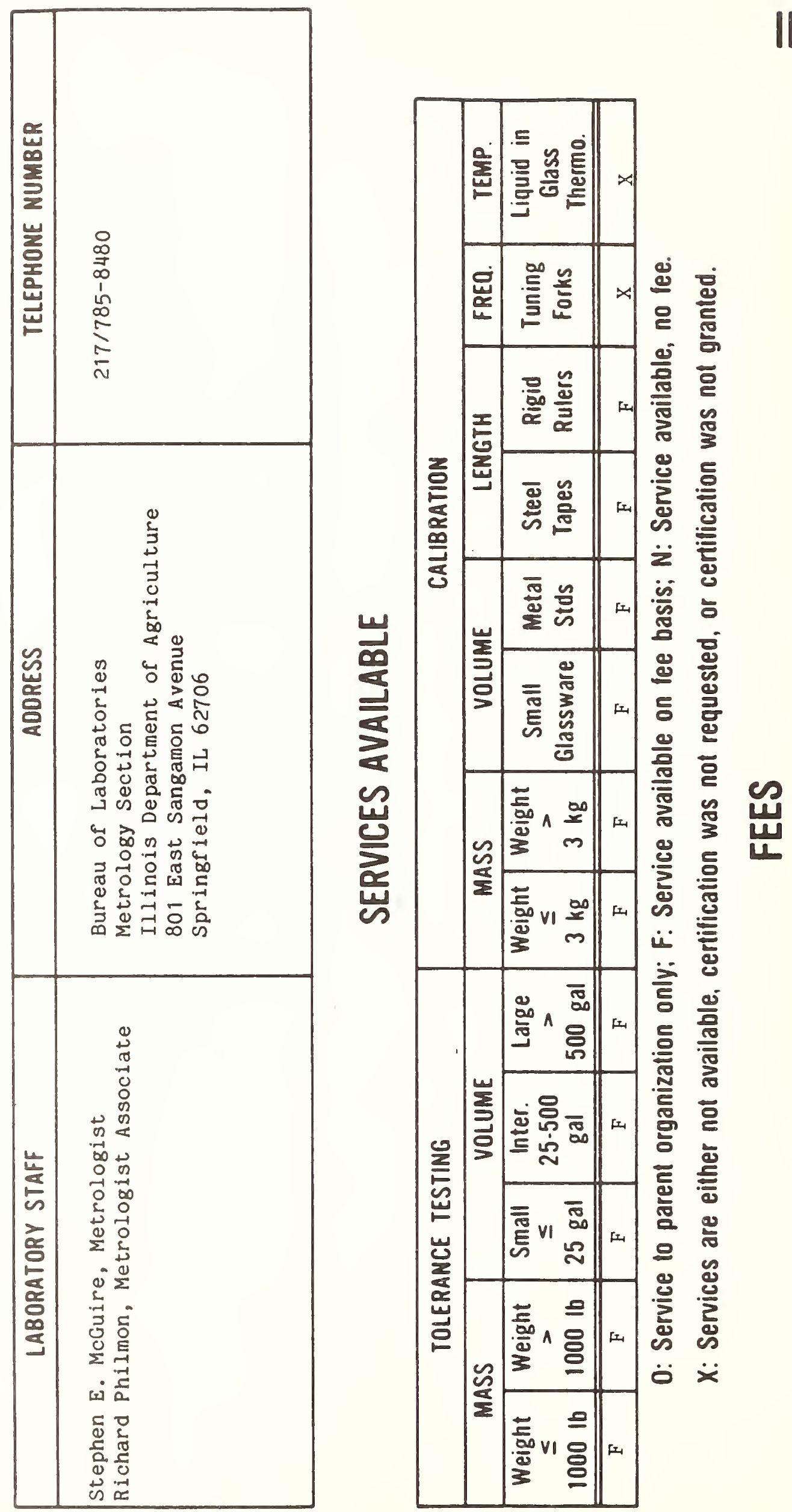

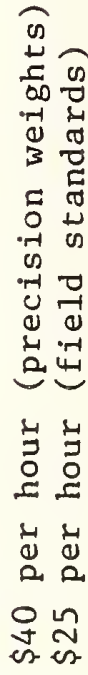



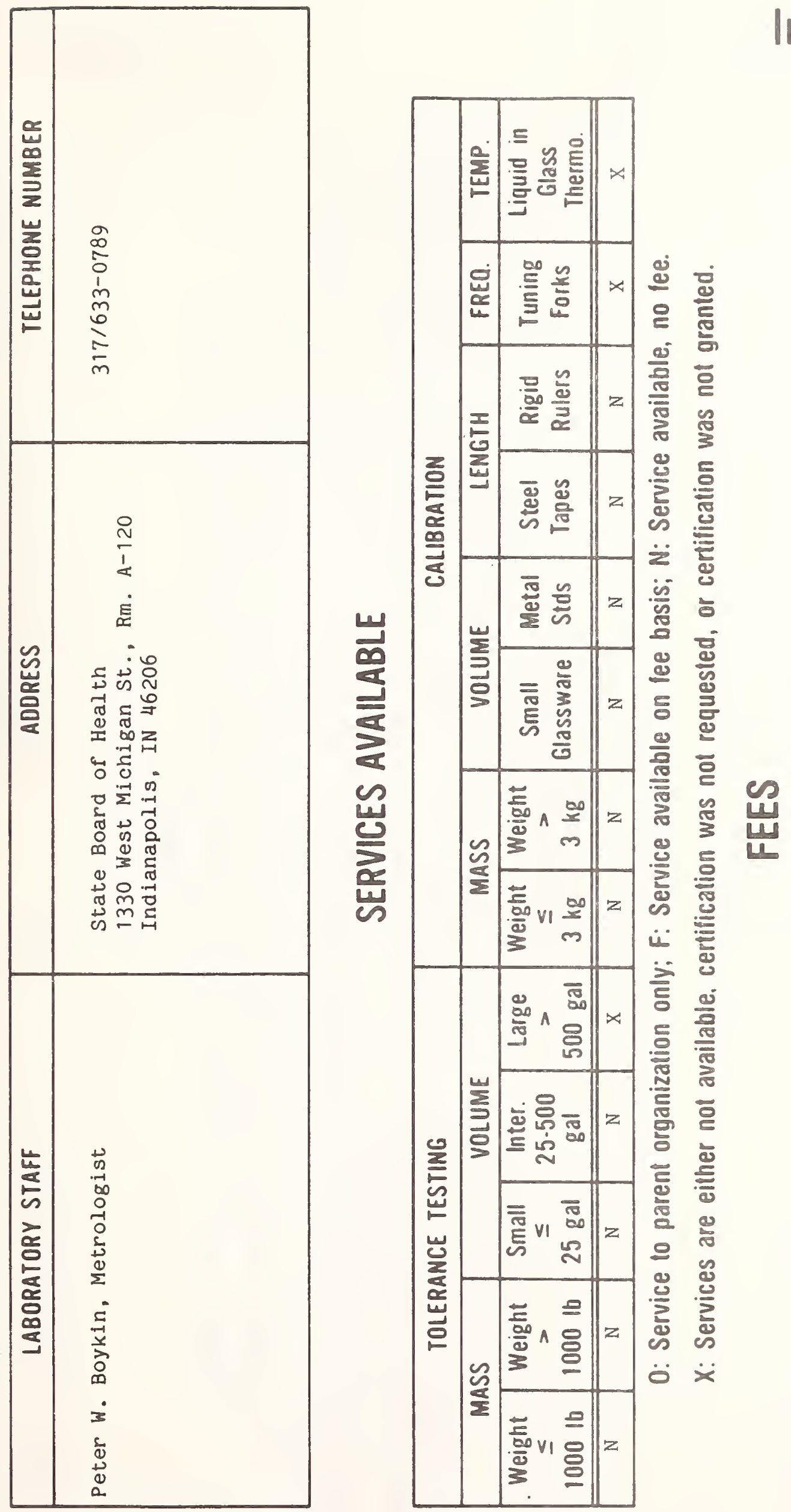

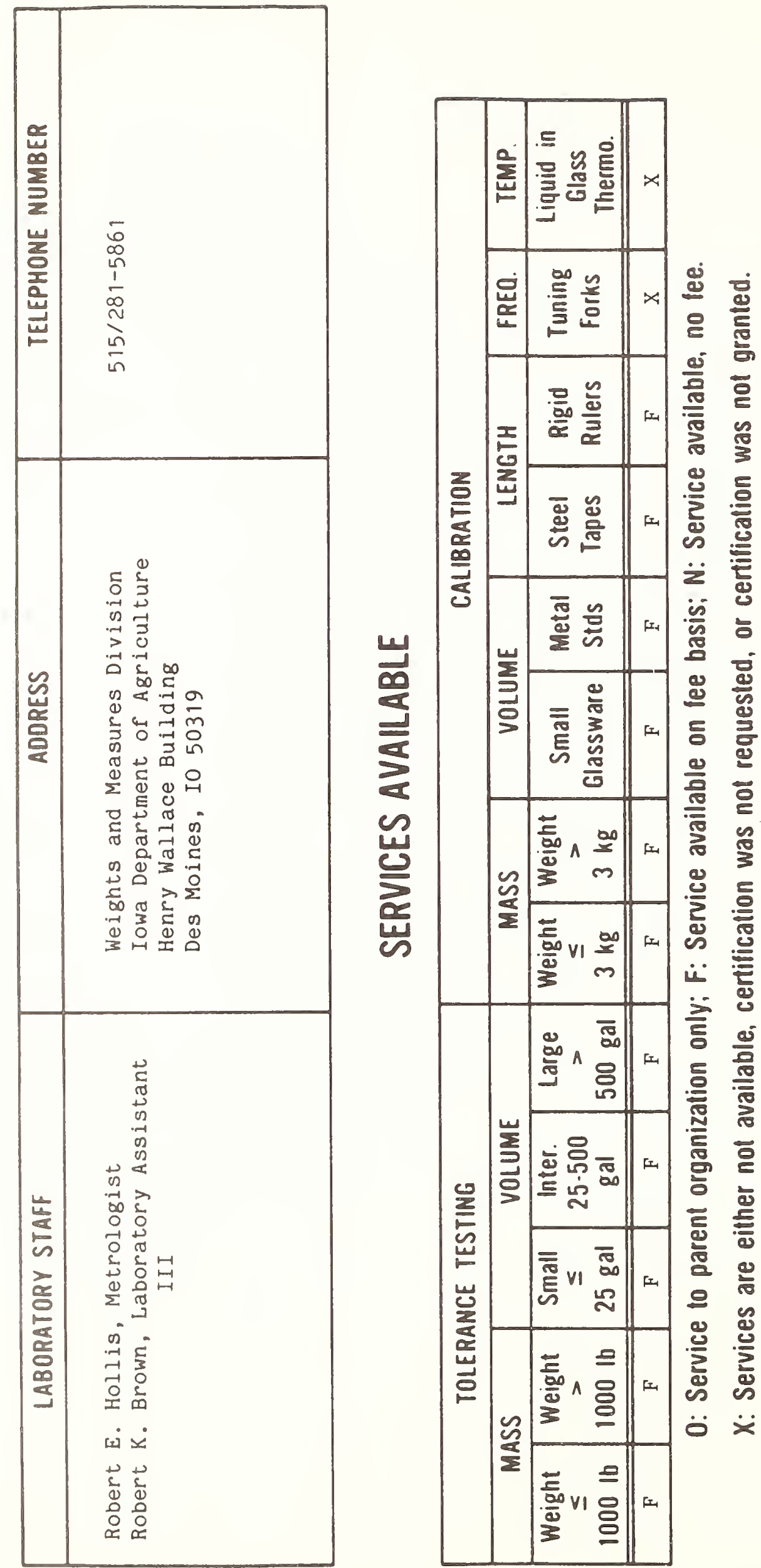

웅ํㅇํ요용

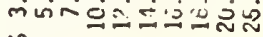

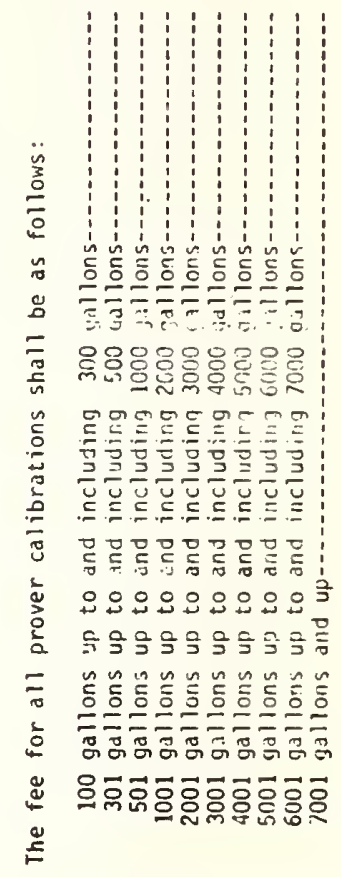

点㽞 능요 8 웅

- 2 iो $\infty$

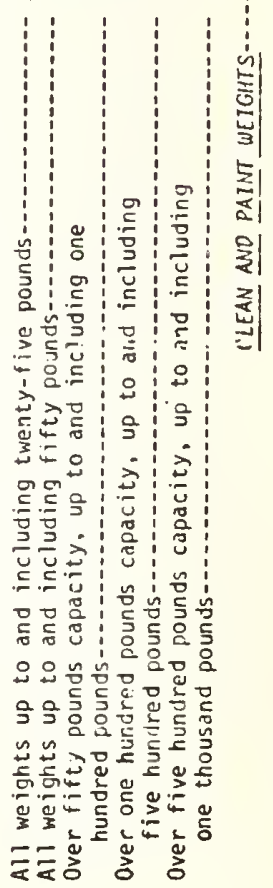




\begin{tabular}{|c|c|}
\hline 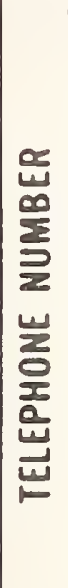 & 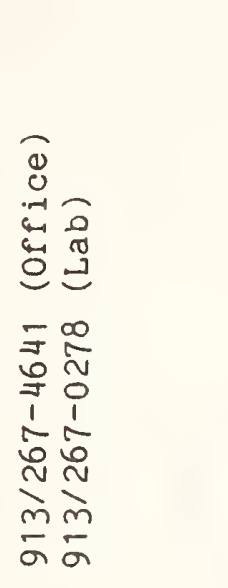 \\
\hline $\begin{array}{l}\tilde{U} \\
\stackrel{\tilde{O}}{0} \\
\stackrel{0}{0}\end{array}$ & 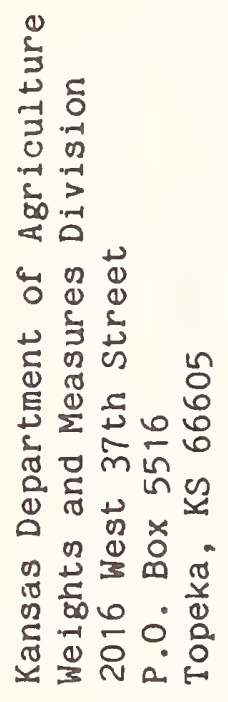 \\
\hline 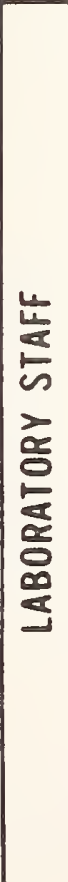 & 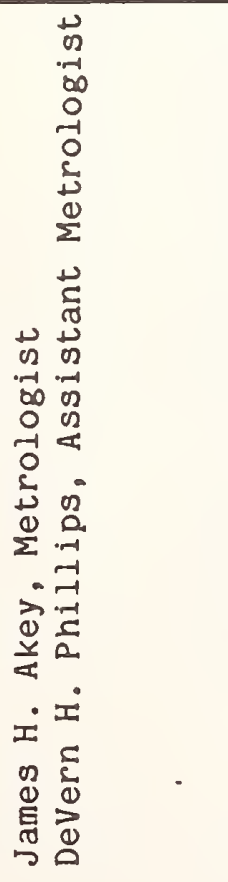 \\
\hline
\end{tabular}

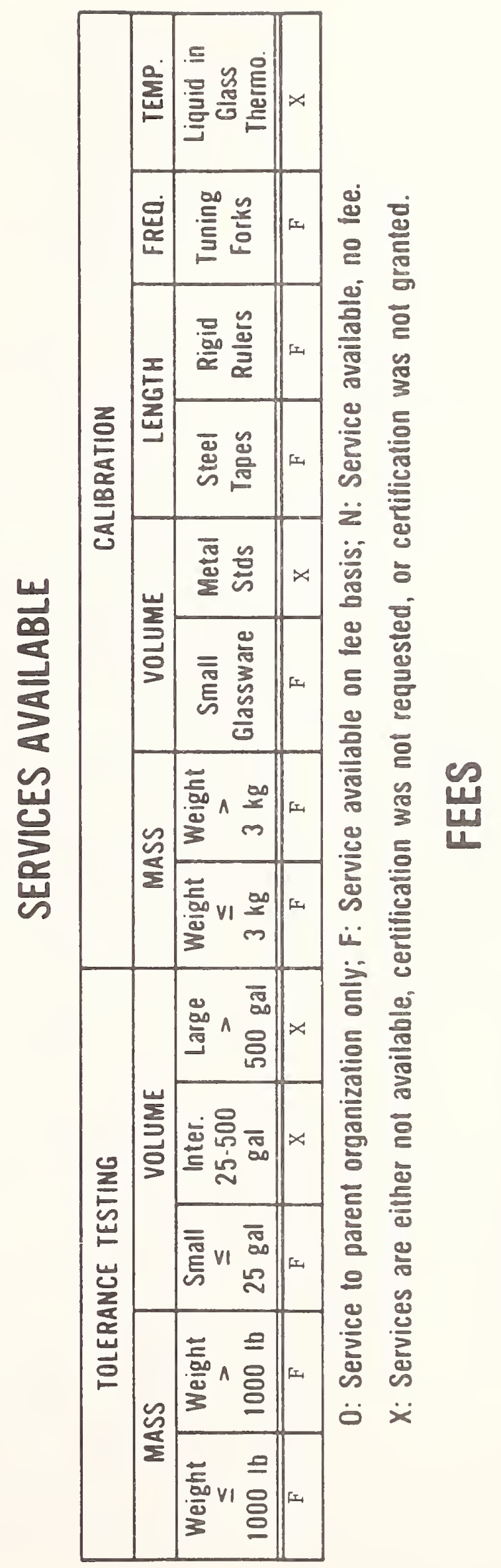




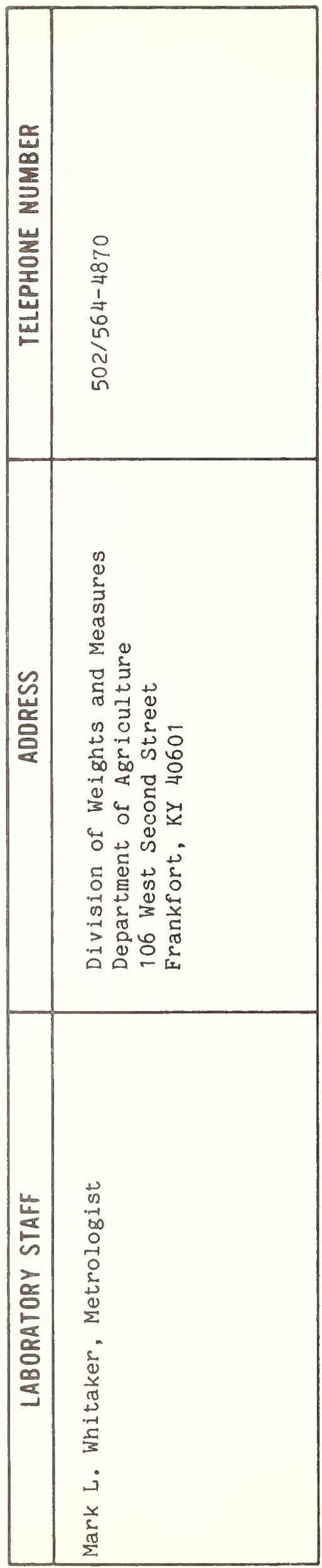

Kentucky

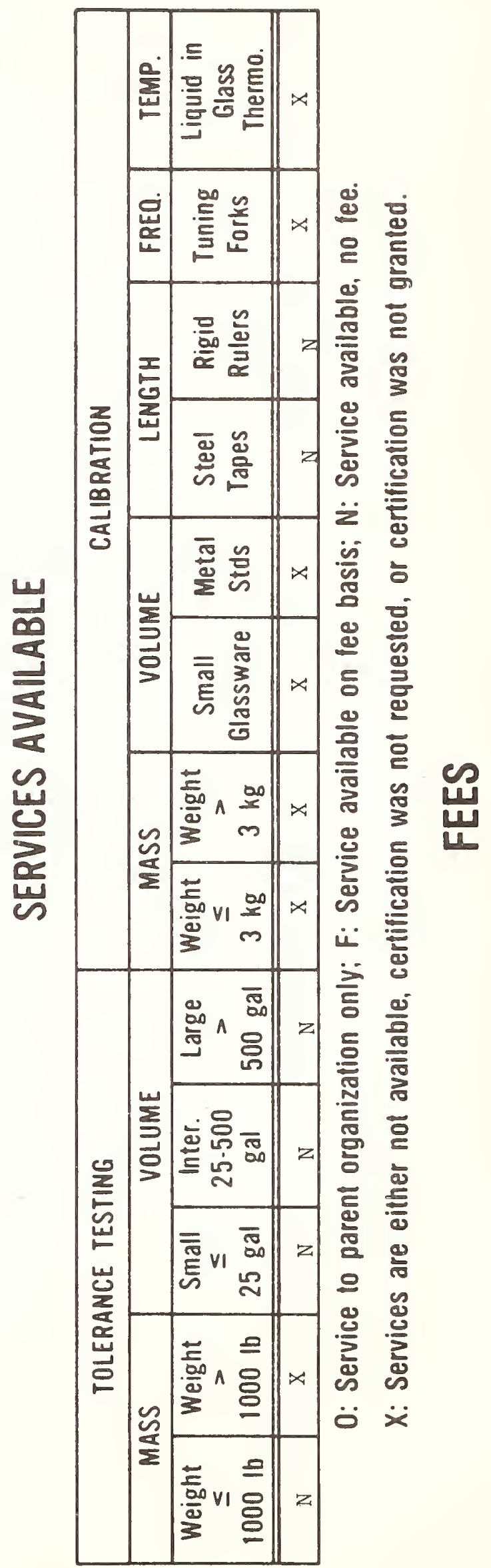




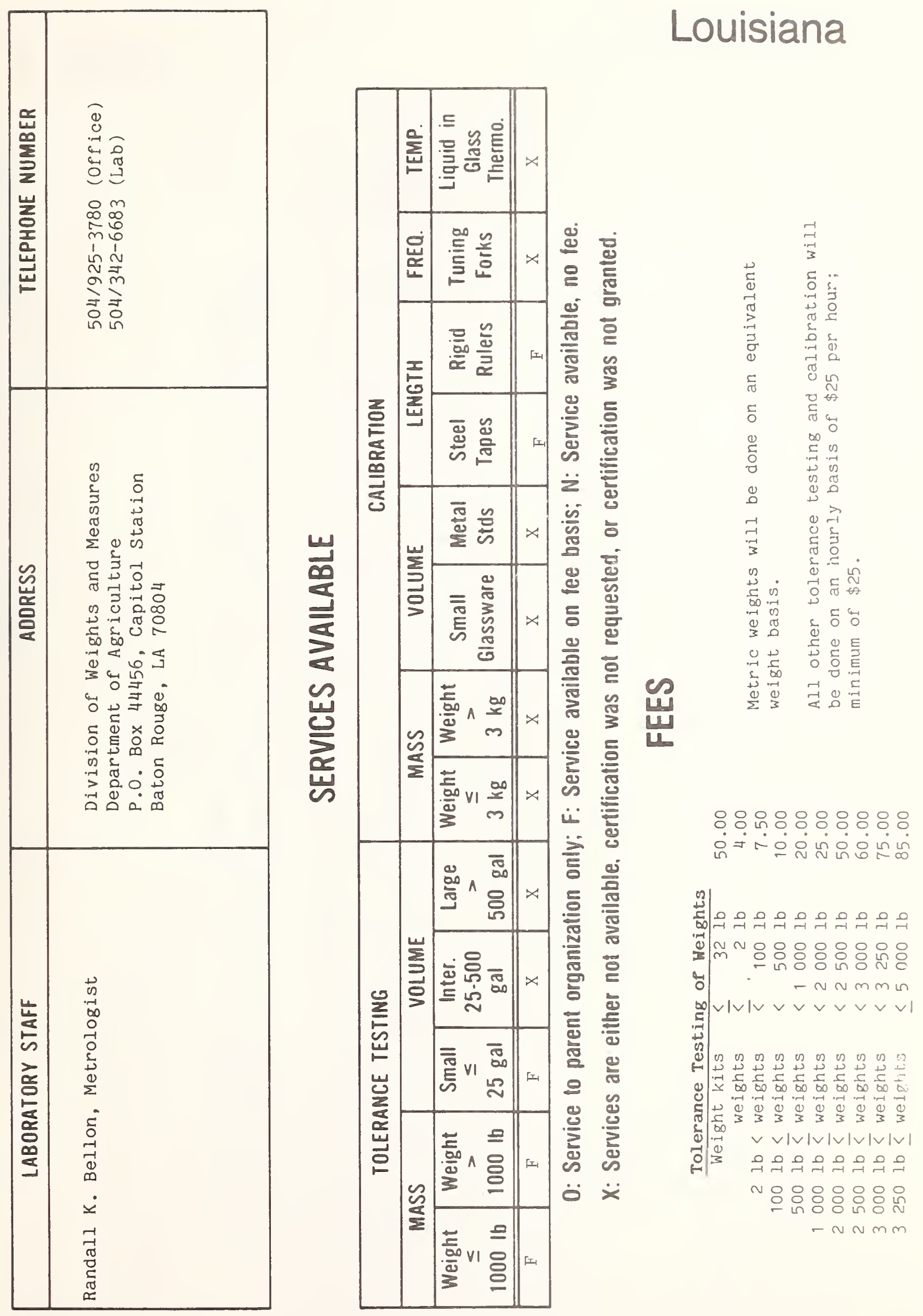



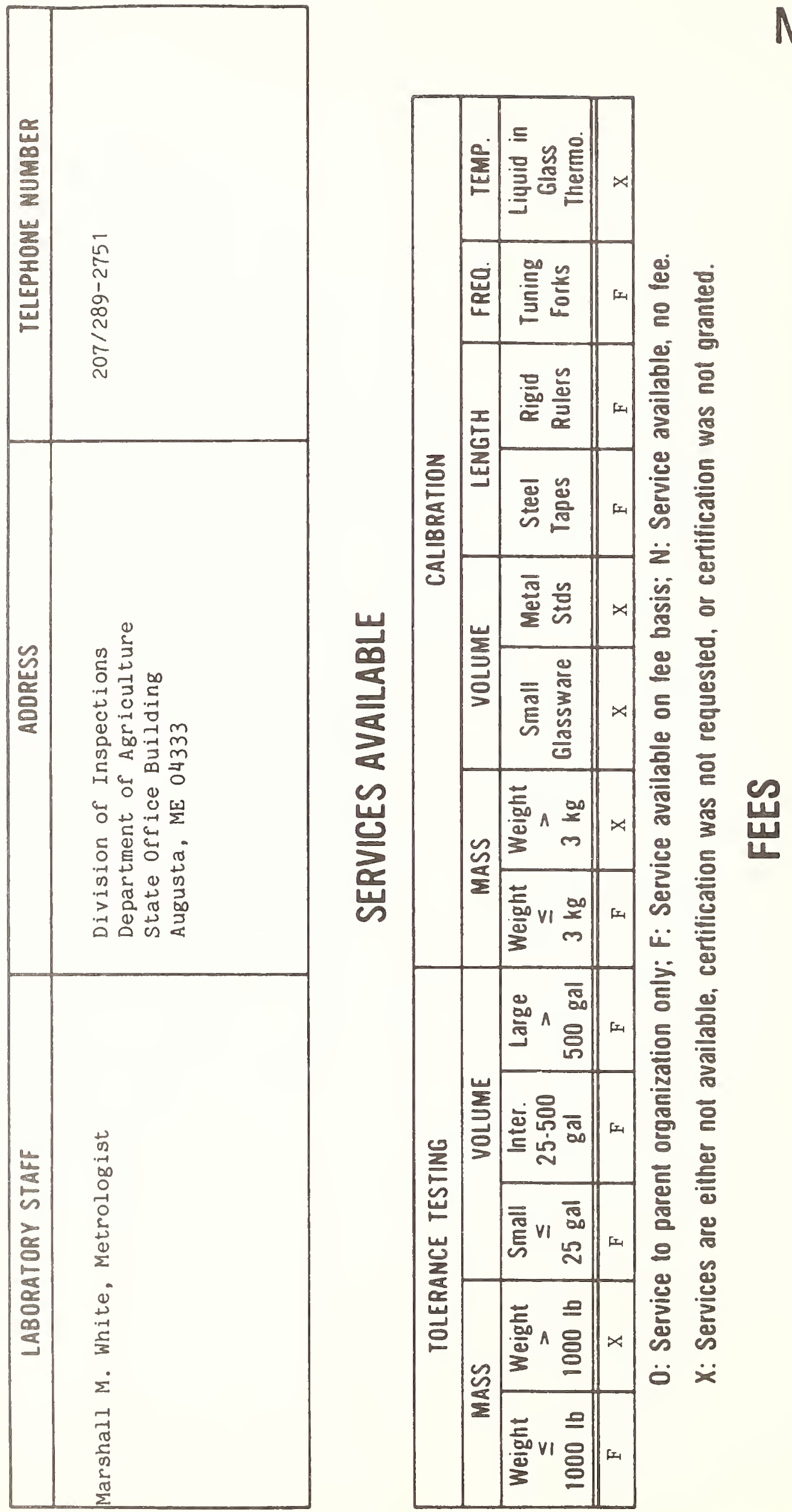

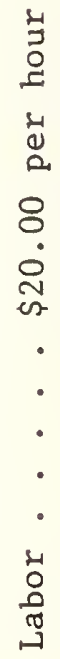




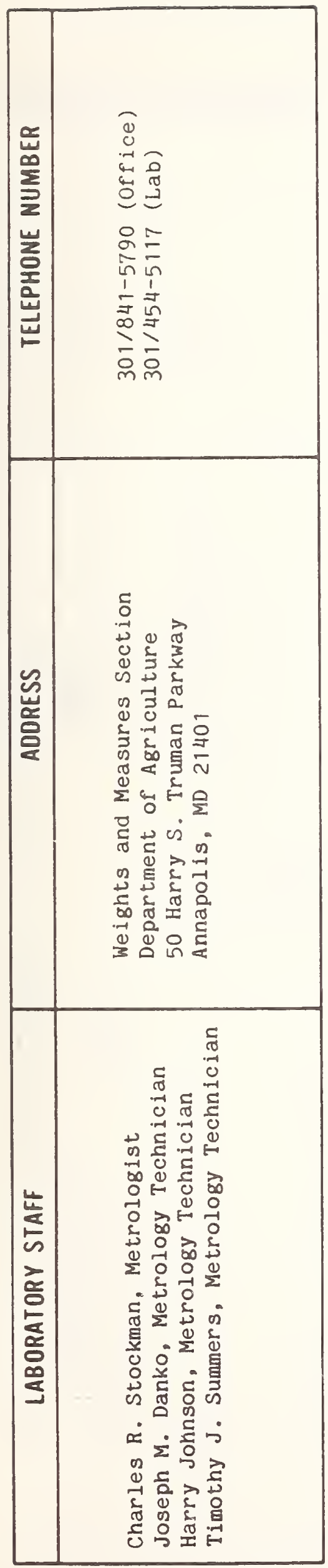

Maryland

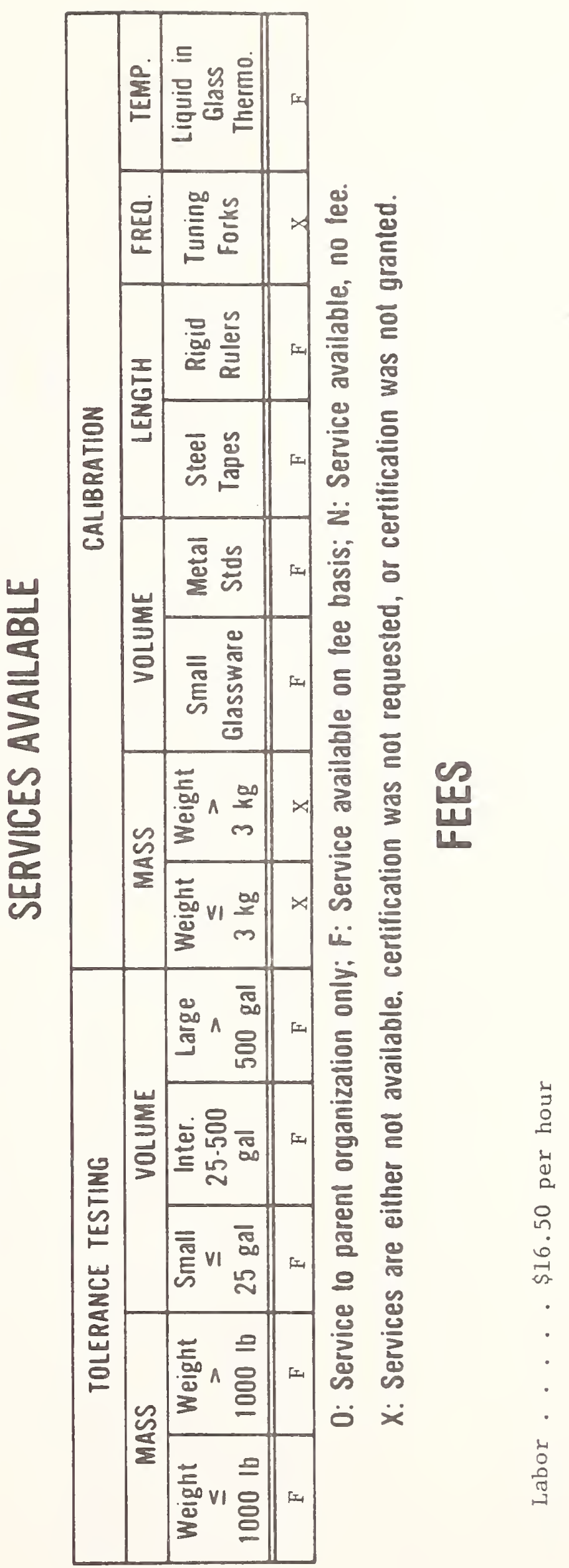




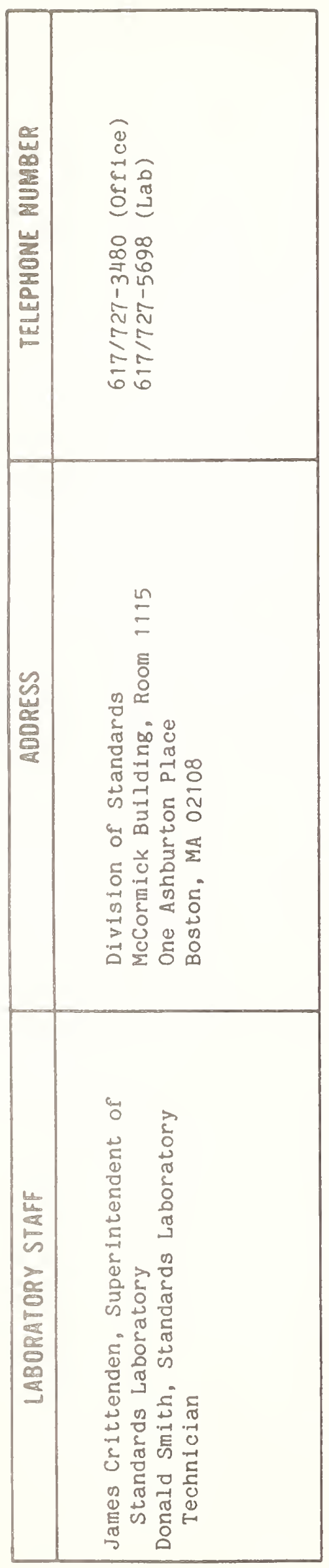

Massachusetts

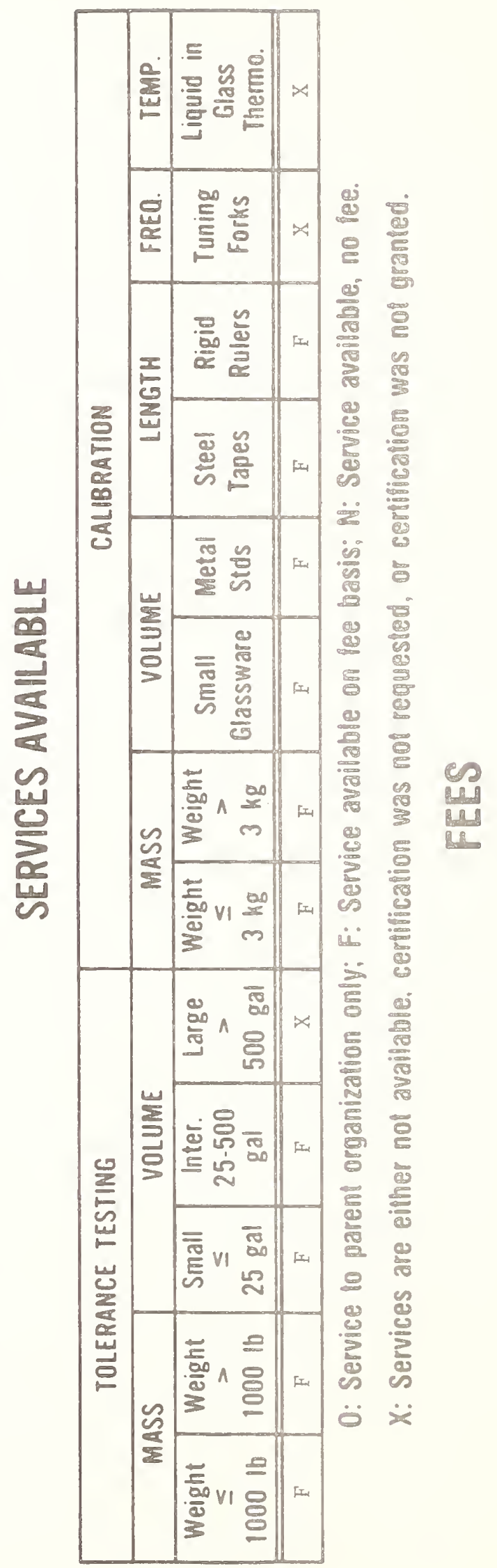

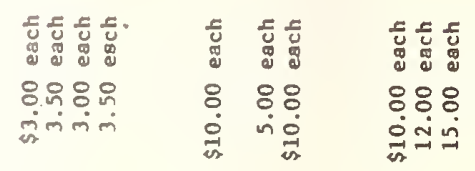
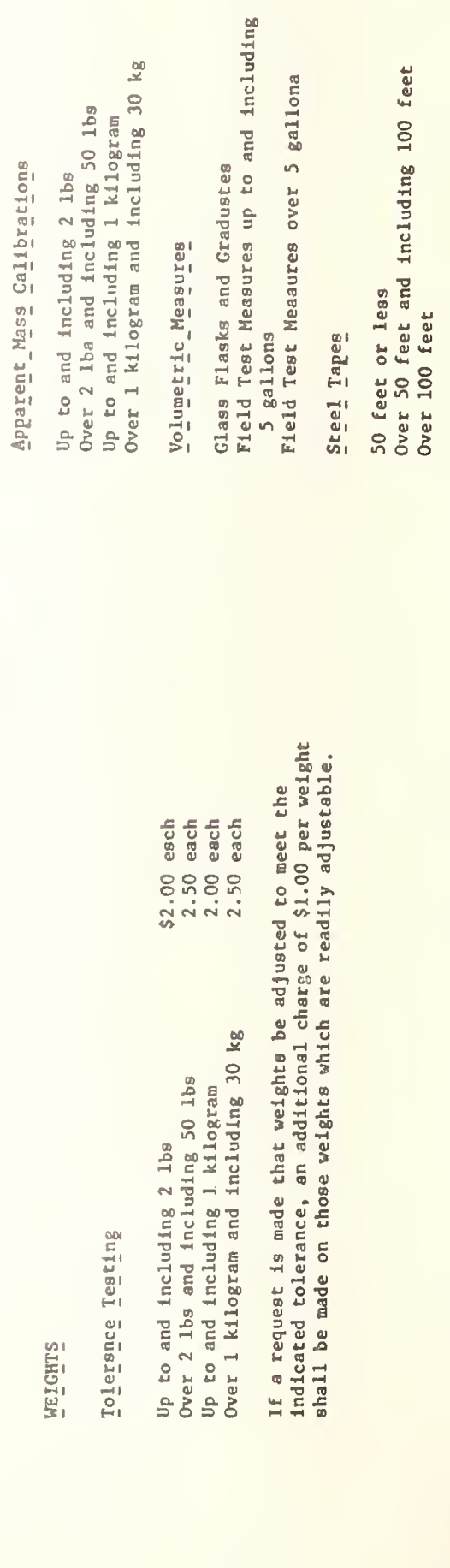


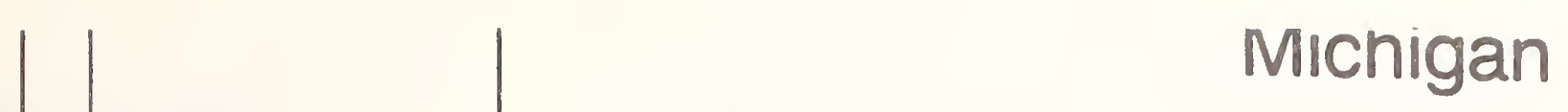

$\circ$
$\frac{0}{0}$
$\frac{1}{m}$
$\frac{m}{n}$
$\frac{1}{n}$

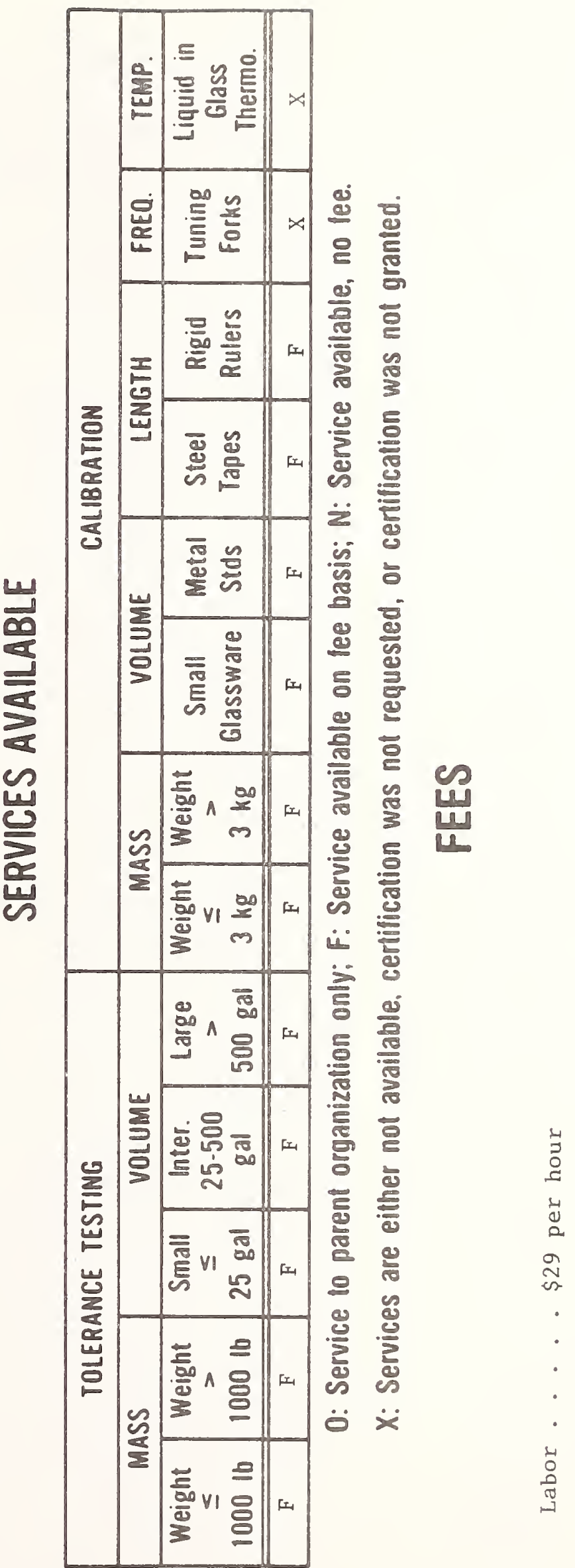




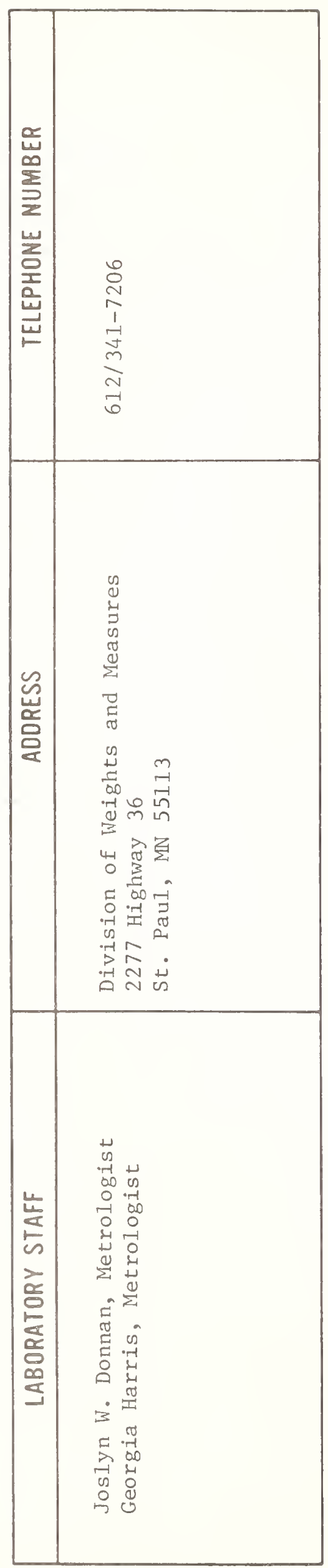

Minnesota

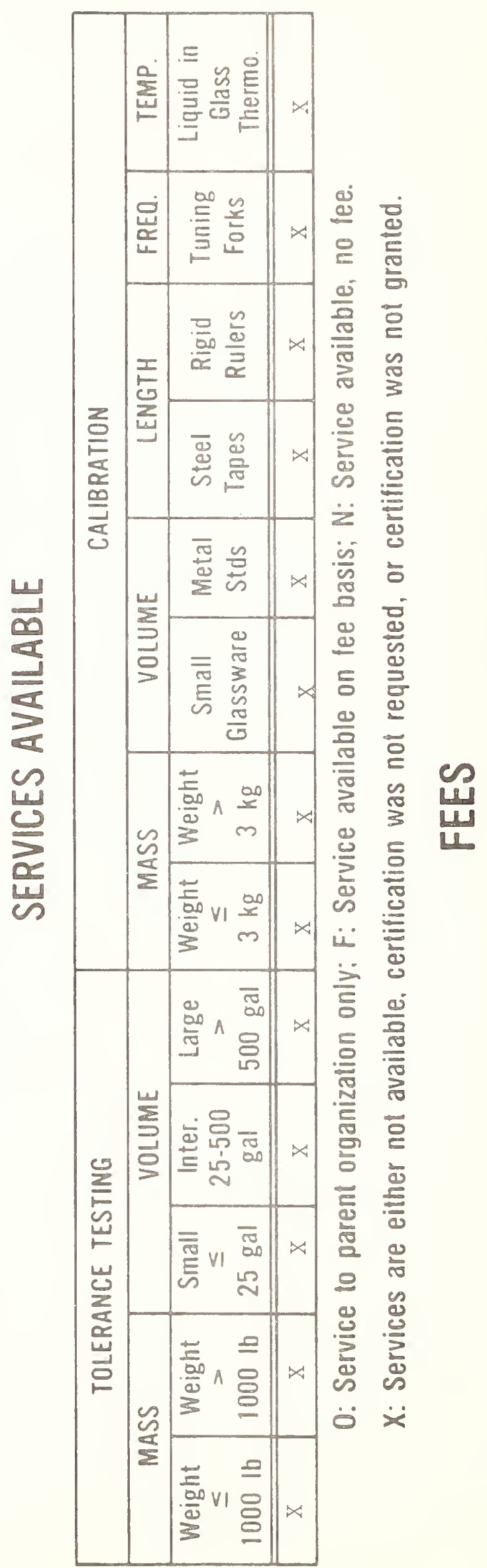




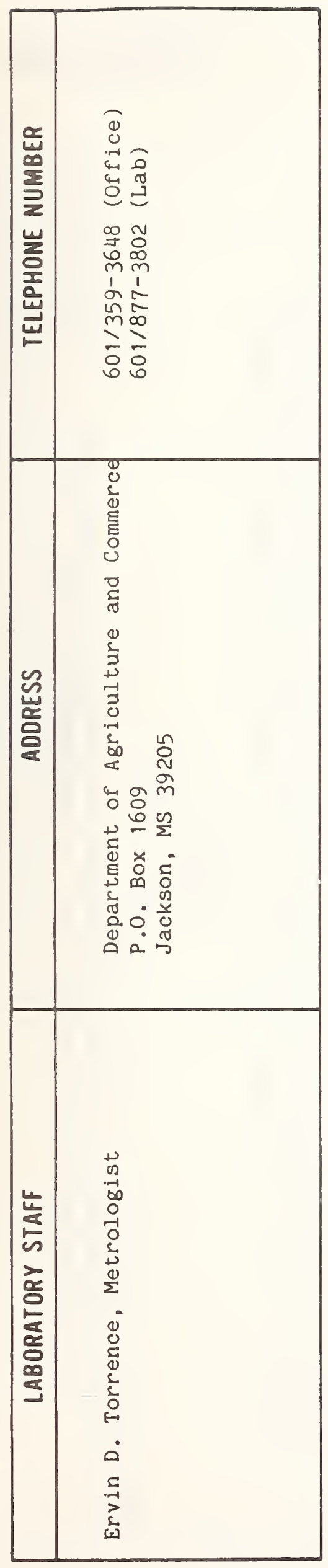

Mississippi

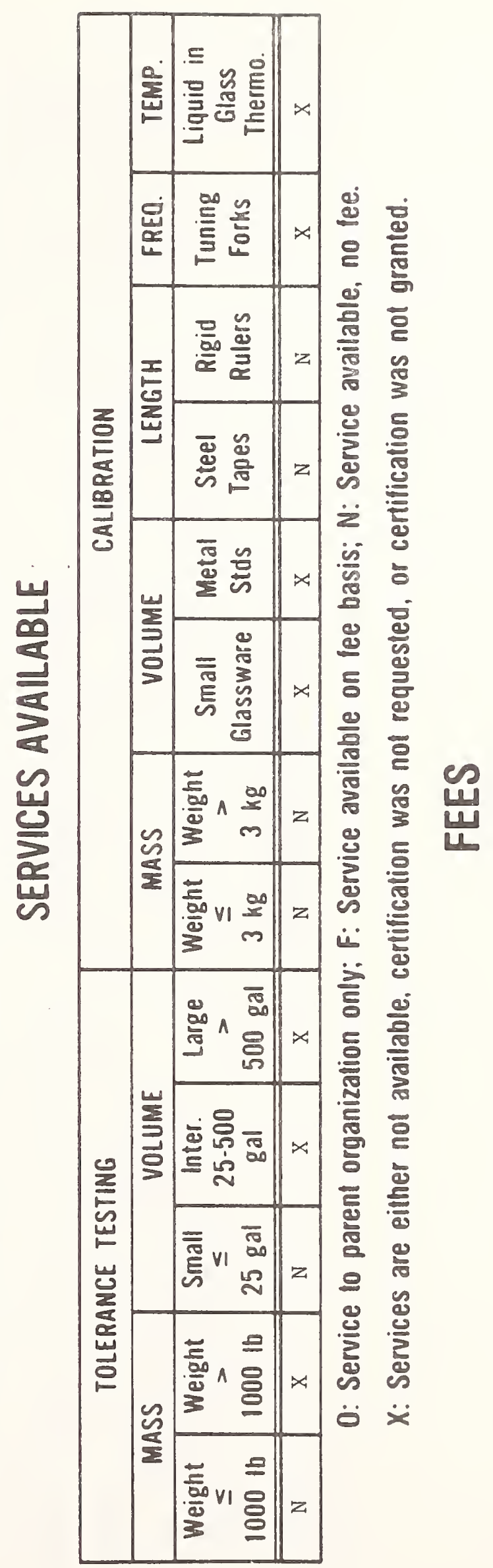




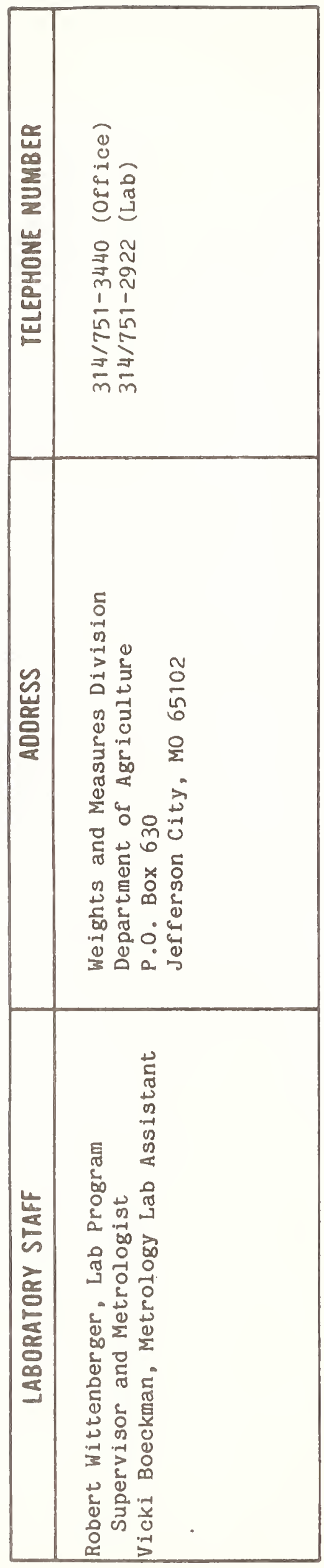

Missouri

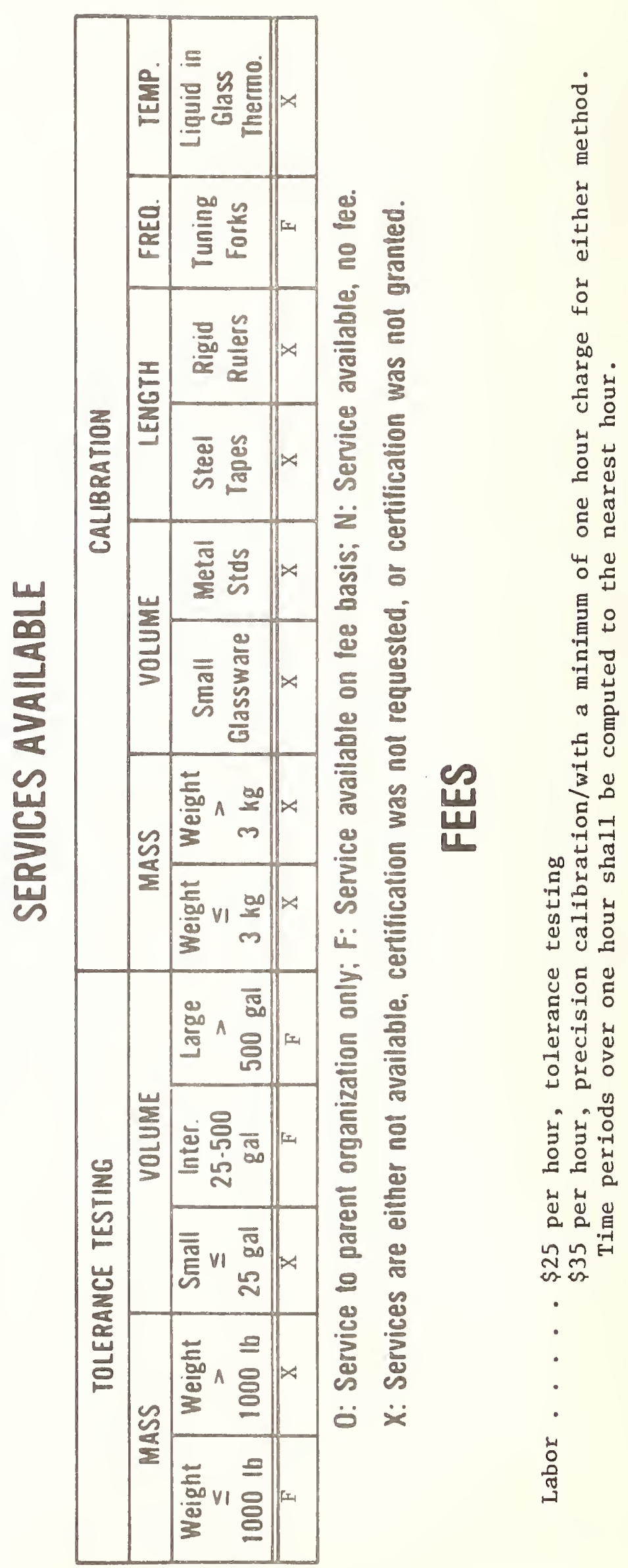




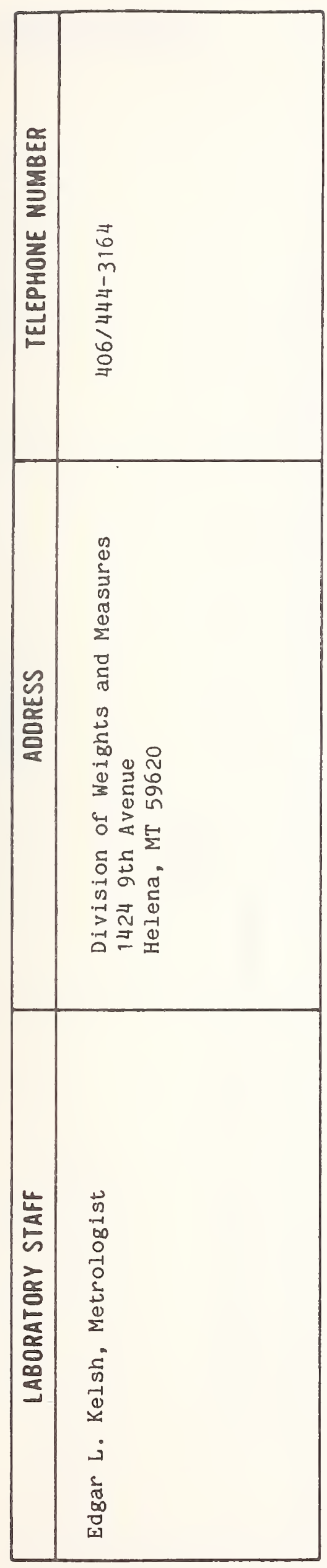

Montana

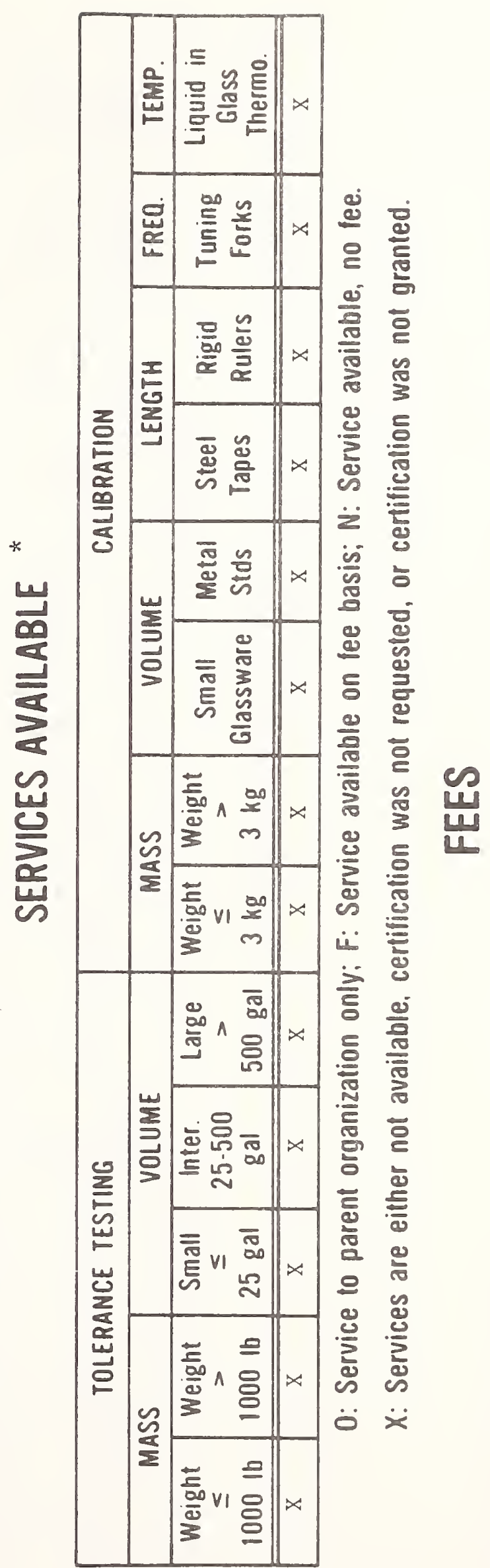

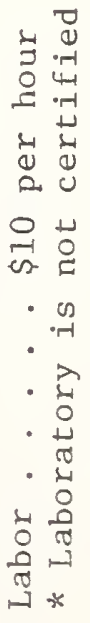



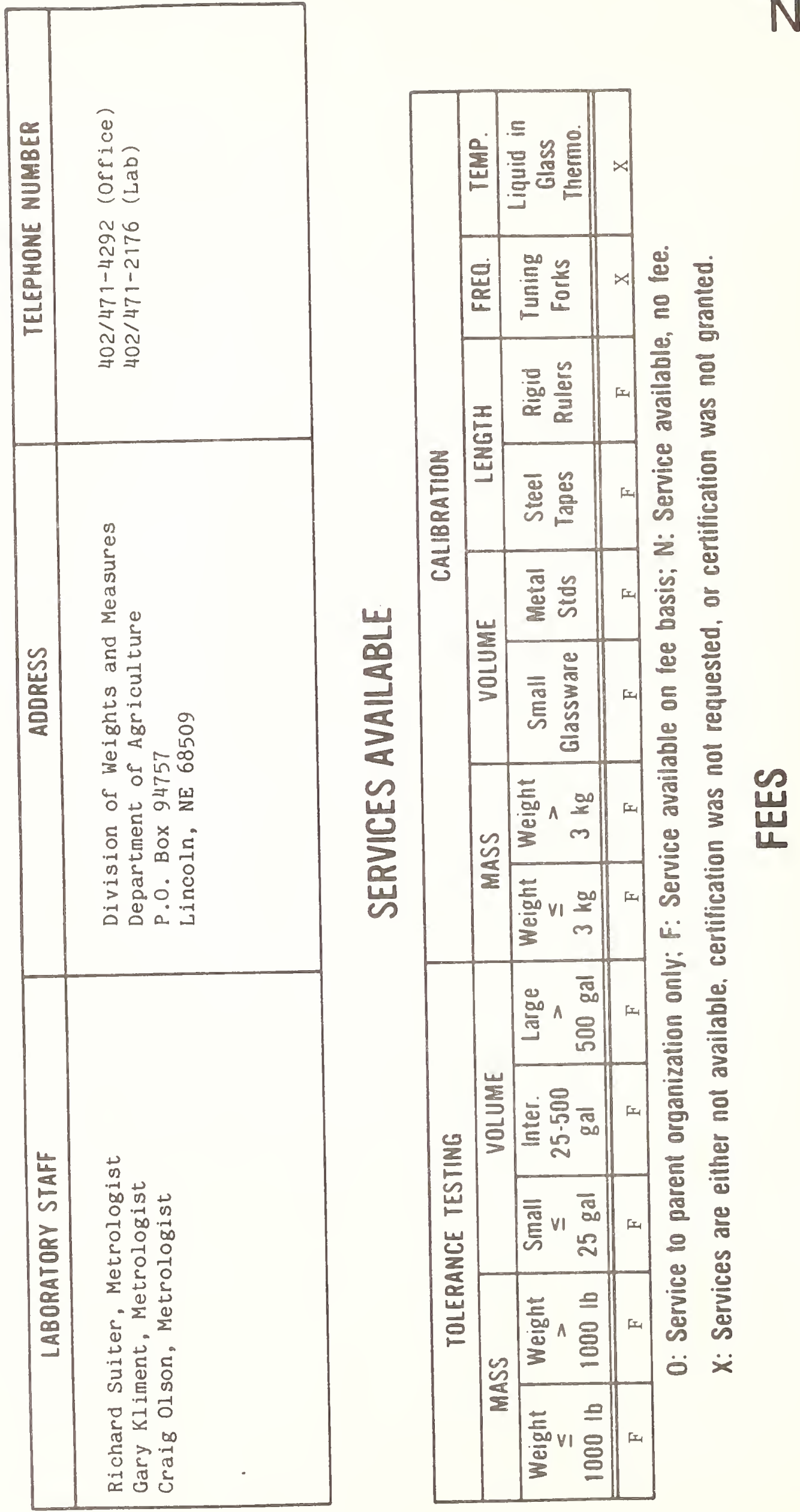

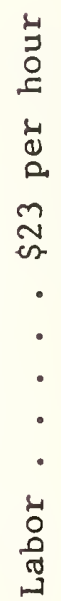



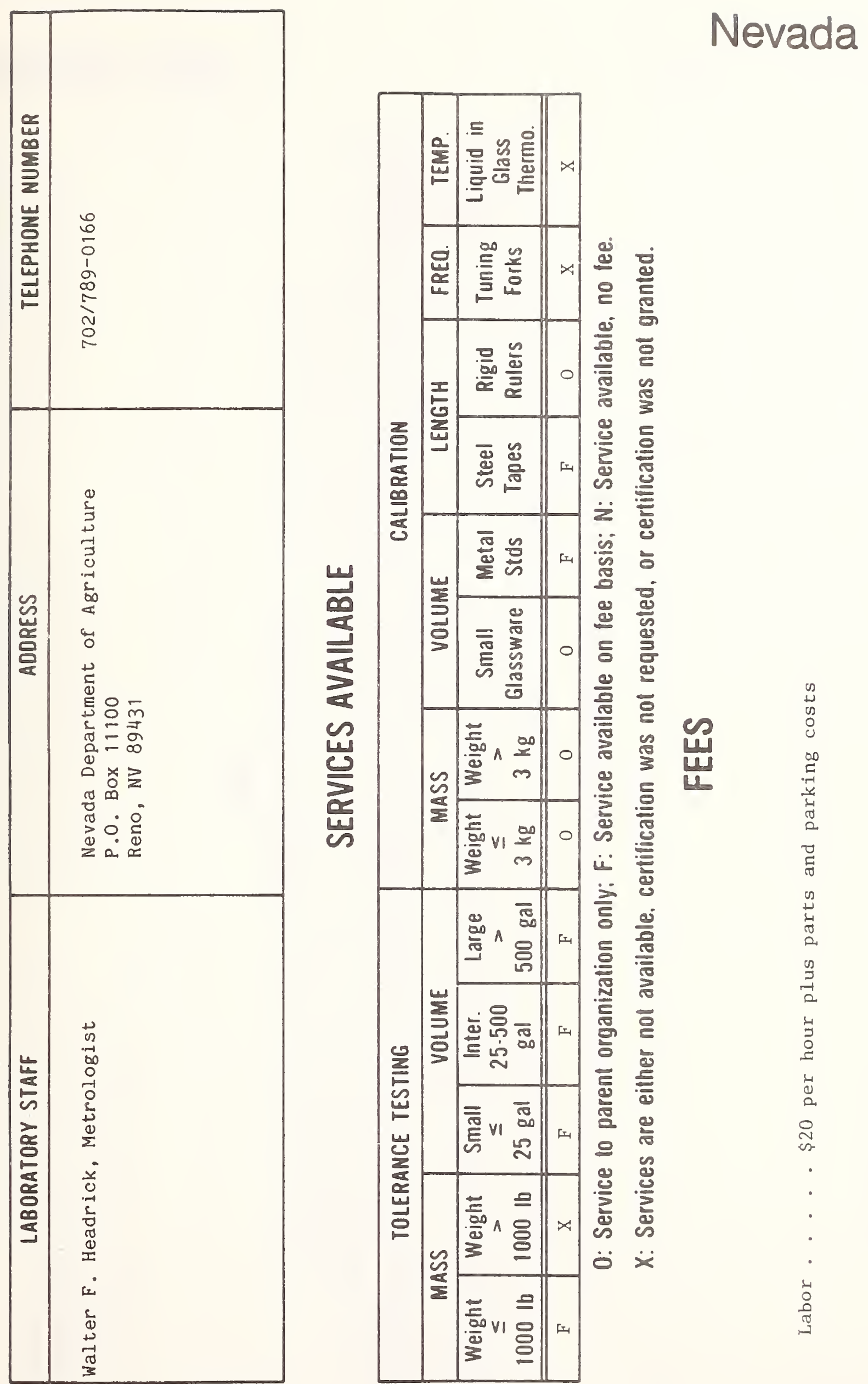


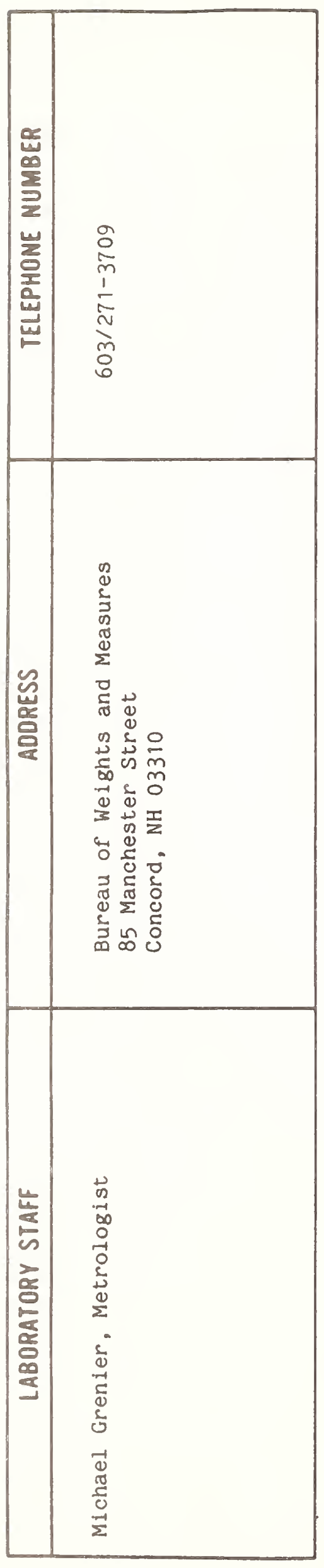

New Hampshire
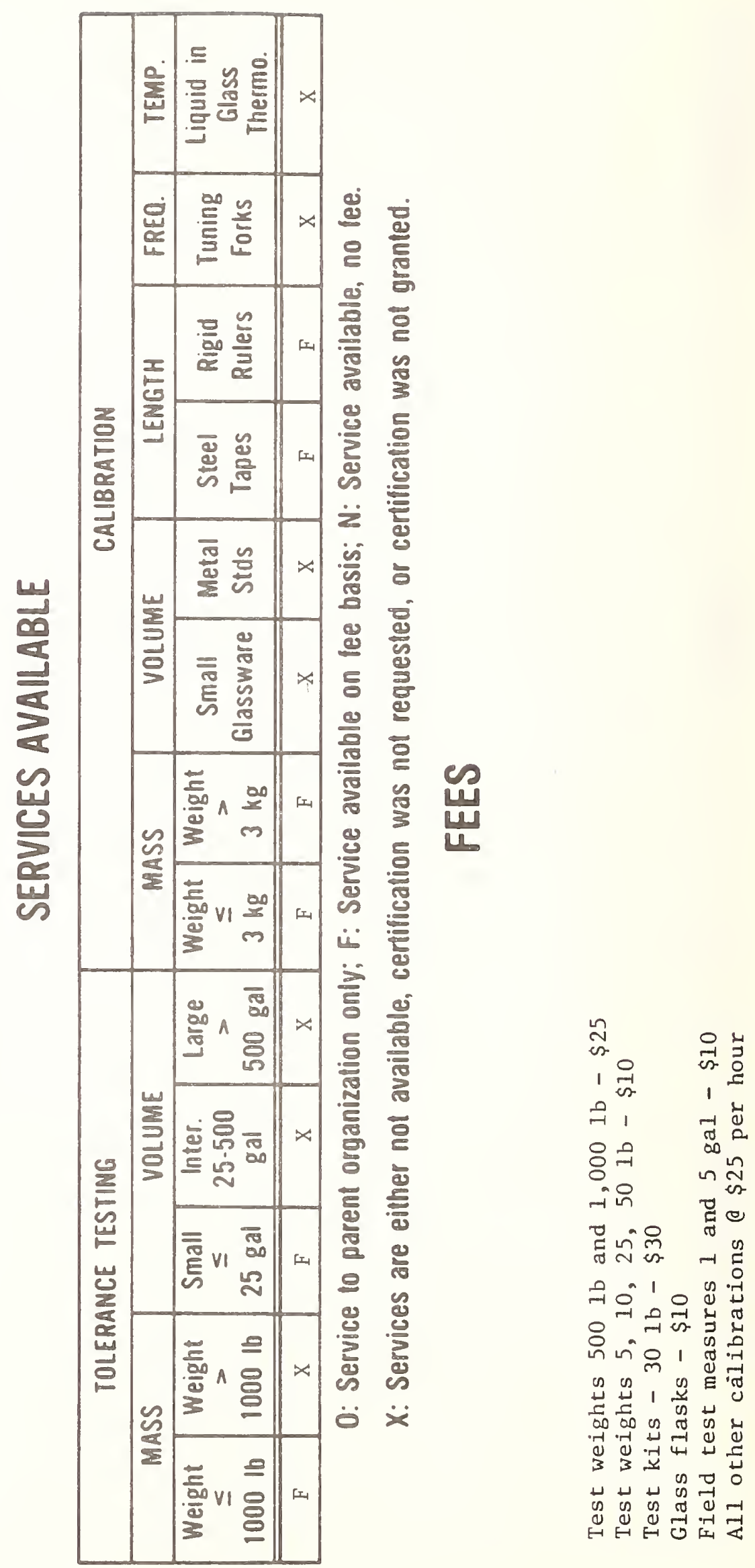


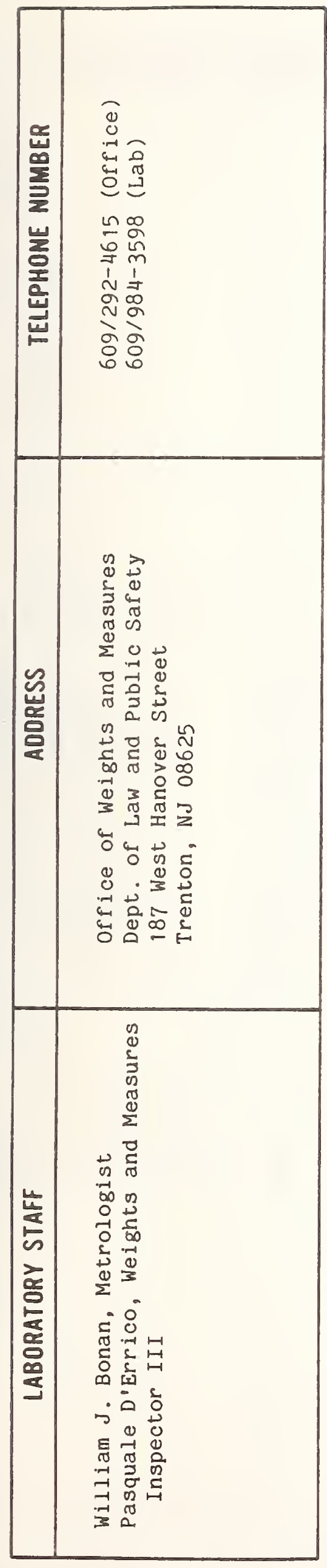

New Jersey

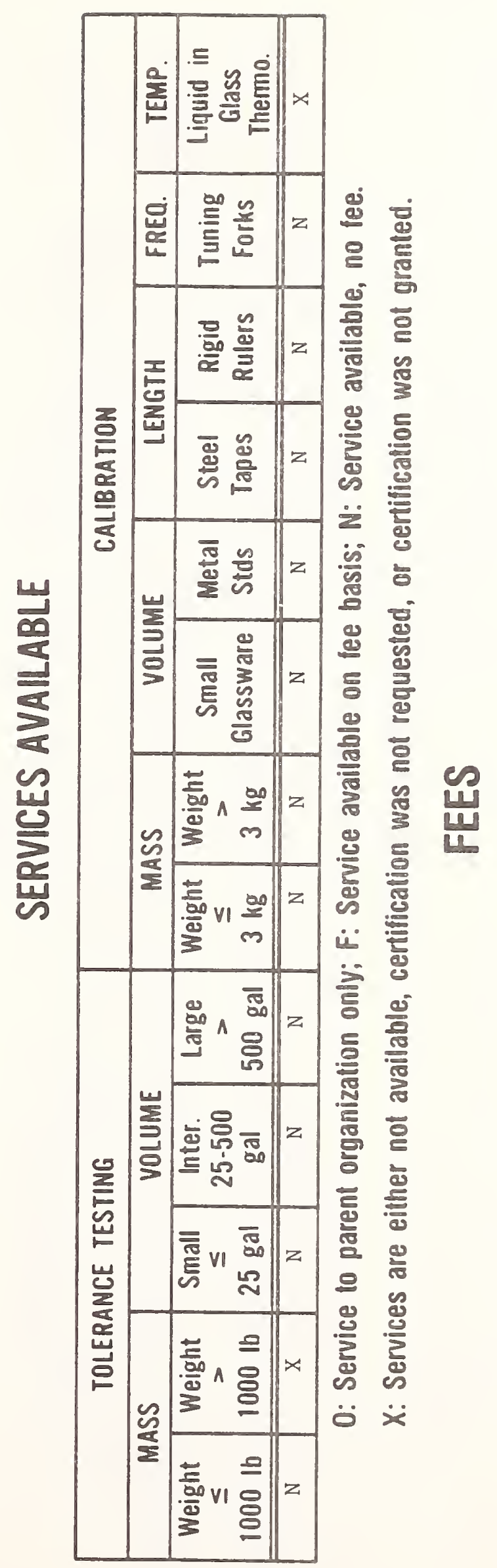




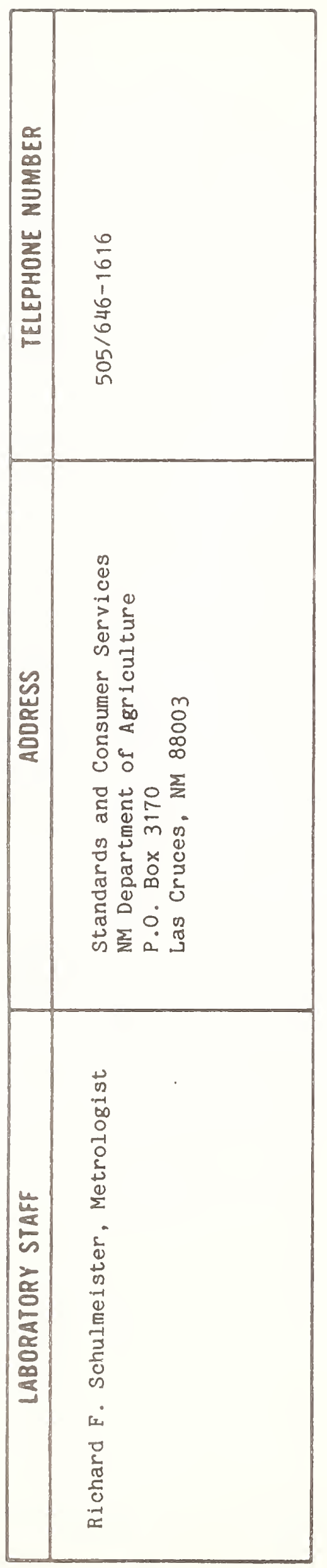

New Mexico

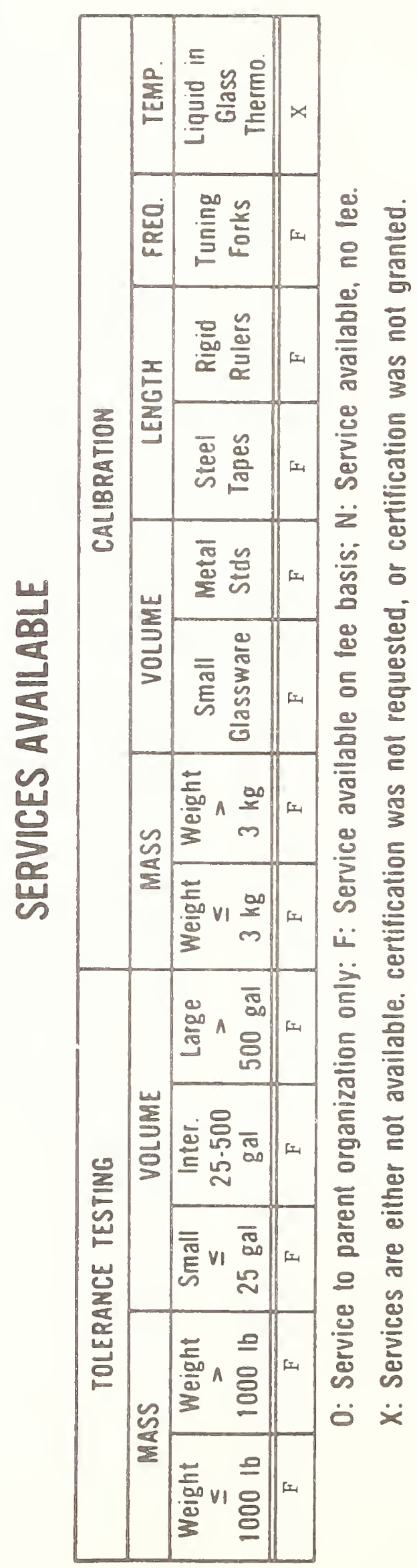

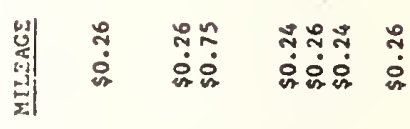

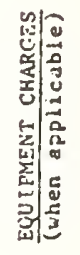

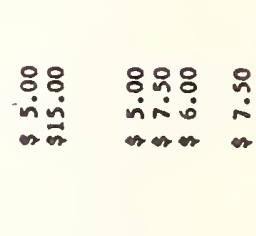

ㄴํㄴ

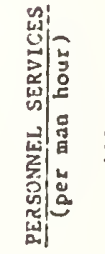

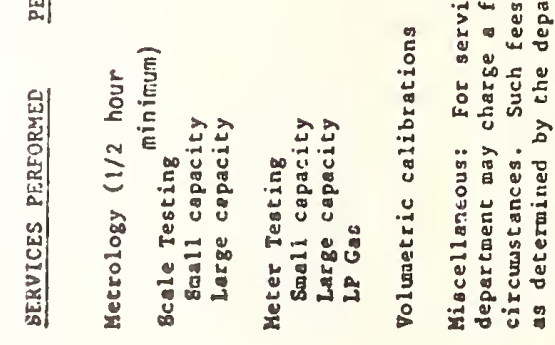




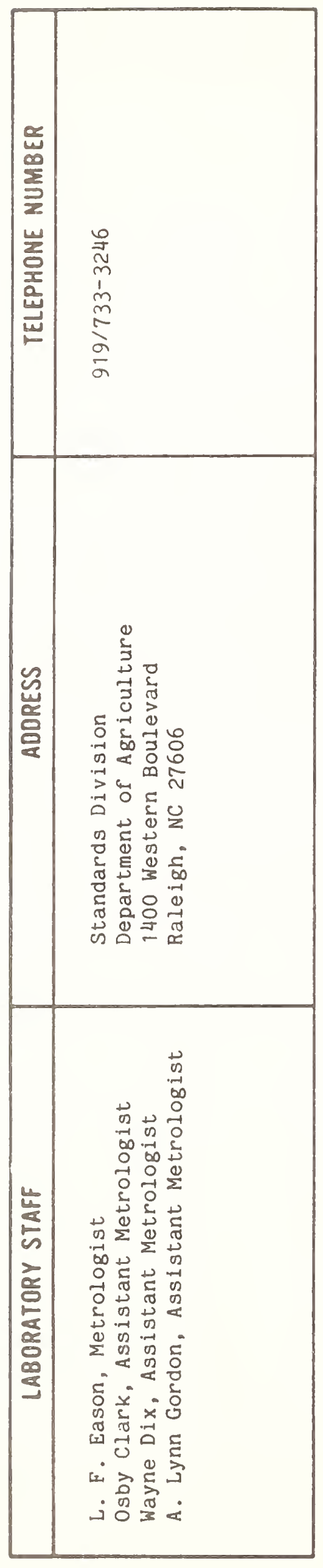

North Carolina

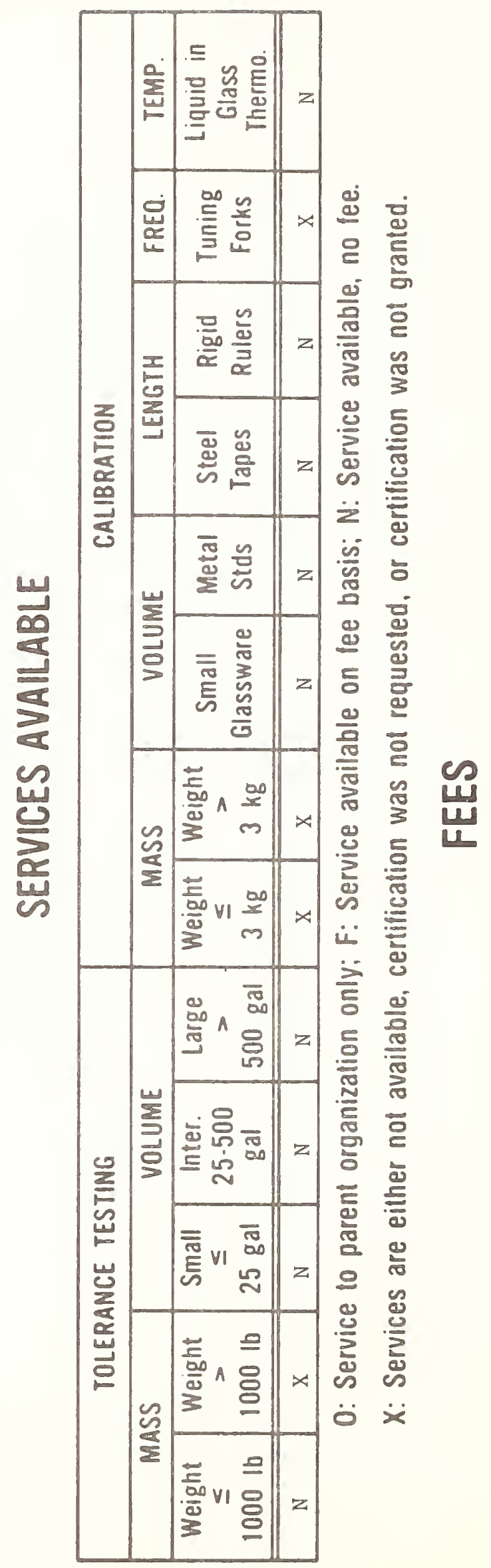



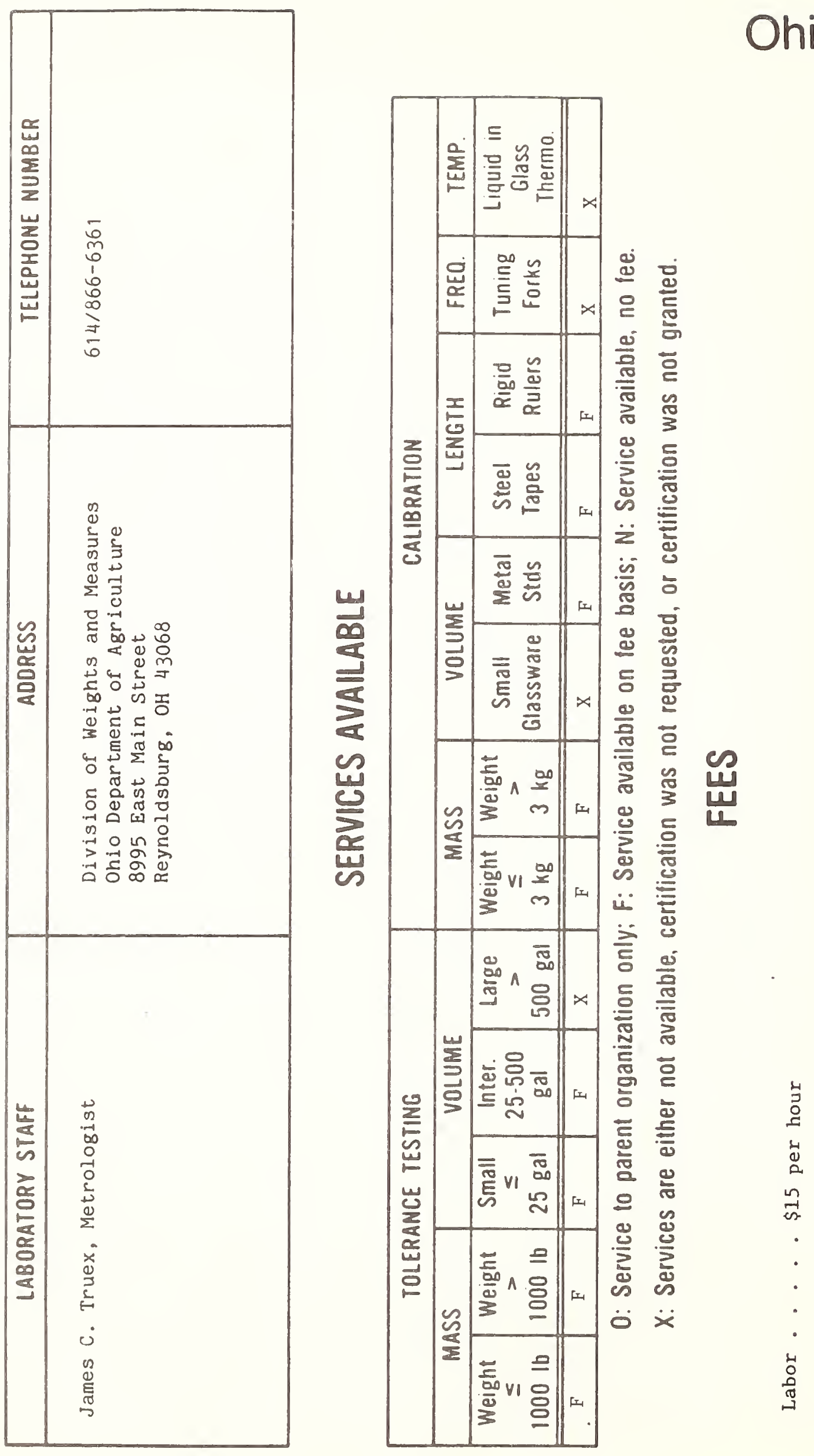


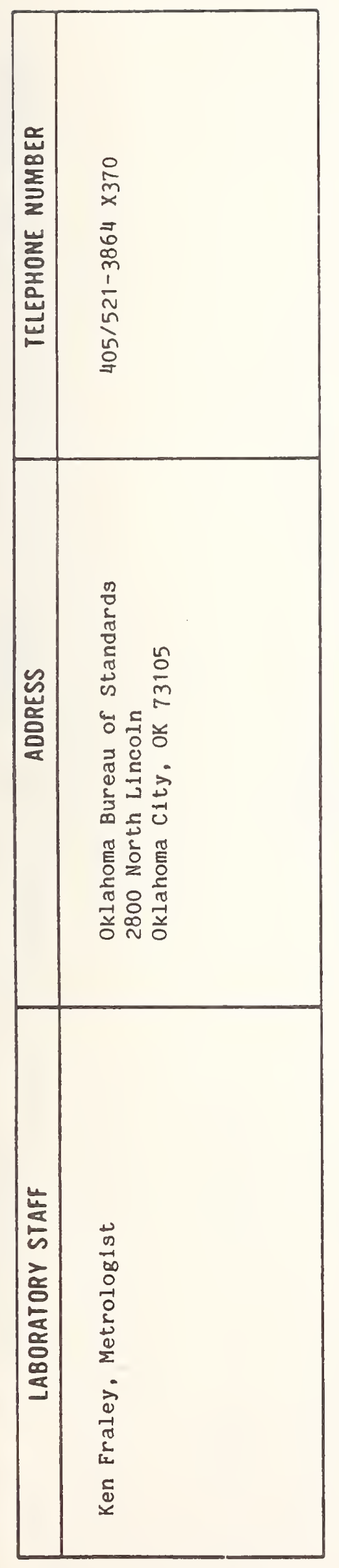

Oklahoma
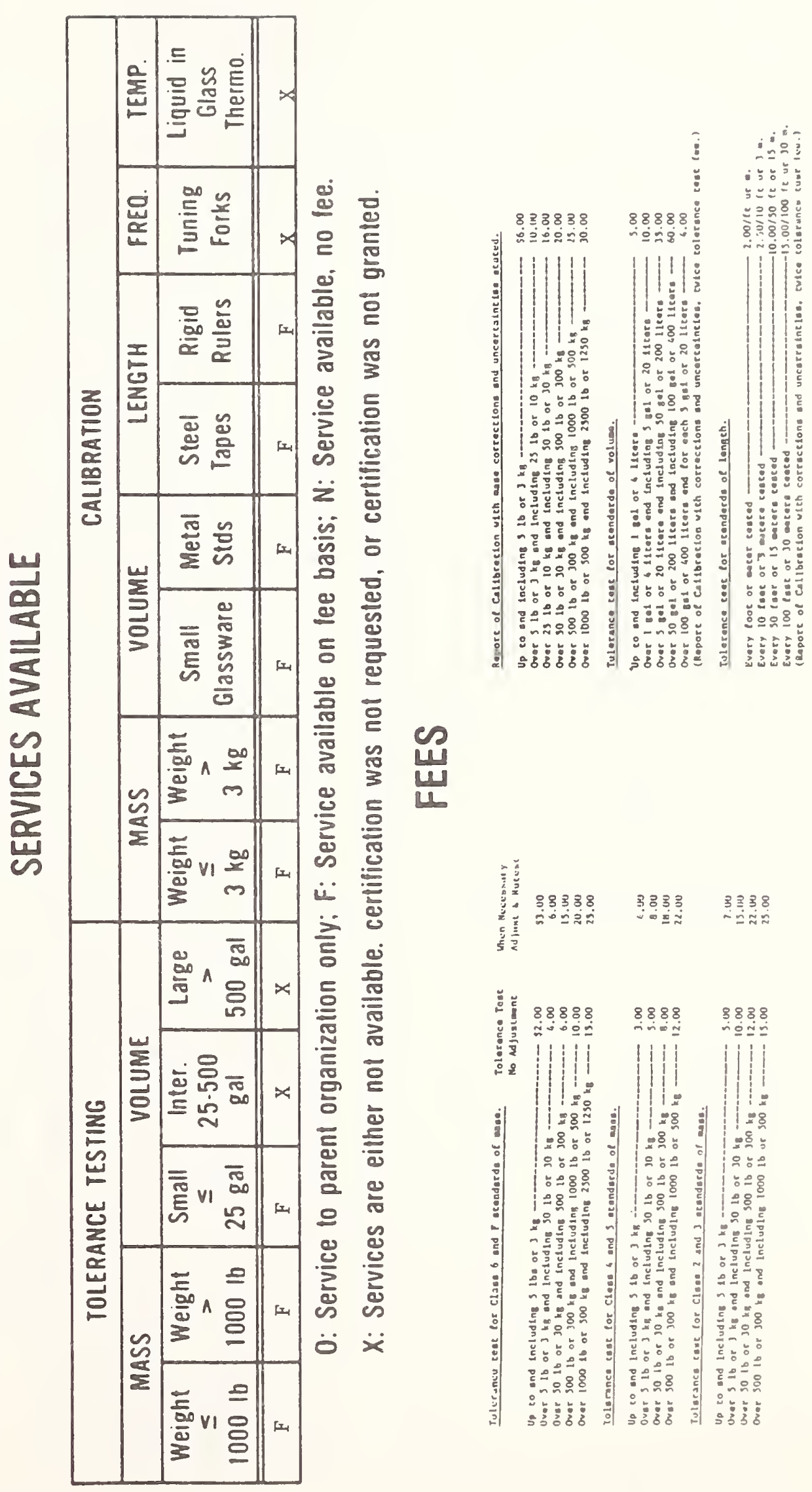


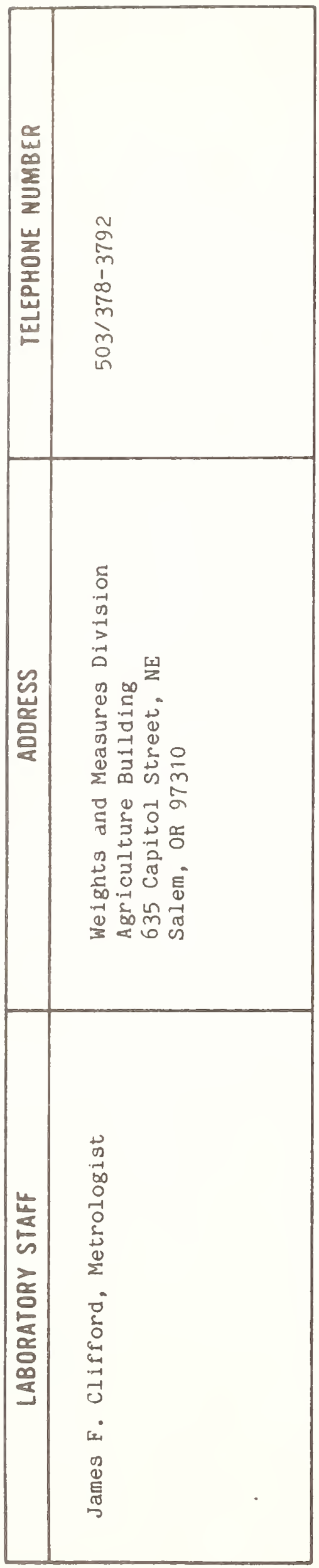

Oregon

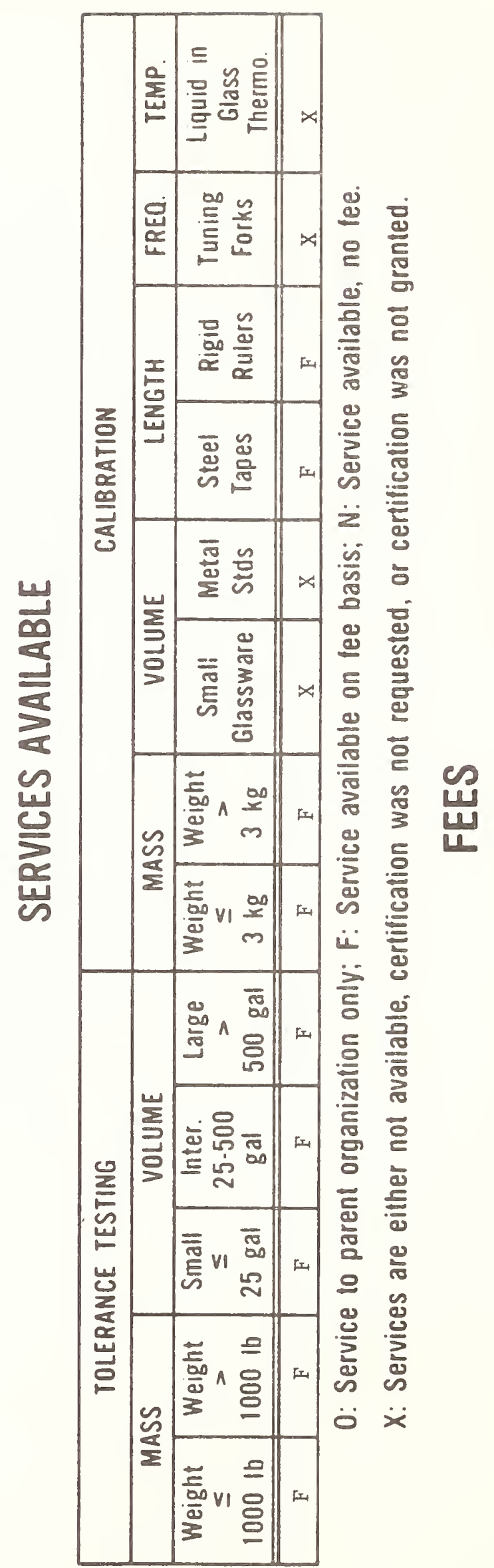

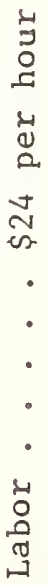




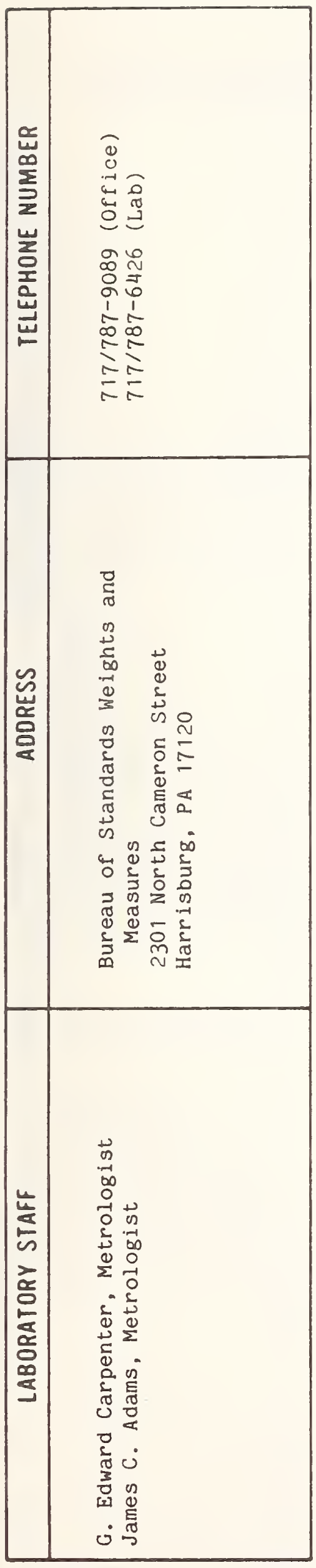

Pennsylvania

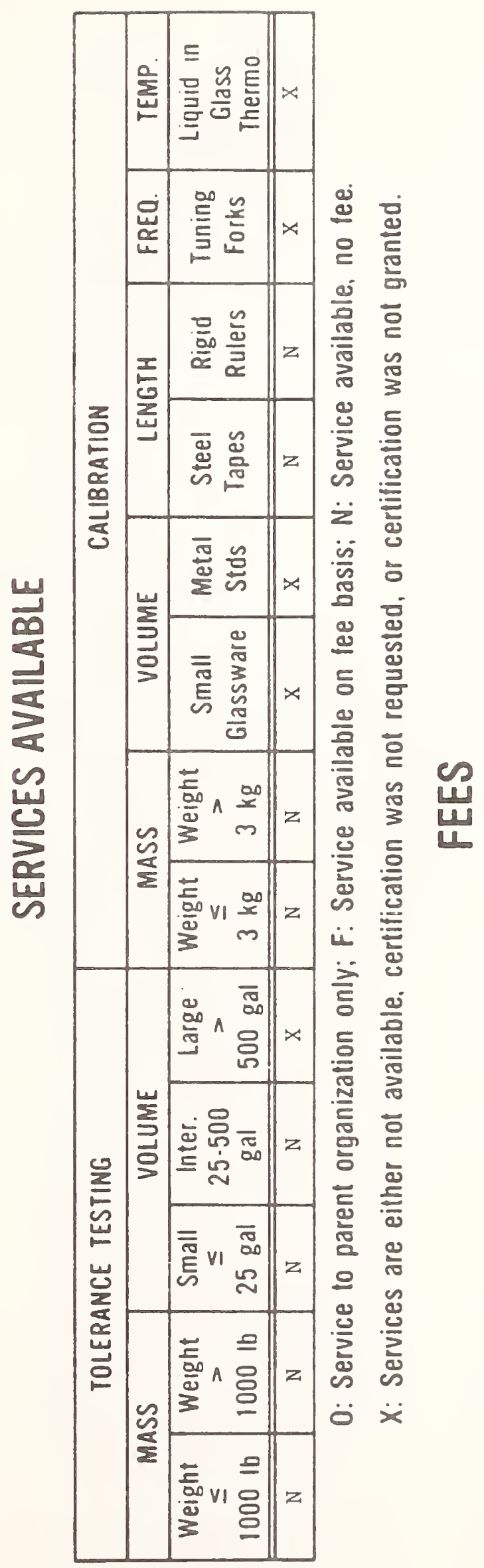




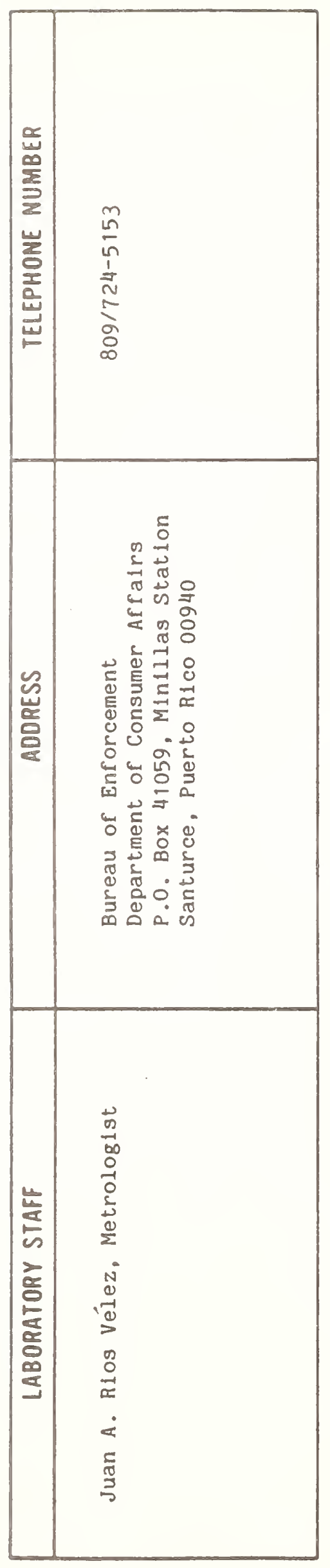

Puerto Rico
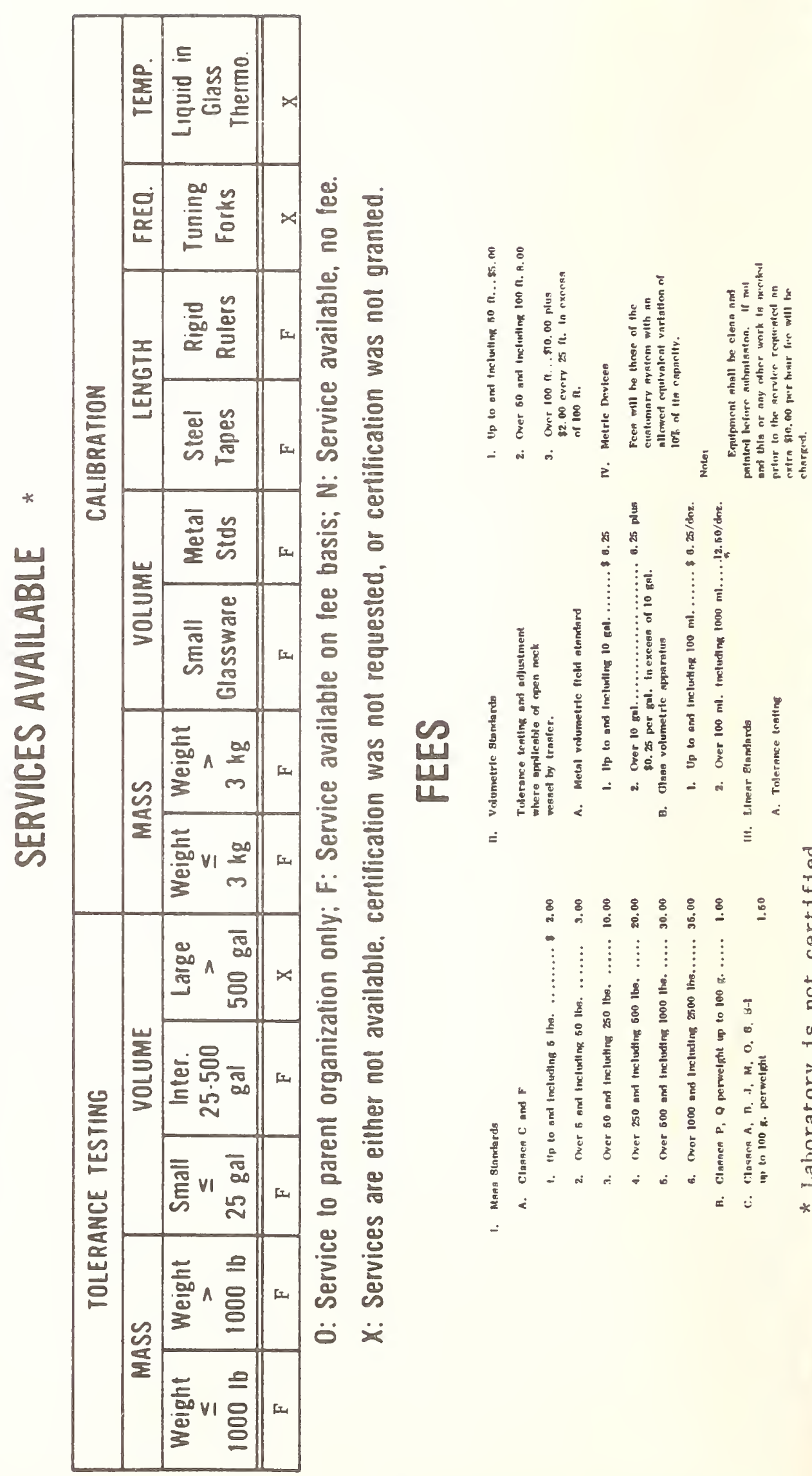

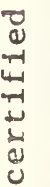

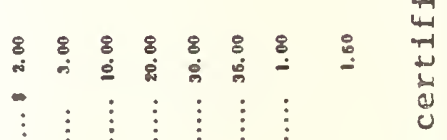

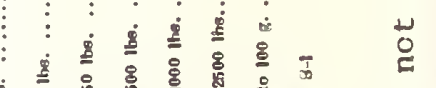

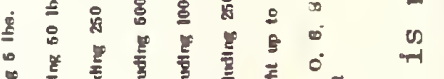

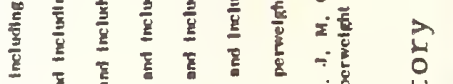

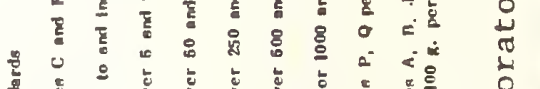

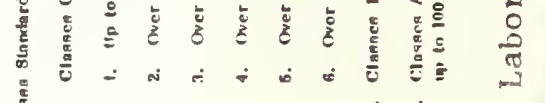




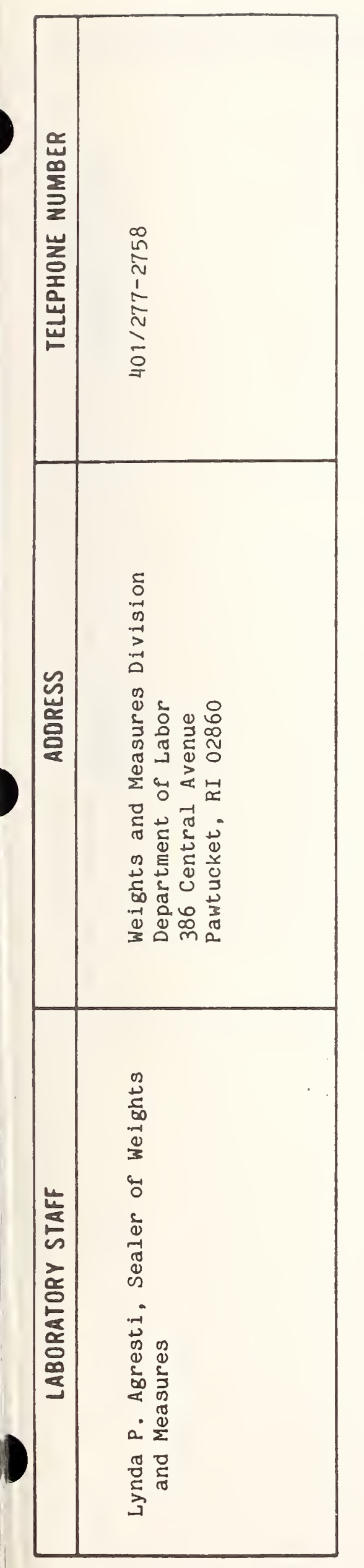

Rhode Island

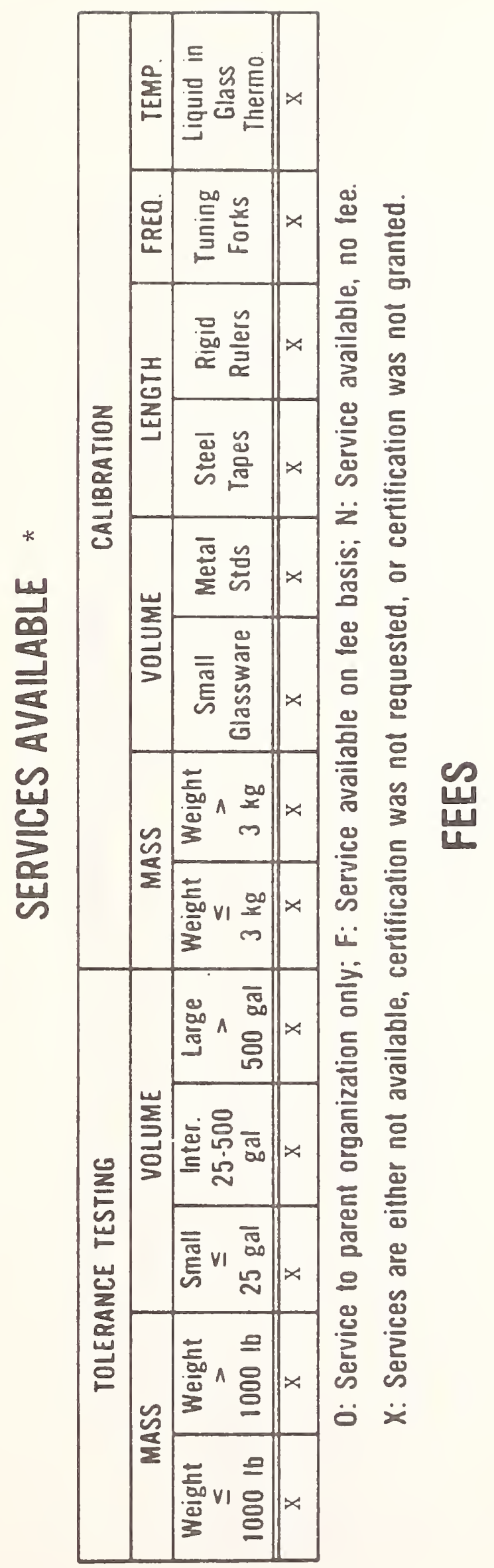

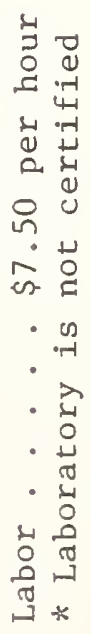




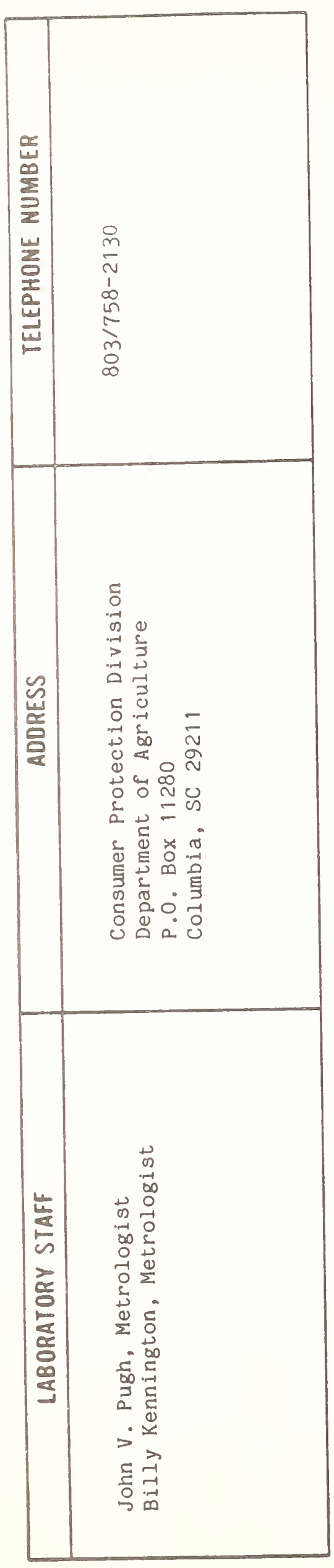

South Carolina

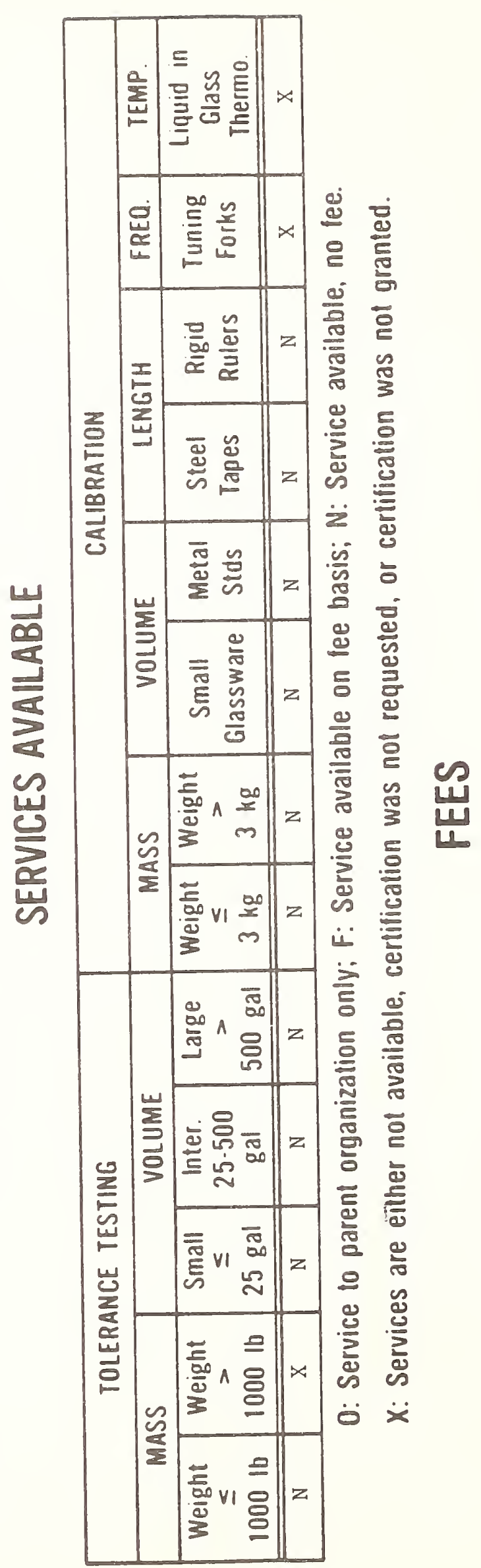




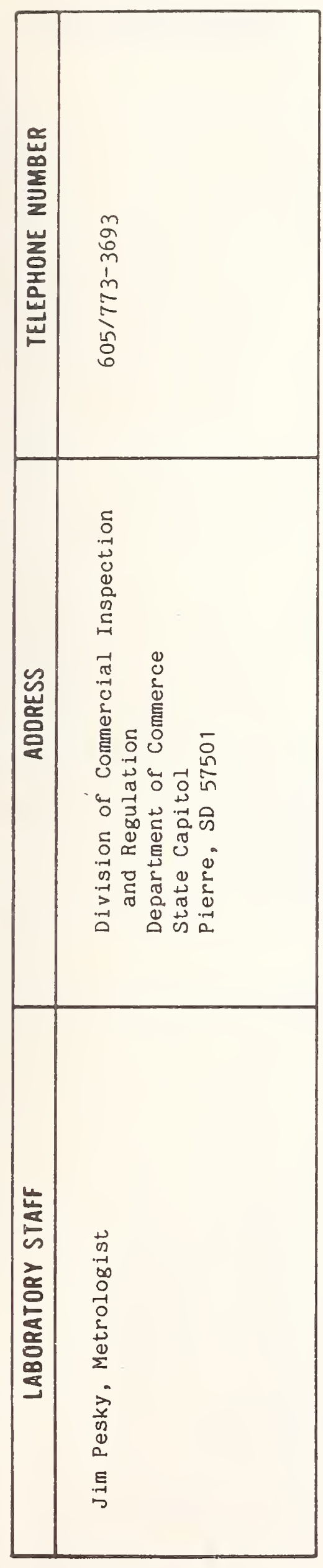

\section{South Dakota}

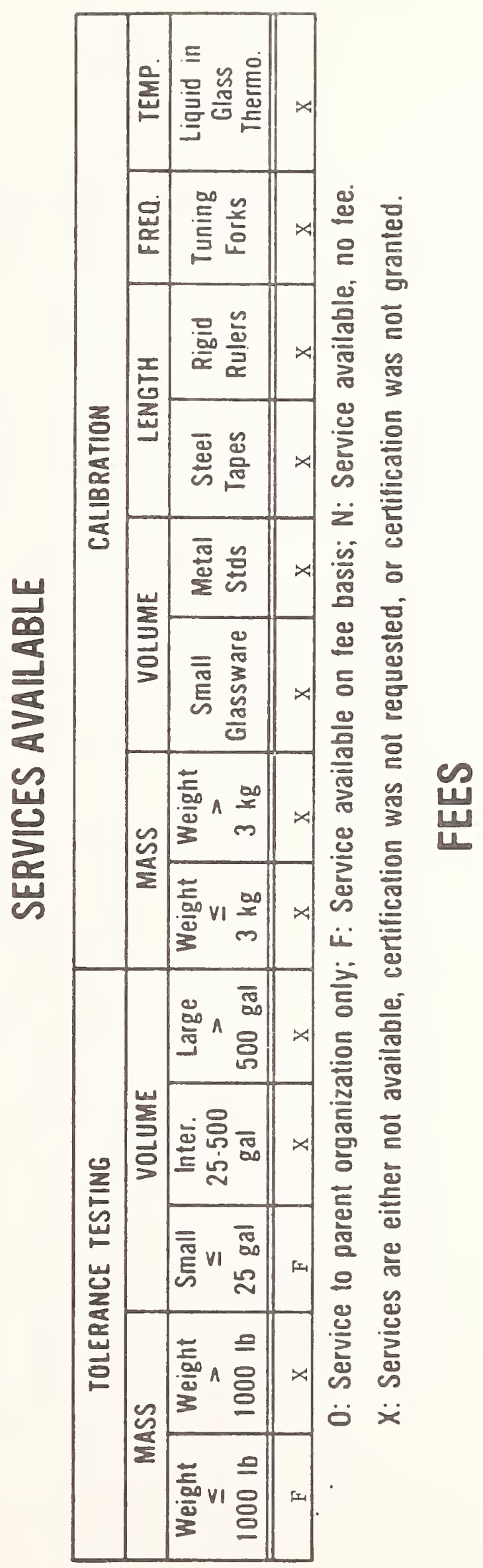

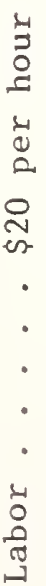




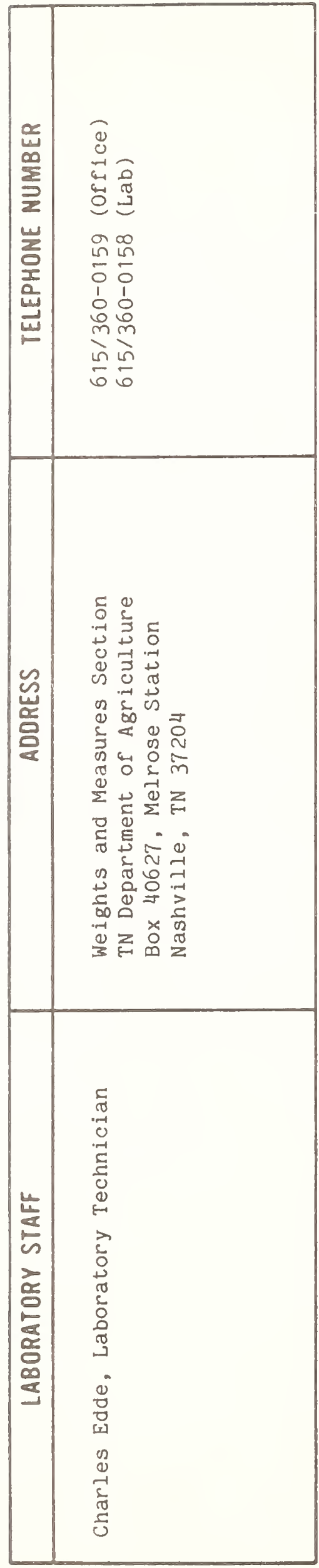

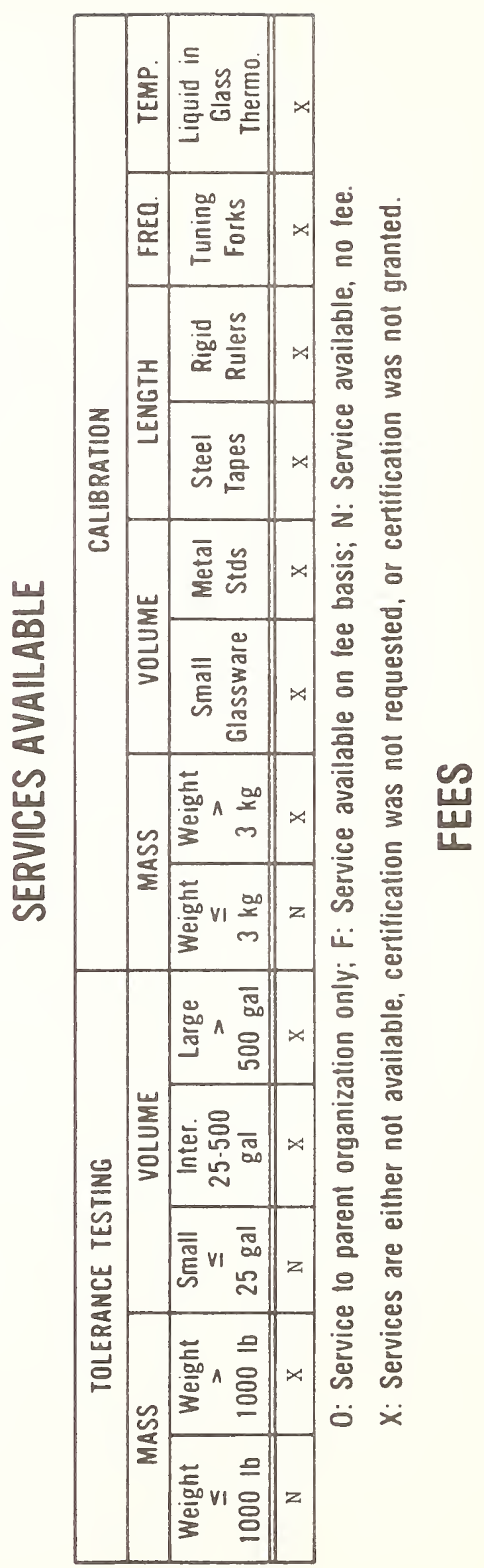




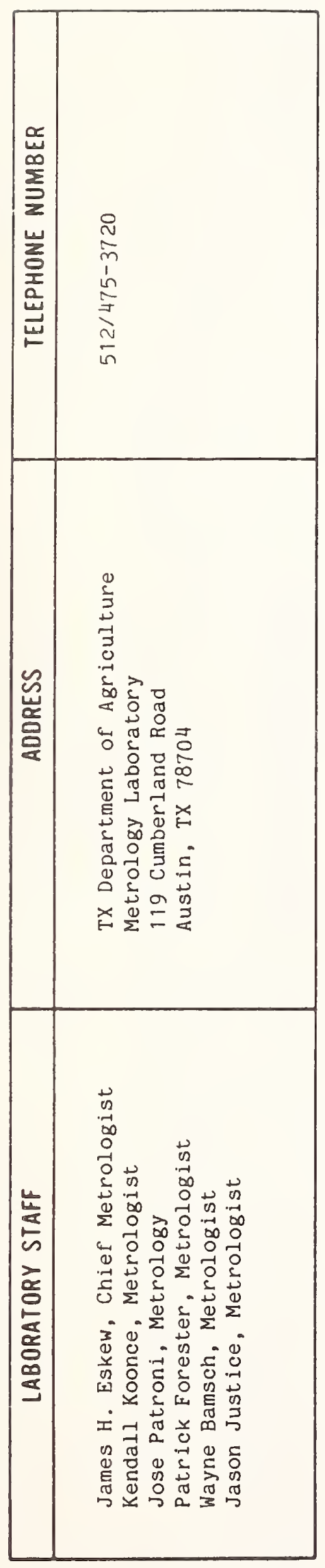

Texas

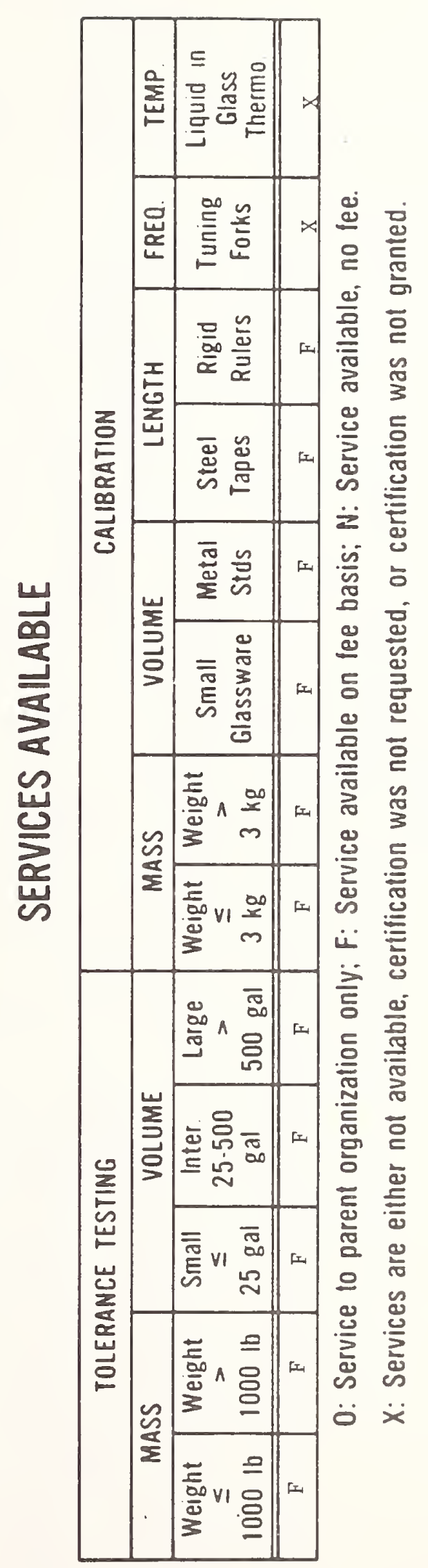

$\stackrel{D_{0}}{=} \sum_{\infty}^{\infty}$

वै 30 व

㟧崖㟧

880

मै जि

ㅇำ

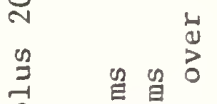

2 施曷

8 क कू त.

i $\exists \exists$ च

n 융유 항

동 온 오

न 7 क

डु ब

in

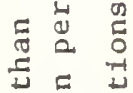

ग 등

U

는

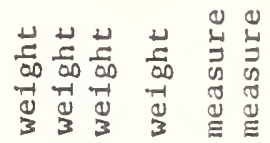

峁岕岕岕岕

ㅇㅇㅇㅇㅇ

iิำ

in

누유루

¿̊ㅇ

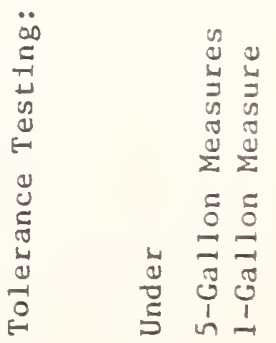



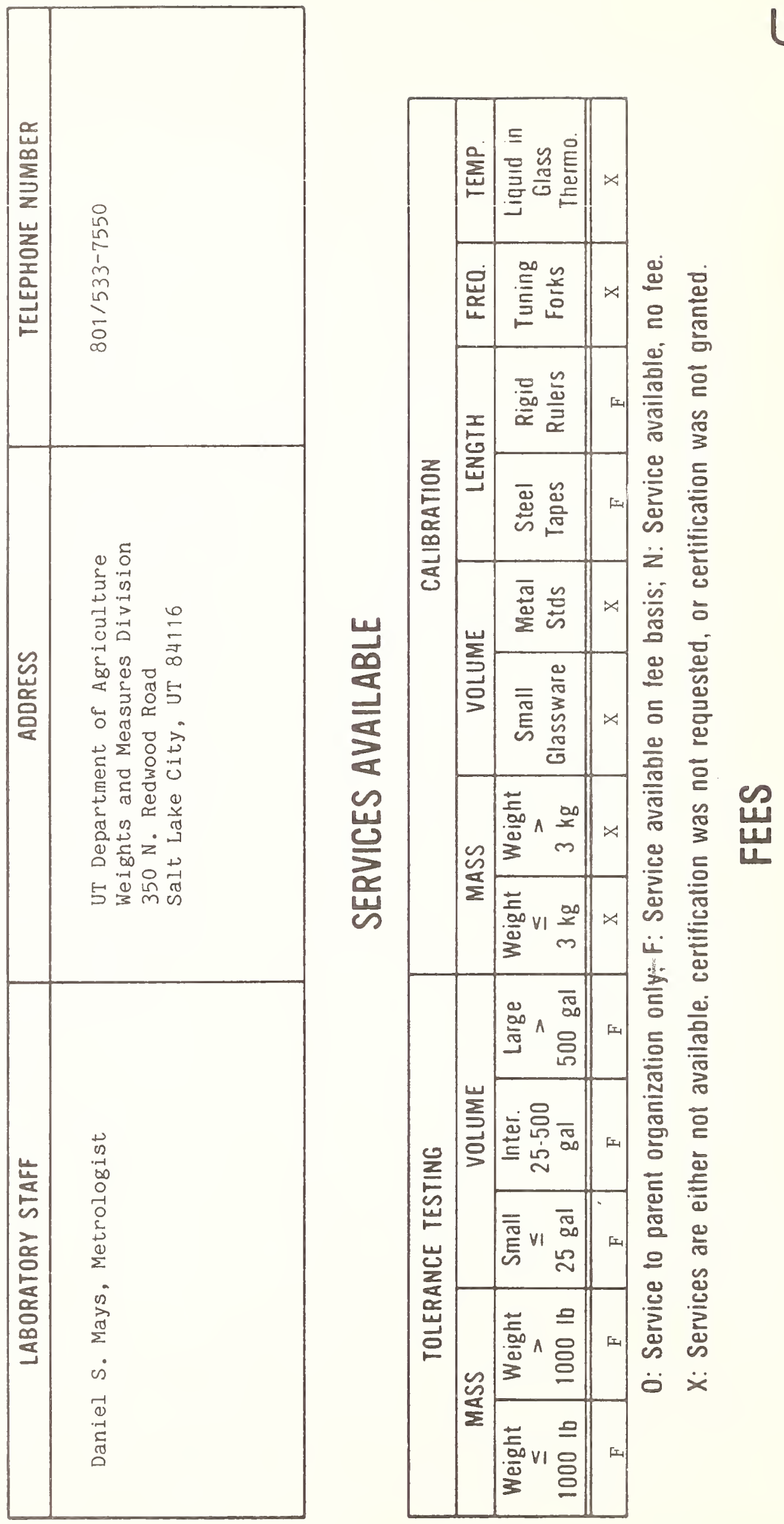


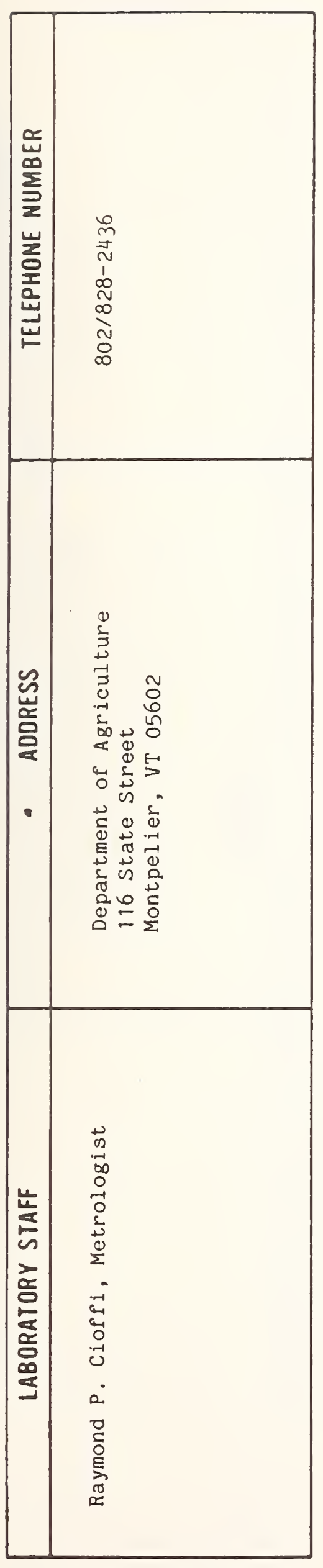

\section{Vermont}

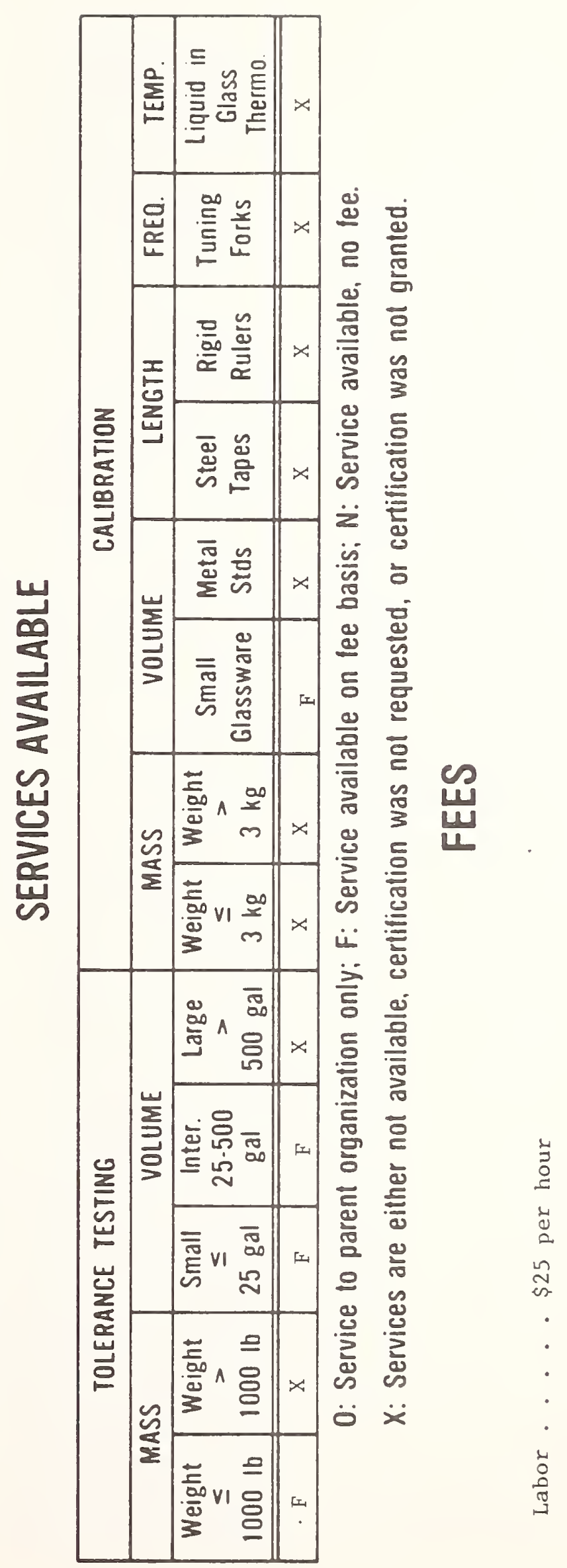



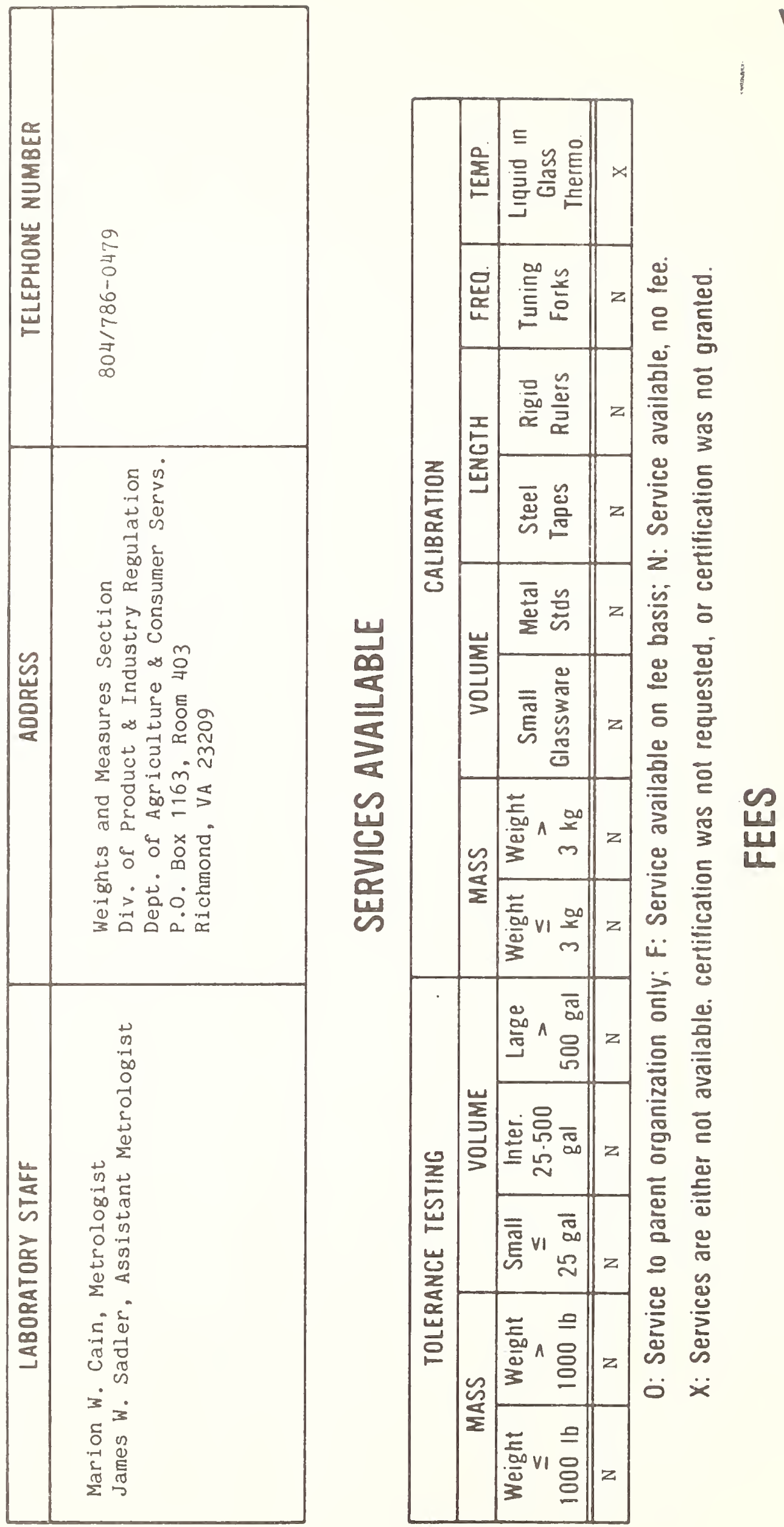


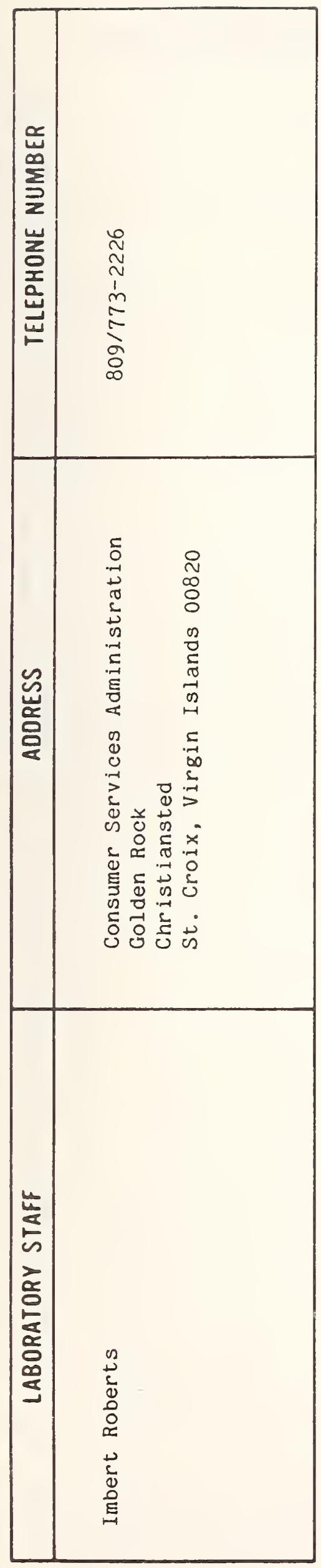

Virgin Islands

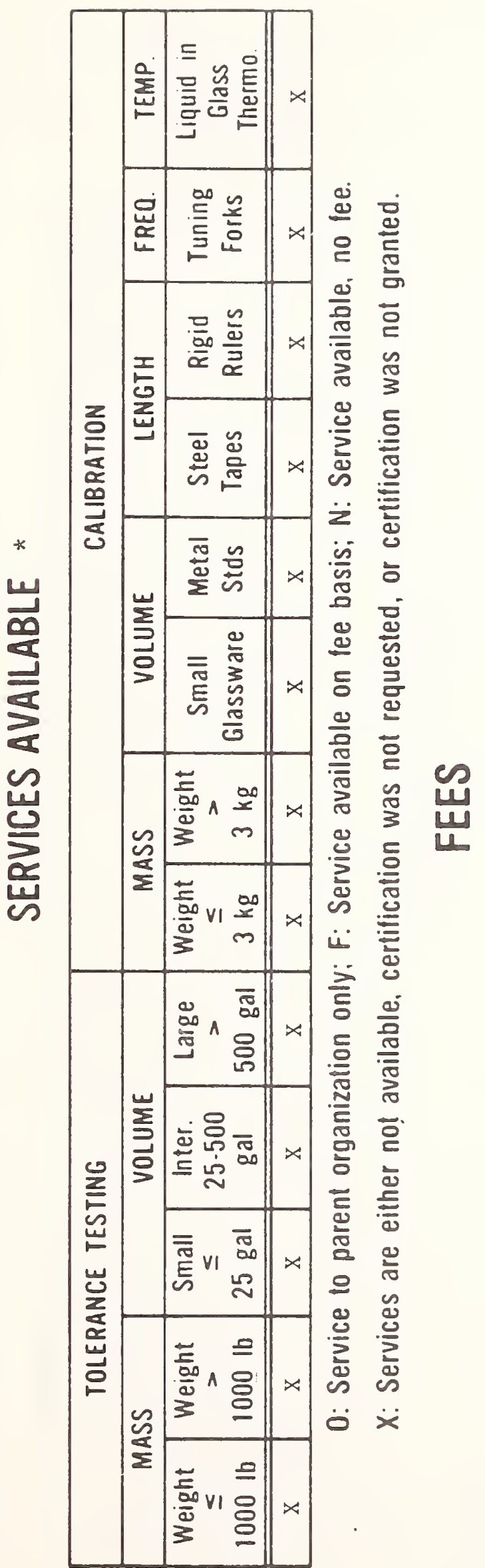




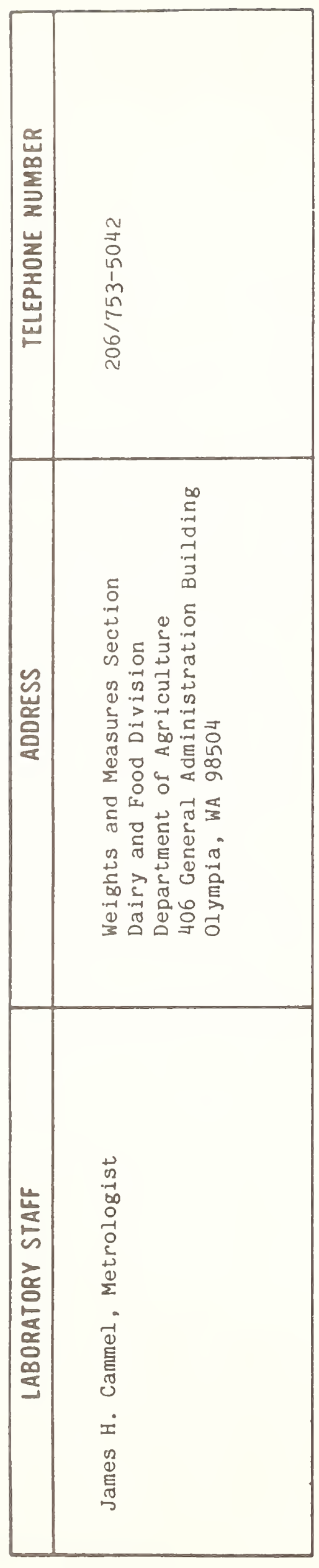

Washington

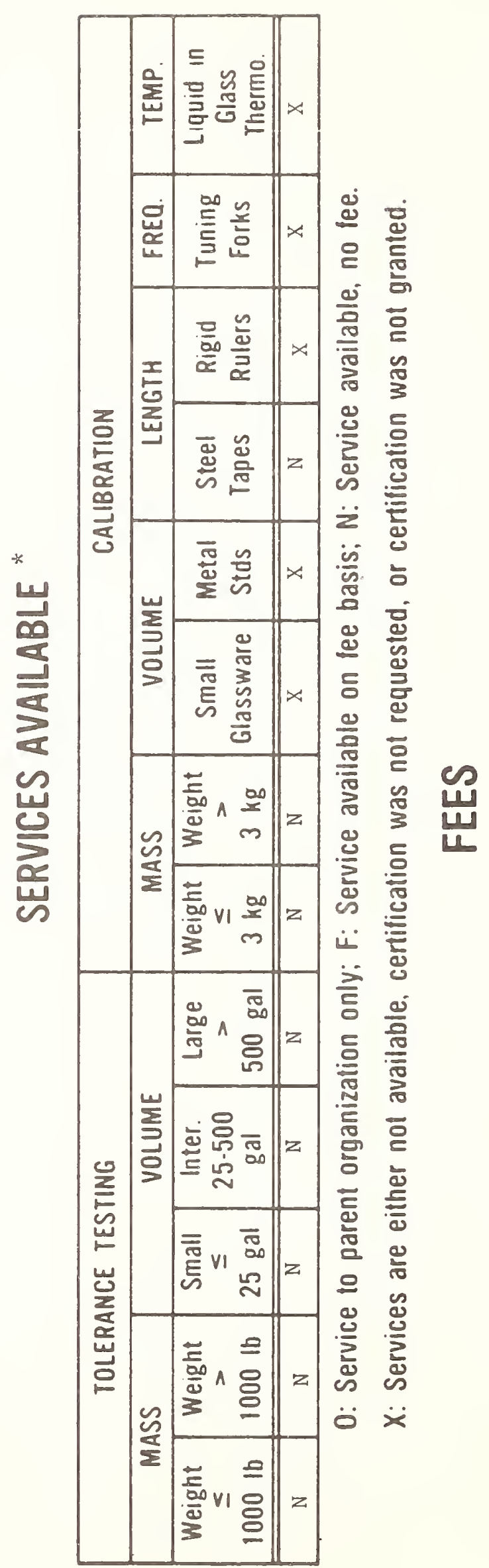




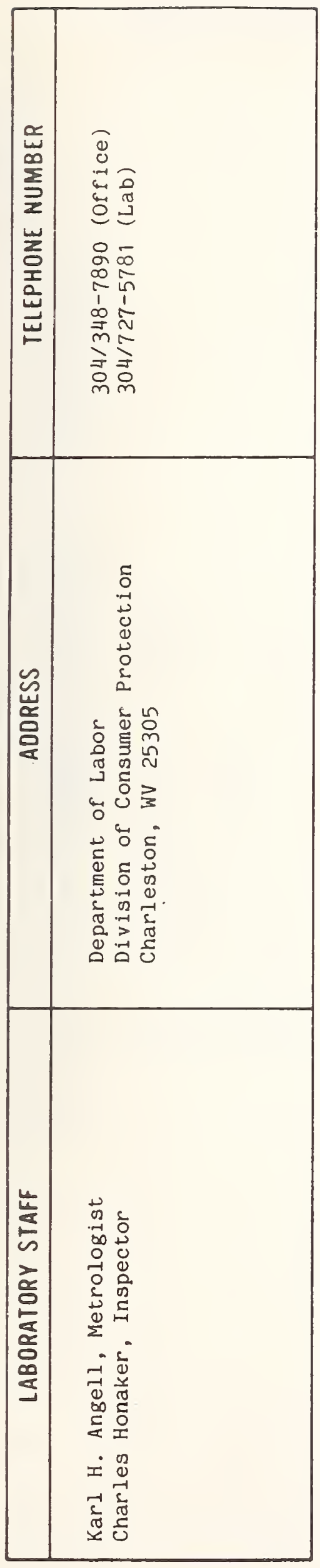

West Virginia

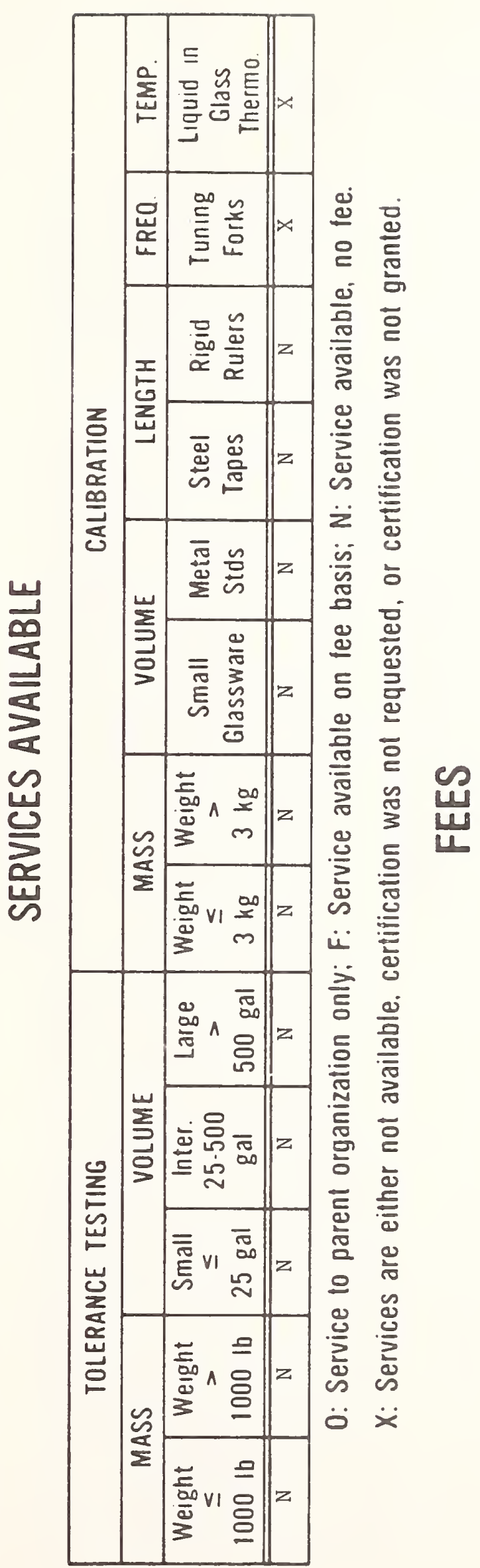



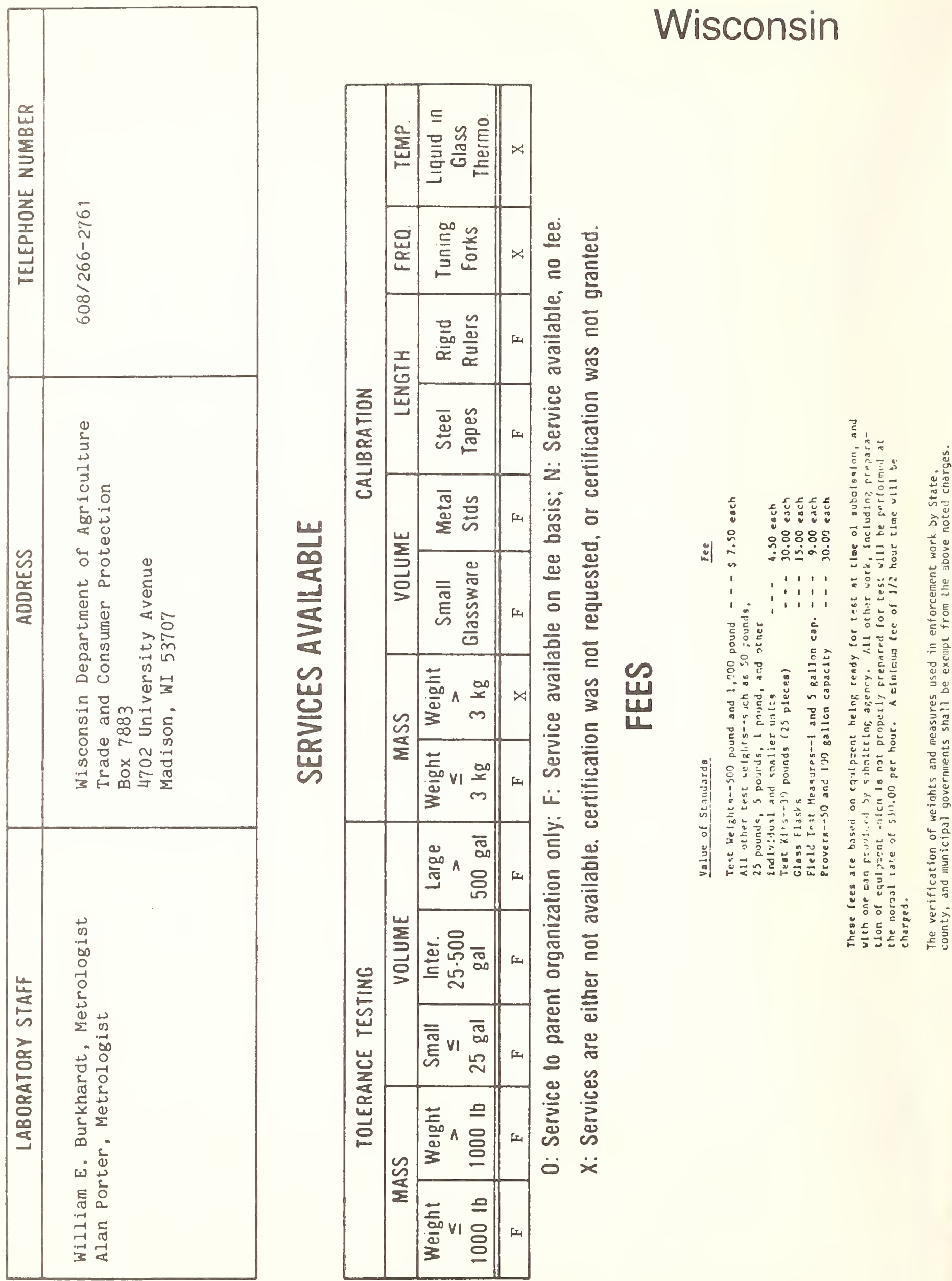

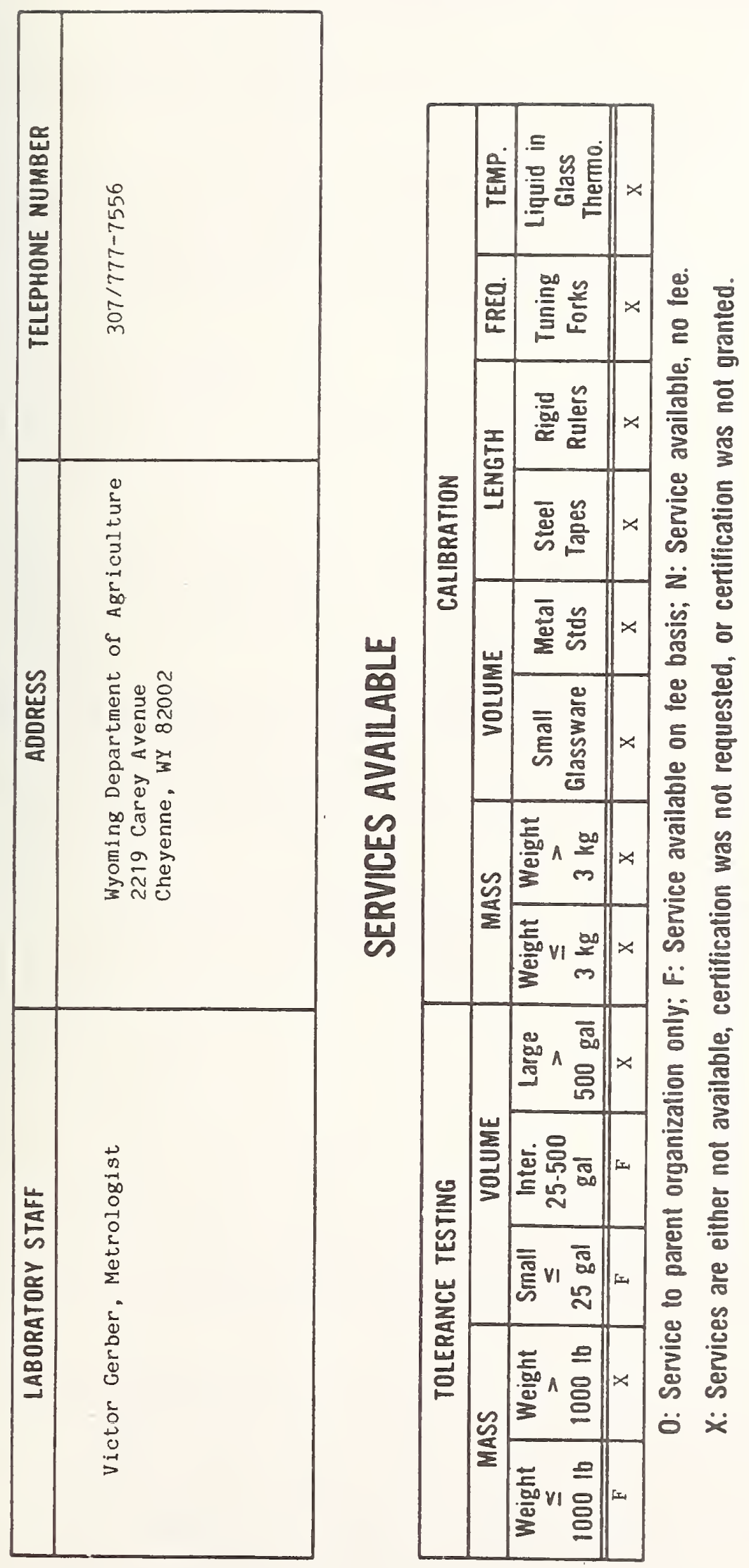

Wyoming

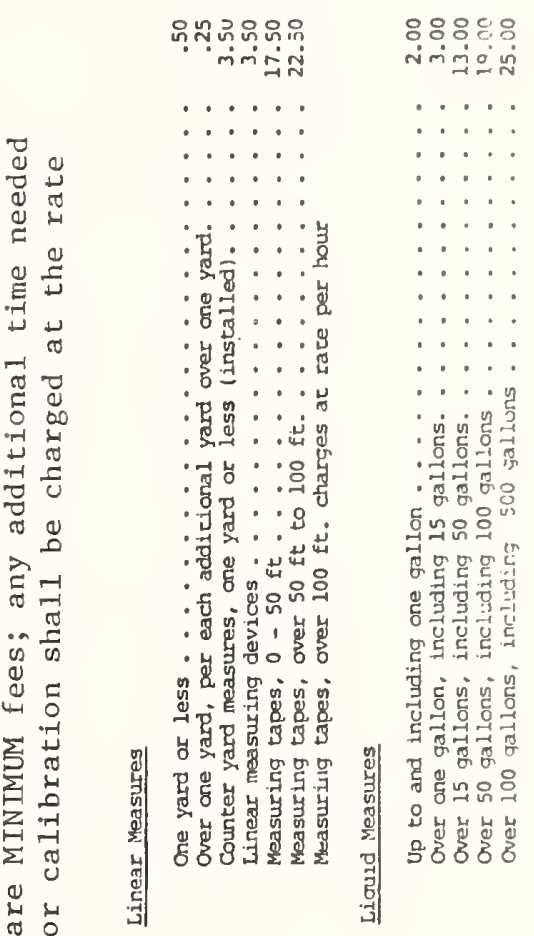

C2 3

范

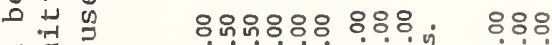

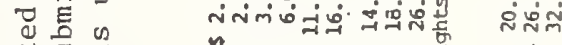

…....

대

过苋苋

矛出 $\quad \cdots \cdots \cdots \cdots$

थ

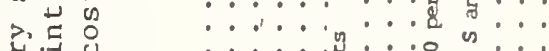

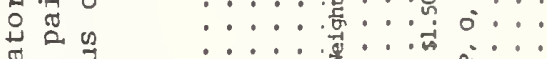

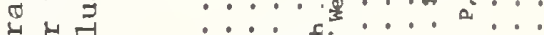

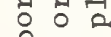

तิ

$\therefore$ ब

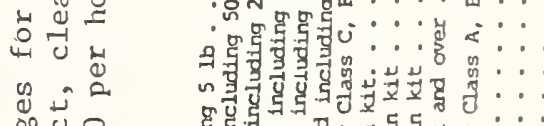

․ㅕㅇㅇㅇㅇㅇㅇ

넝

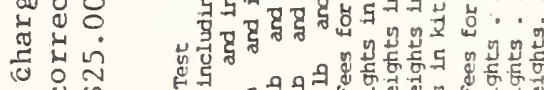

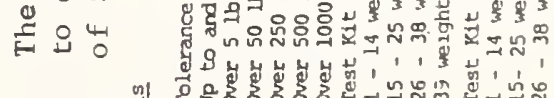

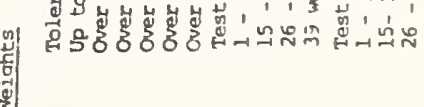




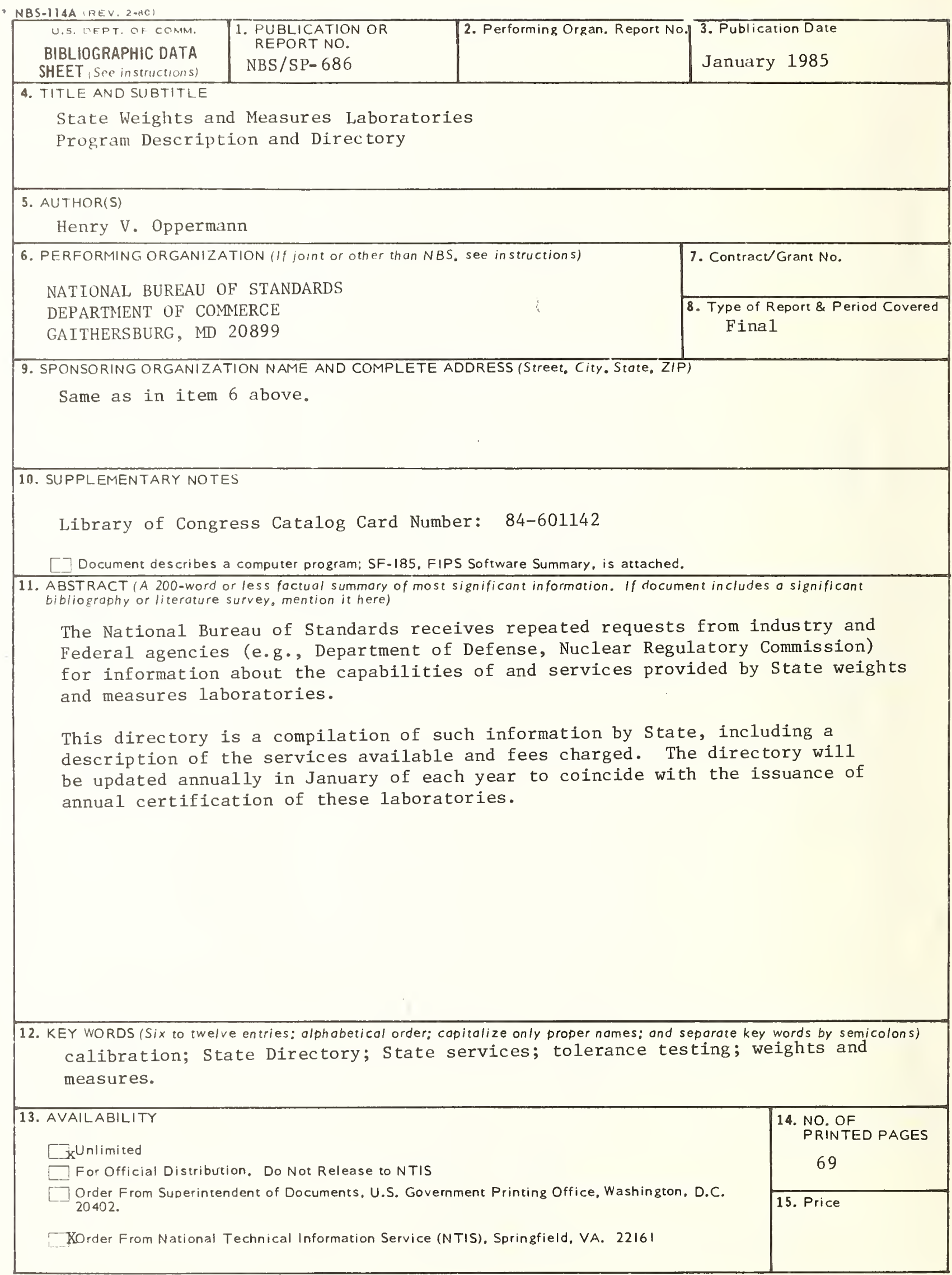




\section{Technical Publications}

\section{Periodicals}

Journal of Research--The Journal of Research of the National Bureau of Standards reports NBS research and development in those disciplines of the physical and engineering sciences in which the Bureau is active. These include physics, chemistry, engineering, mathematics, and computer sciences. Papers cover a broad range of subjects, with major emphasis on measurement methodology and the basic technology underlying standardization. Also included from time to time are survey articles on topics closely related to the Bureau's technical and scientific programs. As a special service to subscribers each issue contains complete citations to all recent Bureau publications in both NBS and non-NBS media. Issued six times a year.

\section{Nonperiodicals}

Monographs-Major contributions to the technical literature on various subjects related to the Bureau's scientific and technical activities.

Handbooks-Recommended codes of engineering and industrial practice (including safety codes) developed in cooperation with interested industries, professional organizations, and regulatory bodies.

Special Publications-Include proceedings of conferences sponsored by NBS, NBS annual reports, and other special publications appropriate to this grouping such as wall charts, pocket cards, and bibliographies.

Applied Mathematics Series-Mathematical tables, manuals, and studies of special interest to physicists, engineers, chemists, biologists, mathematicians, computer programmers, and others engaged in scientific and technical work.

National Standard Reference Data Series-Provides quantitative data on the physical and chemical properties of materials, compiled from the world's literature and critically evaluated. Developed under a worldwide program coordinated by NBS under the authority of the National Standard Data Act (Public Law 90-396).

NOTE: The Journal of Physical and Chemical Reference Data (JPCRD) is published quarterly for NBS by the American Chemical Society (ACS) and the American Institute of Physics (AIP). Subscriptions, reprints, and supplements are available from ACS, 1155 Sixteenth St., NW, Washington, DC 20056.

Building Science Series-Disseminates technical information developed at the Bureau on building materials, components, systems, and whole structures. The series presents research results, test methods, and performance criteria related to the structural and environmental functions and the durability and safety characteristics of building elements and systems.

Technical Notes-Studies or reports which are complete in themselves but restrictive in their treatment of a subject. Analogous to monographs but not so comprehensive in scope or definitive in treatment of the subject area. Often serve as a vehicle for final reports of work performed at NBS under the sponsorship of other government agencies.

Voluntary Product Standards-Developed under procedures published by the Department of Commerce in Part 10, Title 15, of the Code of Federal Regulations. The standards establish nationally recognized requirements for products, and provide all concerned interests with a basis for common understanding of the characteristics of the products. NBS administers this program as a supplement to the activities of the private sector standardizing organizations.

Consumer Information Series-Practical information, based on NBS research and experience, covering areas of interest to the consumer. Easily understandable language and illustrations provide useful background knowledge for shopping in today's technological marketplace.

Order the above NBS publications from: Superintendent of Documents, Governinent Printing Office, Washington, DC 20402.

Order the following NBS publications-FIPS and NBSIR's-from the National Technical Information Service, Springfield, VA 22161.

Federal Information Processing Standards Publications (FIPS PUB)-Publications in this series collectively constitute the Federal Information Processing Standards Register. The Register serves as the official source of information in the Federal Government regarding standards issued by NBS pursuant to the Federal Property. and Administrative Services Act of 1949 as amended, Public Law 89-306 (79 Stat. 1127), and as implemented by Executive Order 11717 (38 FR 12315, dated May 11, 1973) and Part 6 of Title 15 CFR (Code of Federal Regulations).

NBS Interagency Reports (NBSIR)-A special series of interim or final reports on work performed by NBS for outside sponsors (both government and non-government). In general, initial distribution is handled by the sponsor; public distribution is by the National Technical Information Service, Springfield, VA 22161, in paper copy or microfiche form. 
U.S. Department of Commerce

National Bureau of Standards

Gaithersburg, MD 20899

Official Business

Penalty for Private Use $\$ 300$ 